Florida International University FIU Digital Commons

FIU Electronic Theses and Dissertations

University Graduate School

10-29-2014

\title{
Three Essays on the Economics of Defense Contracting, Output and Income Inequality
}

Edward M. DeCambra

Florida International University, edeca005@fiu.edu

DOI: $10.25148 /$ etd.FI14110720

Follow this and additional works at: https://digitalcommons.fiu.edu/etd

Part of the Econometrics Commons, Income Distribution Commons, Macroeconomics Commons, and the Public Economics Commons

\section{Recommended Citation}

DeCambra, Edward M., "Three Essays on the Economics of Defense Contracting, Output and Income Inequality" (2014). FIU Electronic Theses and Dissertations. 1611.

https://digitalcommons.fiu.edu/etd/1611

This work is brought to you for free and open access by the University Graduate School at FIU Digital Commons. It has been accepted for inclusion in FIU Electronic Theses and Dissertations by an authorized administrator of FIU Digital Commons. For more information, please contact dcc@fiu.edu. 


\section{FLORIDA INTERNATIONAL UNIVERSITY \\ Miami, Florida}

\section{THREE ESSAYS ON THE ECONOMICS OF DEFENSE CONTRACTING, OUTPUT AND INCOME INEQUALITY}

A dissertation submitted in partial fulfillment of the requirements for the degree of DOCTOR OF PHILOSOPHY

in ECONOMICS

by

Edward M. DeCambra 
To: Interim Dean Michael Heithaus

College of Arts and Sciences

This dissertation, written by Edward M. DeCambra, and entitled Three Essays on the Economics of Defense Contracting, Output and Income Inequality, having been approved in respect to style and intellectual content, is referred to you for judgment.

We have read this dissertation and recommend that it be approved.

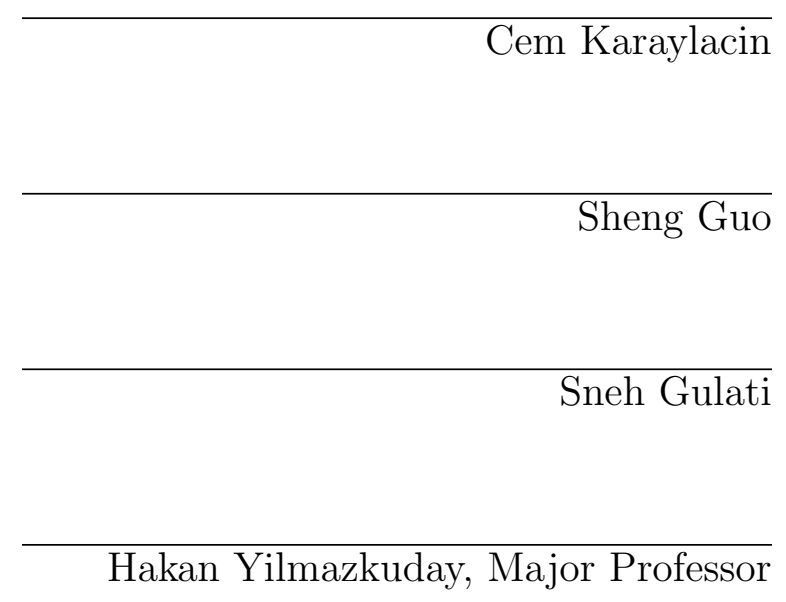

Date of Defense: Octber 29, 2011

The dissertation of Edward M. DeCambra is approved.

\begin{tabular}{r}
\hline $\begin{array}{r}\text { Interim Dean Michael Heithaus } \\
\text { College of Arts and Sciences }\end{array}$ \\
\hline Dean Lakshmi N. Reddi \\
University Graduate School
\end{tabular}

Florida International University, 2014 


\section{DEDICATION}

This work is dedicated to my dear friend Victor, who convinced me originally to pursue graduate studies. You are deeply missed, and will never be forgotten. 


\section{ACKNOWLEDGMENTS}

Many people have provided selfless and invaluable help to me along this journey. I am indebted most to my advisor and mentor Dr. Hakan Yilmazkuday. Without his guidance and advice this work would not have been possible. Thank you for your help, both in research and in providing critical advice about my professional career. I would also like to thank my committee members for their assistance through this process, Dr. Cem Karayalcin, Dr. Sheng Guo, and Dr. Sneh Gulati. Your patience and gracious help has made this stressful process much more bearable. Thank you all.

The economics department staff was fundamental in providing me direction through the process, paperwork and all the deadlines. Thank you all for this help. To my friends and colleagues in this program, past and present. The constructive and critical discussions and camaraderie helped me through, and I hope it helped you as well, thank you.

Finally I owe deep thanks and gratitude to my loving wife. Your encouragement and patience is the primary reason I am here today. 


\title{
ABSTRACT OF THE DISSERTATION \\ THREE ESSAYS ON THE ECONOMICS OF DEFENSE CONTRACTING, OUTPUT AND INCOME INEQUALITY
}

\author{
by \\ Edward M. DeCambra \\ Florida International University, 2014 \\ Miami, Florida \\ Professor Hakan Yilmazkuday, Major Professor
}

This dissertation analyzes both the economics of the defense contracting process and the impact of total dollar obligations on the economies of U.S. states. Using various econometric techniques, I will estimate relationships across individual contracts, state level output, and income inequality. I will achieve this primarily through the use of a dataset on individual contract obligations.

The first essay will catalog the distribution of contracts and isolate aspects of the process that contribute to contract dollar obligations. Accordingly, this study describes several characteristics about individual defense contracts, from 1966-2006: (i) the distribution of contract dollar obligations is extremely rightward skewed, (ii) contracts are unevenly distributed in a geographic sense across the United States, (iii) increased duration of a contract by 10 percent is associated with an increase in costs by 4 percent, (iv) competition does not seem to affect dollar obligations in a substantial way, (v) contract pre-payment financing increases the obligation of contracts from anywhere from 62 to 380 percent over non-financed contracts.

The second essay will turn to an aggregate focus, and look the impact of defense spending on state economic output. The analysis in chapter two attempts to estimate the state level fiscal multiplier, deploying Difference-in-Differences estimation as an attempt to filter out potential endogeneity bias. Interstate variation in procurement 
spending facilitates utilization of a natural experiment scenario, focusing on the spike in relative spending in 1982. The state level relative multiplier estimate here is 1.19, and captures the short run, impact effect of the 1982 spending spike.

Finally I will look at the relationship between defense contracting and income inequality. Military spending has typically been observed to have a negative relationship with income inequality. The third chapter examines the existence of this relationship, combining data on defense procurement with data on income inequality at the state level, in a longitudinal analysis across the United States. While the estimates do not suggest a significant relationship exists for the income share of the top ten percent of households, there is a significant positive relationship for the income share of top one percent households for an increase in defense procurement. 


\section{TABLE OF CONTENTS}

1. THE DISTRIBUTION OF DEFENSE PROCUREMENT $\ldots \ldots \ldots$

1.1 Introduction . . . . . . . . . . . . . . . . . . . 1

1.2 Data Sources . . . . . . . . . . . . . . . . . . 6

1.3 Defense Contracting in the United States . . . . . . . . . . . . . 10

1.3.1 The Defense Contracting Process . . . . . . . . . . . . . . . . . 10

1.3.2 The Distribution of Contract Spending . . . . . . . . . . . . . . 15

1.3.3 Defense Contracting Across Time . . . . . . . . . . . . . . . . . 20

1.3.4 Defense Contracting Across States . . . . . . . . . . . . . . . . . 25

1.3.5 Defense Contracting Across Goods and Services . . . . . . . . . . 27

1.4 Estimation Analysis . . . . . . . . . . . . . . . . . . . 33

1.4.1 Baseline estimates . . . . . . . . . . . . . . . . 36

1.4.2 Contract Structures and Cost Types _. . . . . . . . . . . . 38

1.4.3 Finance options available for Contracts . . . . . . . . . . . . . . 41

1.4.4 Extent of Competition in Contract Bidding . . . . . . . . . . . . . 44

1.4.5 Role of Signing Date and Duration . . . . . . . . . . . . . . . . . . 45

1.5 Concluding Remarks . . . . . . . . . . . . . . . . . . . . 49

2. ESTIMATING A STATE FISCAL MULTIPLIER . . . . . . . . 79

2.1 Introduction . . . . . . . . . . . . . . . . . . . . . . . 79

2.2 Data Sources . . . . . . . . . . . . . . . . . . . . . . 83

2.3 Trends in Military Procurement: 1977-2006 . . . . . . . . . . . 84

2.4 Estimation . . . . . . . . . . . . . . . . . . . . . . . . . 87

2.4 .1 Results and discussion . . . . . . . . . . . . . . . . . . . 91

2.5 Concluding Remarks . . . . . . . . . . . . . . . . . . 93

3. MILITARY PROCUREMENT AND INCOME INEQUALITY $\ldots \ldots \ldots$

3.1 Introduction . . . . . . . . . . . . . . . . . . . . . . . . . . . . 100

3.2 Defense and Inequality: Literature Review . . . . . . . . . . . . . 103

3.3 Data Sources . . . . . . . . . . . . . . . . . . . . . . 107

3.4 Estimation and Analysis . . . . . . . . . . . . . . . . . . . 108

3.4 .1 Alternative Measures of Inequality . . . . . . . . . . . . . . . . . 114

3.5 Concluding Remarks . . . . . . . . . . . . . . . . . 116

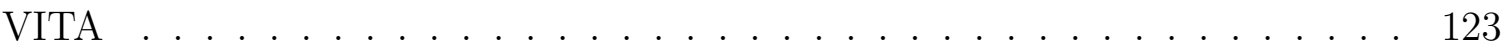




\section{LIST OF TABLES}

TABLE

PAGE

1.1 Sample of Typical Observation . . . . . . . . . . . . . . . 53

1.2 Contract Distribution Accross Competition Factors . . . . . . . . . . . . 54

1.3 Contract Distribution by Contract Pricing Structure . . . . . . . . . . . 55

1.4 Contract Distribution by Contract Payment Structure . . . . . . . . . . 56

1.5 U.S. Federal Contracting . . . . . . . . . . . . . . . . . 57

1.6 Distributional Statistics Across Administrative Changes . . . . . . . . . 59

1.7 Distribution Tail Descriptive Statistics . . . . . . . . . . . . . . . 61

1.8 Distributional Statistics: Outlier Exclusions . . . . . . . . . . . . . 62

1.9 Obligated Contract Dollars by Monthly Duration . . . . . . . . . . . . . 69

1.10 ANOVA estimates: Subsets Across FSC Groups . . . . . . . . . . . . . . 72

1.11 FSC Summary Statistics: Goods Versus Services . . . . . . . . . . . . 73

1.12 Decomposition of Regression Variance . . . . . . . . . . . . . . . . . 74

1.13 Coefficient Estimates for Contract Types . . . . . . . . . . . . . . . 75

1.14 Coefficient Estimates for Finance Types . . . . . . . . . . . . 76

1.15 Coefficient Estimates for Extent of Competition . . . . . . . . . . . . . 77

1.16 Coefficient Estimates for Time Dimension Covariates . . . . . . . . . . . 78

2.1 Percent of Total Government Procurement Spending by State . . . . . . 98

2.2 Volatility of Spending Across States . . . . . . . . . . . . . . . . 99

2.3 Regression Coefficient Estimates . . . . . . . . . . . . . . . . 99

3.1 Baseline Regression Estimates . . . . . . . . . . . . . . . 120

3.2 GLS Regression Estimates . . . . . . . . . . . . . . . . . 121

3.3 GLS Regression Estimates: Autocorrelation Adjusted . . . . . . . . . . 122 


\section{LIST OF FIGURES}

FIGURE

PAGE

$1.1 \quad$ Sample Form DD-350 . . . . . . . . . . . . . . . . . . . . 52

1.2 Individual Reported Contracts Share of Total . . . . . . . . . . . . 58

1.3 Dollar Density Estimates _. . . . . . . . . . . . . . . . . 60

1.4 Aggregate Dollars: Total v.s. Threshold . . . . . . . . . . . . . . 63

1.5 Annual Spending Statistics: Total v.s. Threshold . . . . . . . . . . . . . 64

1.6 Aggregate Dollars: Outlier Exclusion . . . . . . . . . . . . . . . . 65

1.7 Annual Spending Statistics: Outer 0.01 Percentile Exclusion . . . . . . . 66

1.8 Seasonal Frequency of Contract Obligation _. . . . . . . . . . 67

1.9 Weekly Spending Statistics _ . . . . . . . . . . . . . . 68

1.10 Decade Average Annual Total by State . . . . . . . . . . . . 70

1.11 Contract Spending by State . . . . . . . . . . . . . . 71

2.1 Military Procurement as a Fraction of Output . . . . . . . . . . 96

2.2 Aggregate U.S. Relative Spending . . . . . . . . . . . . . . . . . 97

3.1 Contract Spending by State . . . . . . . . . . . . . . . . . . . . . 118

3.2 Income Inequality by State . . . . . . . . . . . . . . . . . 119 


\section{LIST OF ACRONYMS}

Analysis of Variance

ANOVA

Budget Control Act of 2011

BCA

Bureau of Economic Analysis

BEA

Bureau of Labor Statistics

BLS

Competition in Contracting Act of 1984

CICA

Consumer Price Index

CPI

Difference-in-Differences estimation

DD

Feasible General Least Squares

FGLS

Federal Acquisition Regulation

FAR

Federal Supply Classification

FSC

Fiscal Year

FY

Gini Coefficient

GINI

Gross Domestic Product

GDP

Gross State Product

GSP

Internal Revenue Service

IRS

Least Squares Dummy Variable Regression

LSDV

North American Industry Casssification System

NAICS

Research, Development, Test and Evaluation

RDTE

Science, Technology, Engineering, and Math

STEM

Standard Industrial Classification

SIC

Structural Vector Autoregression

SVAR

Two Stage Least Squares

2SLS

U.S. Department of Defense

DoD

U.S. Government Accountability Office

GAO 


\section{CHAPTER 1 \\ THE DISTRIBUTION OF DEFENSE PROCUREMENT}

\subsection{Introduction}

Military contracting has long been a highly politicized and often controversial subject. This has especially been the case in the post World War II political landscape of the United States where, for the first time, an extremely well-trained and equipped peacetime military presence was formed (?). It was in the new military era that D.W. Eisenhower coined the poignant moniker the "Military Industrial Complex" at a time when the U.S. was heading into the Cold War. The U.S. has since dealt with seemingly endless waves of wartime threats, with the drumbeats of past exercises echoing into the next. These wars combined with global policing has established a large and poorly understood institution solely devoted to the development and production of goods and services for the U.S. Department of Defense (DoD). This essay aims to improve understanding of defense contracting by quantifying and describing a multitude of contracting characteristics, using the vast pool of data on individual contracts.

The tacit agreement among lawmakers of establishing a permanent, relatively large defense budget seems to now be on shaky ground. Recent episodes of fiscal crises in the federal government of the United States have created a climate of increased willingness for cuts from all forms of federal spending, driving many previously unwilling politicians towards the defense budget. With no abatement of the Budget Control Act of 2011 (BCA), sequestration of the DoD budget took effect to the amount for 37 billion dollars for the second half of 2013, and will amount to 470 billion dollars over the following decade (?). As currently written, the sequestration is designed as an intentionally ham-fisted approach to reduce spending, cutting all programs it 
targets equally hard $(?)^{1}$. As reported by http://USAspending.gov/ ${ }^{2}$, from 2002 to 2013 the department of defense has contracted between 171 and 361 billion dollars per fiscal year. Relative to the size of procurement spending, these cuts are far from insignificant, and those in charge must find innovative ways to improve the efficiency of operations to minimize the negative effects of reduced budgets.

The goal of this essay is to catalog the behavior of defense contracting to provide some insight into the sources of expense in the contracting process, with the hope that the information can be used to develop more efficient structures of contracting going forward. To achieve this, I will use a broad analysis of contract prices; both their distributional landscape as well as influences from a number of factors. By using a rich dataset of individually recorded contracts, the information here will describe how contracts behave, and what factors such as their timing, location, duration, administrative structures, and other characteristics possibly influence their dollar obligation. Having a detailed economic description of the motivating factors that influence contract cost will be a valuable tool for efficiency improvements in the defense procurement process. Also if Capitol Hill can find common ground, the cleaver of sequestration may be replaced with the scalpel that many politicians want. While the sequestration was designed to be a temporary political bargaining tool, politicians now see that cuts to defense have become a political possibility, foretelling the future for defense contracting regardless of the lifespan of the BCA. The results presented here bring valuable information to those appropriating funds, including how

\footnotetext{
${ }^{1}$ All appropriation programs and activities are affected at the individual program level by an equally sever percentage except those contained within operations and maintenance $(\mathrm{OM})$, which is applied at the overall account level. Within OM There is flexibility to allocate the portion of cuts they must enact, in a more efficient way across programs to minimize the ill effects of the cuts, but not for procurement generally

${ }^{2}$ The website http://USAspending.gov/ was launched in 2007 as a response to the Federal Funding Accountability and Transparency Act (FFATA) of 2006, and established by the Office of Management and Budget within the U.S. federal government.
} 
to best allocate what may prove to be a significantly slimmed budget over the years to come.

Furthermore, a detailed account of both the dollar distribution and of influential factors for contracting may provide insights into how to correct often cited systemic flaws and inefficiencies in the process. The Government Accountability Office has attributed a 31 billion dollar rise in the cost of major defense systems to inefficiencies in the procurement and production process for the fiscal year of 2011 alone (?). Authors have long scrutinized the defense contracting process from many vantage points; political underpinnings and motivations (??), contractor corruption and impropriety (?), and economic incentives motivating contractors (??). The majority of these studies focus on either aggregated data or on anecdotal incidents of abuse ${ }^{3}$. Going straight to the individual contract will provide the information necessary for evaluating various policies and procedures that influence costs more directly.

The first chapter will also benefit studies that utilize government procurement as a source of fiscal spending shocks, by providing guidance on the suitability of defense procurement data in answering one's policy question. Defense procurement is by far the largest source of federal procurement spending, accounting for typically 70 percent of all contracting dollars for the past several decades (see table 1.2). Considering the substantial size of the appropriations, defense spending has long been an attractive source of data used to answer broad macroeconomic questions. Aggregate defense spending is often cited and used for its purported exogeneity from economic events that are otherwise difficult to estimate precisely, and used with the hope of yielding unbiased estimates of the causal effects (???). Better understanding of the behavior of individual contracts can provide clearer direction for the use of this subset of federal

\footnotetext{
${ }^{3}$ See ?, ?, ? and ? for cases of State level aggregated studies regarding total dollars contracted, with various analytical techniques applied. Alternatively, using a disaggregated analysis ? conduct a study based on press reports of contractor impropriety.
} 
spending in these aggregate level studies. Studies that attempt to answer political economic questions regarding national defense that use aggregated spending typically only indirectly estimate those effects, using aggregate federal budget outlays as proxies for the actual obligated dollars (??). By using the micro-data one can isolate and control for geographic, time, and good level characteristics. Accounting for these unobservable effects allows more precise estimation of the directly measurable effects of interest, not otherwise possible in aggregate level studies.

A few studies do however analyze the influences on contracts at the micro level. ? looks more broadly at federal contracting, using the individual actions of appropriation ordered by congress to estimate the impact that congressional political distribution has on contract size. ? studied individual contract dollar obligation from the federal government to measure timing effects of year end spending. The present study differs from earlier studies first in its focus solely on defense related contracting, and second in the scope of this project which has a substantially longer time span than previous studies. This study will serve as a modest catalog of defense contracting facts, utilizing the large pool of individual data points to produce a series of summary statistics about the functioning and idiosyncrasies of the defense process. These statistics will prove helpful in motivating later studies by elucidating the influential determinants of government contracting, and suggest aspects of the process that may prove fruitful for efficiency gains with respect to cost.

To foreshadow the results, there are a series of seven main results that are developed throughout this essay. First, the distribution of individual contract dollar obligations is highly rightward skewed, with a relatively small amount of expensive contracts stretching the distribution substantially. Second, the geographic distribution is also skewed, where a few states account for significant portions of contract spending, measured by both frequency and total dollars. California consistently is 
the State where the majority of contracts are awarded. While during recent years states experience relatively greater geographic dispersion, the general trend of concentration in relatively few states holds across the dataset. Third, regression estimates suggest that annual aggregate fixed effects collectively account for the largest portion of variation in contracting dollars, in the range of 20-25 percent of total dollar obligation variance. The influence of annual effects suggests that annual aggregate shocks have historically had the strongest impact on individual contract awards, where these shocks can take the form of changes in political directives, military missions and goals, or even actions by foreign agents.

Fourth, firm-fixed price contracts are by and large the most economical contract type, from the government's perspective. Firm, fixed price contracts of contract accounts for the majority of awards but far from all, and alternative contract types cost significantly more for the government: fixed price contracts with additional fees paid to contractors experience increases in contract obligations from 50 to 116 percent, and cost type contracts push contract prices up anywhere from 120 to 400 percent. Fifth contract financing ${ }^{4}$ is associated with increases in obligations by anywhere from 62 percent up to 400 percent. Across all financing the government has a preferred hierarchy of finance types, determined by the perceived riskiness of each type of financing. Estimates suggest that the most preferred financing type (the least risky) also corresponds to the financing type with the largest average increase in contract dollars. In fact the order of preferred financing is exactly opposite to the order of average costliness of those financing types, which brings into suspect the justification for this preference ordering in the first place. These two findings highlight potential sources for future process restructuring and possible savings.

\footnotetext{
${ }^{4}$ Contract financing is the early payment of a contract by a portion of the contract, or entirely, prior to the delivery of goods or services or the end of a contract.
} 
Sixth, increased duration of a contract are associated with increased dollar obligations. Specifically, for an increase in the duration of a contract by ten percent, the associated rise in obligated dollars is around 4 percent. And seventh, promotion of competition does not seem to be as powerful a tool for potential savings as it is often suggested to be, particularly when compared to the cost impacts associated with contract types and financing mentioned above. While contracts that are not awarded through competitive means are more expensive, the increase in cost is as low as 3 percent and only as high as 14 percent. Combining the relative unimportance of competition in dollar variation with the results surrounding contract types and contract financing previously mentioned, a shift from solely the promotion contract competition towards a restructuring of the process may prove to be the most effective way in reducing contract costs.

The rest of the chapter will progress as follows. The next section will discuss the data sources for this project, along with some potential pitfalls contained therein and how they are addressed. Section three will go through the meta-data on the pool of individual contracts to provide a set of descriptive statistics on contract dynamics and characteristics. The set of descriptive characteristics is compiled by both pooling and filtering the contracts across time, state, and goods, in order to get a detailed and comprehensive understanding of the dimensions of contracting. The fourth section will estimate relationships between individual contracts and a number of influential factors: time, geography, good types and contracting structures. Finally concluding remarks will be provided.

\subsection{Data Sources}

The data employed in the analysis here is compiled from a variety of sources, including the Bureau of Economic Analysis, the Bureau of Labor Statistics, the United 
States Census Bureau, the Department of Defense, and the Federal Procurement Data System. Combined, these data sources form a panel of contracts from 1966 - 2012.

As mentioned previously, data from individual prime military contracts are the crux of this study. The records of military prime contracts are provided by the United States Department of Defense, recorded on forms DD-350. The fiscal years of 1966-2006 are cataloged by the Statistical Information Analysis Devision (SIAD) of the Department of Defense ${ }^{5}$. Form DD 350 was required to summarize individual contracts with a net dollar amount above a threshold, where contracts below this threshold are collectively described. For the data from 1966-1983, the amount pertains to contracts whose net value is above 10,000 dollars. As a result of administrative changes brought on by the Competition in Contracting Act of 1984 (CICA) this threshold increased to 25,000 dollars. To provide clarity, a sample of form DD 350 from 1998 is presented in figure 1.1. The dataset contains observations on dollar obligations, deobligations, and contract modifications that may be below the threshold or even a zero dollar observation, as these observations modify previous actions, where the net amount exceed the threshold. Also as a result of moves to modernize the Federal Procurement Data System (FPDS) starting in 2004, this threshold was no longer utilized, and all contract actions were reported ${ }^{6}$.

These data provide a wealth of information. Each contract form may contain information on the contractual details such as the type of contract, dollar obligation, financing of the contract, the signed date of the award, the expected terminal

\footnotetext{
${ }^{5}$ Legacy data is stored on the Internet for fiscal years 1966 to 2006, at http://siadapp.dmdc.osd.mil/procurement/Procurement.html.

${ }^{6}$ In the fiscal year of 2004, the FPDS began a shift in data reporting structures that no longer separated contracting actions below 25 thousand dollars from larger dollar contracts. The practice of collectively summarizing the lower dollar amounts began to be phased out in FY 2004 and this transition was completed in FY 2007. As a result the data sets beginning in 2005 contain many more observations than early fiscal years, principally because they include all contracts.
} 
date of the contract, the location of the work to be performed, depending on the record keeping requirements of that fiscal year. For contracts during the period of 1966-1983, each observation contains upwards of 31 different data points. After the CICA in 1984 we see the collection of information increase substantially to about 90 different data points. These data points include more detailed information on the terms of the contract like financing of the contract if applicable and details on the individual contractor such as whether the business is women or minority owned, the size of the business at various degrees of precision, etc. The increased collection of data evolved in an effort towards increased accountability for various legislative economic mandates ${ }^{7}$. To provide some insight into how the data appear, an individual observation from the fiscal year file of 1998 is provided in table 1.1. While not intended to be representative of the entire panel, the content of the observation presented provides the general flavor of the information contained here. While the exact information changes over time depending on current and phased out legislation and various political programs that come and go, a great deal of this information used in the subsequent analysis is available for periods of greater than 10 years, allowing significant scope for interesting and telling estimations.

For more recent years, 2007-2012, contract procurement data are garnered from the Federal Procurement Data System and stored at the website developed by the Office of Management and Budget, at http://usaspending.gov/. This information will further be supplemented with data from the Federal Procurement Data System - Next Generation (FPDS-NG) found at https://www.fpds.gov/ which collects information on federal contracting more broadly. These data are used in effort to provide a frame of reference to understand defense contracting in the context of over-

\footnotetext{
${ }^{7}$ As an example, federal laws aimed at bolstering small disadvantaged businesses or minority owned enterprises that developed out of Small Business Administration programs.
} 
all contracting. These more recent observations have richer set of information than the previous ones, mostly because of changes in data reporting standards within the federal government and the ease of digital reporting. These files are merged with the earlier data points to generate a time span of slightly more than 46 years, between 1966-2012, with upwards of 22 million individual contract observations available for analysis.

As is common in databases that were compiled from sources existing prior to widespread computer usage, the early datasets contain many missing observations for some variables other than the date, location and primary dollar obligation. The relative sparseness is not the case for observations existing from 2005 and on, as the FPDS-NG was implemented and greatly improved the precision of record keeping within federal procurements. Therefore depending on the type of study, and level of refinement or aggregation, these errors may or may not greatly affect the results. With such an extensive pool of individual contract action observations, one can expect improved precision and robustness against such measurement errors, and throughout this study care will be taken to appropriately address possible issues around sample size and irregularities in record keeping across time

Aggregate CPI data is gathered from the BEA, and is available in monthly and annual frequencies with a base year of 1983-1984. Unfortunately historical data on State level prices is not available, where the BLS only publishes CPI data at national and regional level ${ }^{8}$. As such, a great deal of the analysis within is conducted contract dollars deflated with the aggregate annual CPI for the full time span of our panel of 1966-2012.

\footnotetext{
${ }^{8}$ These regions are also somewhat broad; Northeast, Midwest, South and West. One can easily imagine large variation of prices within these regions, say between Montana and California, both in the Western region.
} 


\subsection{Defense Contracting in the United States}

In order to fully characterize contracts and the processes that motivate procurement, this section will build the foundational information regarding defense contracting. First the process of defense contracting will be briefly outlined, describing the regulations that dictate the process and how scholars have characterized it since. Second I will describe the general distribution of contracting from many dimensions to provide insight into what questions can and can not be answered using defense spending. Then the distribution of contracts across both time and geographic regions will be discussed and how these factors may influence any subsequent analysis. Finally we will focus on procurement across goods and service categories.

\subsubsection{The Defense Contracting Process}

For obvious reasons, defense contracting is a politicized and often controversial subset of federal spending, and as such regulations that dictate their solicitation, obligation, and enforcement are outlined at length by several hundreds of pages of federal law ${ }^{9}$. In addition to this, the Federal Acquisition Regulation (FAR) issues almost 2000 pages of procedures in finer detail regarding procurement more generally, which also applies to defense related contracting. Therefore it is prudent to briefly outline the contracting process to provide a baseline of understanding and context for this analysis.

\footnotetext{
${ }^{9}$ US code pertaining to the armed forces defines the rules around procurement is 10 U.S.C §2301-2335 devotes roughly 150 pages to the broad codification of US law around defense procurement. Further US code title 41 U.S.C $\$ 1301-1312$ issues the authority to establish the Federal Acquisition Regulation.
} 


\section{Contract Competition}

The legislation is written so the principle preference for contract officers should be to allow for full and open competition of each procurement advertisement through competitive procedures ${ }^{10}$. While this is the preference, full and open competition for contracts is not always strictly required, and the majority of the legislation pertaining to procurement competition is devoted to describing caveats to this requirement. Such caveats are typically described as circumstances where concern for future supply, national defense, lack of capable sources, or urgent need exist, to name a few. Furthermore the head of the agency, specifically the Secretaries of Defense, the Army, the Navy, and the Air Force have significant latitude to limit competition, but must justify such reasoning to congress. The nature and degree of competition in procurement is among the most controversial dimensions of defense contracting. In March of 2009, President Obama issued a memorandum stating that federal agencies must inspect their contracting practices in order to promote competition and reduce sole source contracts as much as is possible in order to reduce waste and increase efficiency in procured goods and services (?). Considering the official reports of waste and inefficiency (?) and various academic studies inspecting contractor abuse which provide anecdotal reports of misuse and waste (???), efforts to increase competition has long been the most politically attractive method for efficiency gains in contracting.

There are the obvious benefits of reduced costs, improved quality or both as a result of increasing competition for each contract awarded. Increased competition mayh also come with the downside however of longer award-decision timetables than noncompeted contracts, which may unduly delay needed procurements. Also consider the negative impacts of increased award uncertainty on research and development

\footnotetext{
${ }^{10}$ Competitive procedures are typically defined as sealed bidding or competitive proposals $(?)$.
} 
decisions. The increased award uncertainty may push firms away from bidding on contracts, even if they have a potentially innovative process, or solution to any particular contract solicitation. The inclusion of otherwise omitted contractors is one reason that a contracting officer may restrict the degree of competition or eliminate it all together if there are clear benefits to the government.

This dataset contains information on the extent of competition each contract faces; describing the extent of allowable competition and also the number of offers received. Of the more than 22 million contract observations contained within this dataset, 56.4 percent of all contracts were subject to full and open competition while 18.5 percent were subject to non-compete procedures, and of the contracts subject to full and open competition, 17.5 percent received only one offer. Table 1.2 describes how contract dollar obligations are split across degrees of contract competition. One aspect that is unclear from the dataset is a direct measure of contractor performance, i.e., contract outcomes. However we can look at the signed price of a contract, and it is clear that there are reductions in mean if not median dollar obligations as a result of competition. In section 1.4 we will directly estimate the impact of competition on individual contract dollars to see the potential for savings by promotion of competitive procedures.

\section{Contract Types}

The DoD can enter into procurement contracts that fall into one of two broad categories: fixed-price contracts or cost-reimbursement contracts. The primary difference between these two categories is which party assumes the risk of an unforeseen rise in costs during the duration of the contract, with the former falling on contractors and the latter falling on the government and ultimately the taxpayer (?). The government can choose the appropriate type of contract pricing to best meet its needs while 
procuring the highest quality and most cost effective item or service, and arguments for or against either type of contract are closely related to promotion of competition listed above. Again FAR language is clear that preference is to sign fixed-price type contracts, which taxpayers would also prefer as they shift the risks onto the contractor. However this shift in risk burden may discourage or limit contractor participation in current, and perhaps more importantly future bidding, depending on the product or service being procured. Cost type contracts are often geared towards research and development work, or work with non-profit institutions or universities, where the risks are significantly higher and this discouragement effect would be significant. Therefore beyond a few restrictions the contracting officer can choose the type of contract that best benefits the government during solicitation; on the basis of the complexity, degree of market competition, urgency and a number of other factors that apply to the contract at hand, or decide on the contract type upon negotiation with a specific contractor. Within these main two types are the following levels of refinement: firm-fixed-price, fixed-price-with-economic-price-adjustment, fixed-price- redetermination, fixed-price-level-of-effort, cost-contract, cost-sharing, cost-plus-fixed-fee, cost-plus-award-fee, fixed-price-incentive, cost-plus-incentive-fee, time-and-materials, and labor-hour.

To provide some detail of the distribution across types contract pricing and payment structures, table 1.3 provides some summary statistics. As is clear in the table, firm fixed price contracts account for the majority of all contracts signed at 78.5 percent. The cases of cost type contracts, with the risk all or mostly falling on the government, account for fewer but far from an insignificant amount of all contracts. With the discussion surrounding risk which ultimately translates to expense, one should expect that fixed price type contracts typically cost the government less and exhibit less spread in their distribution. The risk seems to be born out in the data 
in the form of higher priced contracts, with both the mean and median of various fixed price contracts significantly lower than those seen across cost type contracts. Furthermore the skewness of fixed price contracts is also less severe than cost type contracts whose end dollar amount is less certain at the original signing date.

\section{Award, Payment, and Financing of Contracts}

As outlined in the FAR ${ }^{11}$ a contract invoice must be paid no later than the $30^{\text {th }}$ day after either the receipt of the contracted item or services, or the receipt of the invoice by the appropriate billing office, which ever comes later. Typically this payment occurs upon delivery of the products or completion of the contract.

Alternatively the government can opt for contract financing, where the government pays for a portion or all of a contract in advance of receiving items or before the completion of the contract. Contract financing, while not applicable to all contractors or contracts, is intended to be another tool for the contracting officer to promote effective competition and inclusion of the best possible sources for each contract. The government can opt to finance contracts in the form of partial or percentage of progress payments, advance payments or other terms. Furthermore, contractors are invited to submit individual financing terms for contract payments into original proposals, which will be taken into account during the award stage. Information on a particular contract's financing is available from fiscal years 1989 to 2011. Although the details of the terms of financing for valid contracts are not known, the data will provide insight into the impact that various types of financing have on the obligated dollars of a contract. The levels of contract financing presented in this dataset are: progress payments, percent completion progress payments, unusual progress or ad-

\footnotetext{
${ }^{11}$ The section of the Federal Acquisitions Regulations that pertains to contract financing is subpart 32.9.
} 
vance payments, commercial financing, performance based financing or if financing does not apply.

Furthermore, the type of contracts, be they fixed price or cost, does not preclude that contract from receiving financing. The distribution of contract types among financed contracts is roughly consistent with the distribution of contract types across all contracts more broadly. Table 1.4 provides the distribution across various types of financing for that contract. If financing terms are included in a contract, the FAR directs contracting officers towards a preference for financing via progress or percentage of completion payments, which comes through in the data accounting for more than 70 percent of all financed contracts ${ }^{12}$.

\subsubsection{The Distribution of Contract Spending}

Defense contracting has historically accounted for the lion's share of federal procurement. As stated in ?, the United States made a permanent shift towards maintaining a significant standing army, in part as response to the threat of communism and in part as corporate welfare to the defense industry. As such, the Department of Defense has accounted for on average 71.5 percent of all federal procurement dollars and typically between 60 and 80 percent of spending in the past several decades, as shown in table 1.5. The immense size of defense contracting, both relative to all federal contracts and in absolute terms, suggests significant potential to influence the economy, and part of why defense spending is such an attractive source of fiscal shocks for researchers. The size and power of defense spending however only further

\footnotetext{
${ }^{12}$ As with much of the FAR, the reasoning for limiting usage of advanced payments is to provide limited governmental exposure to financial loss in the event of a failure to deliver any contracted goods or services.
} 
motivates the need for better understanding of what influences contract dollars, and the following exposition will cover the landscape of contracts with this goal in mind.

Furthermore when addressing the general distribution of contracts, one must account for changes in administrative record keeping that may affect the shape of the distribution. As previously mentioned the data in this study are gathered from the individual contracts described on the DoD's form DD-350 for internal record keeping purposes. Until 2004, the DoD would send monthly reports to the Federal Procurement Data System that summarized reports below 25,000 dollars, reported on form DD 1057. During the modernization to the Federal Procurement Data System-Next Generation (FPDS-NG), there was a move to eliminate this distinction, and subsequently all contracts were individually summarized regardless of dollar size. These restrictions on the data availability of contracts applies primarily to the number of actions, and not necessarily the dollar value. ? suggest that contract dollar size is highly skewed from 2004-2009. Extending the analysis back to the 1980's, figure 1.2 suggests this case still holds true for the time span of 1980-2011. Note that on the basis of frequency counts, defense contracts reported on form DD-350 account for a relatively small percent of all Federal contracts. However these relatively few contracts account for the vast majority of both defense contracting dollars and all federal contracting dollars. Depending on the type of one's study, these distinctions may make a huge impact, i.e, consider utilizing aggregated dollars. A study deploying aggregate dollars would not see a huge impact in the results, but if a study is using micro level data, the skew could greatly influence any subsequent results.

To further illustrate the degree of skewness in contract dollars, figure 1.3 displays the kernel density estimation of all dollar observations in the inner $80^{\text {th }}$ percentiles. Clear in the illustration is the extreme degree of skewness in contract spending. If observations are constricted further to the inner quartile, significant skewness is still 
evident. The pattern of serious skew indicates that care should be employed when looking at contracts on an individual basis, where such extreme outliers may bias one's results.

To gain some insight into how the administrative changes may impact any study on contracts, the dataset is split into sections. There are two significant changes in administrative record keeping. First occurred when the summarization threshold was raised, and second change was the elimination of a threshold entirely, in FY 1984 and FY 2004 respectively. Fiscal year 2004 particularly important in this regard, where the elimination of the summarization threshold means that all contracts are now recorded, instead of just those above the threshold. By including all of the smaller contracts could significantly diminish the skewed nature of the data, masking its severity in the data. As seen in top half of table 1.6, this is exactly the case. The period of 1984-2003 displays the most sever, positive skew, with the fattest right tail of any subset of fiscal years. The latter period, 2004-2012 exhibits the least skewed data, but is still slightly rightward skewed. Therefore, beyond an inspection of outliers mentioned above, one should also be cognizant of these clerical changes and the influence it may exert on any results. For example the estimations in the next section have the potential to be significantly affected if the estimation sample spans these events, and the structural breaks were unaccounted for. These breaks will be dealt with more explicitly in subsection 1.3.3.

To further inspect these outliers, table 1.7 lists the statistics for the tails of the contract spending distribution; below the $10^{\text {th }}$ percentile and above $90^{\text {th }}$ percentile. After sub-setting the outer deciles into several groups it becomes clear that a great majority of the skew in spending comes from the most extreme observations. For example, the coefficient of skewness is 1267 for the entire last decile, but for decile observations excluding those above the $99^{\text {th }}$ percentile, the skewness is only 1.88 . This 
behavior is similar to the pattern displayed in the first decile. With this information we further restrict our analysis to the outer one percentiles as the source of the best possible candidates for a purge of outliers.

Table 1.8 repeats calculations from table 1.3 after a series of less restrictive outlier cuts are made for the outer $1,0.1$ and 0.01 percentiles. It is clear that these extreme percentile of either tail are responsible for a great deal of skew in the data. The most evident change between table 1.3 and table 1.8 is the fall in the skewness coefficient by more than 67 percent. Another result of this sub-setting is a significant drop in the variance, as measured through the standard deviation of each subset. While this reduction in the variance should be expected, the shift is substantial regardless of the outlier grouping. A third significant difference is the smoothing of previous structural record keeping changes across the observations from different fiscal year groupings. Without the extreme observations, we see that the statistics across all groups of contracts are much more comparable, yielding a dataset of contract dollars that is less skewed, less noisy and smoother over its span.

As this outlier analysis is further refined, the outer .01 percent finally yields a sample small enough to comb through directly. As may be inferred from table 1.7, some the most extreme observations display almost concurrent offsetting amounts, first obligated then quickly deobligated. These may come about as a result of clerical mistakes, impropriety on the part of a contractor or unforeseen events which will result in a contractual breach. To look at the most extreme cases with the observations are sorted by spending size, the top and bottom ten contracts contain several observations that represent initial obligations, followed by the subsequent deobligation of a majority of the dollar amount. For example, the single largest contract by dollar value in the entire dataset was originally signed for 116,091,716,928 and obligated on August 24, 2009, only to be deobligated three days later to net result of 358,227 
dollars owed by the contractor. Also the next two largest contract obligations, for 24 and 13 billion dollars were later modified to a net of zero and 15 million dollars respectively ${ }^{13}$.

Whether these outliers represent clerical or administrative errors or possible yearend signing push, it poses serious empirical issues to researchers looking to utilize this data at the contract level. Directly digging through more than the outer 10 most contracts quickly becomes intractable, particularly with the multitude of observations in the dataset. Aggregation of the data will typically net out these issues, depending on the resolution and time frequency of that aggregation ${ }^{14}$. However if one is utilizing individual contracts in a study these extreme outliers have potential to bias the results. The potential for bias further strengthens the argument for the parsimonious and seemingly effective drop of the outer .01 percentiles. With the evidence that outliers significantly stretch the distribution and may bias results from micro level studies, it would behoove researchers to seriously consider a purge of extreme observations with regard to dollar obligations.

\footnotetext{
${ }^{13}$ The second largest contract in the dataset was for a total of $24,051,635,569$, signed on October 31, 2006, and deobligated fully on the same day. The third largest contract, totaling 13,917,176,427, was signed on September 29, 2008, and deobligated the next fiscal year on January 7, 2009 to net 15,252,000, which represents a drastic drop from the original amount. Also the three largest observations in the entire panel are also the only three observations that are over 10 billion dollars, with the next largest starting at 3.9 billion

${ }^{14}$ Depending on the time frequency if the data is utilized in a time series or panel framework, issues arise when these irregular contracts are not corrected immediately. This may result in one time period spending observation being unduly large and the next unduly small. Intuitively the less frequent the time periods the less this is potentially a problem, but in the example provided by the third largest contract, aggregation across calendar years instead of fiscal years would still cause this to be an issue.
} 


\subsubsection{Defense Contracting Across Time}

Defense contracting has seen significant shifts in the past few decades. ? and ? describe several periods that exhibit a significant military buildup, in both the frequency of contracts and the dollar amount of spending on procurements. Two of these periods are entirely covered by the data contained in the present study: the Carter-Regan era military buildup which began in January, 1980 and the events of September 9, 2001. These authors also suggest a third buildup that is partially contained in this panel, namely that of the Vietnamese war, beginning in 1965. Figure 1.4 charts the annual totals of contract spending, with both the current value and inflation adjusted figures pictured. The evidence of the benefits of deflating the contract dollars is inherent and observable in the charts. Also note that the timing of buildups indicated by ? is displayed quite clearly, particularly when adjusting for inflation. Each of these dates displays the beginning of significant military buildups, as displayed by large, multi-year expansions of contract spending ${ }^{15}$.

As alluded to in the previous section, one could make further restrictions on the data to help improve consistency across the data panel by fully eliminating any observations below the summarized reporting thresholds. The right two graphs in figure 1.4 display this very filter, where below threshold contract observations were purged prior to the calculation of these statistics ${ }^{16}$. Note that while there is a nominal shift in the data, the general trend of the annual totals is relatively unaltered. The

\footnotetext{
${ }^{15}$ As suggested by ? and ?, these dates signify large scale and prolonged buildup in defense spending, as well as the Korean war which is outside of the timespan of this panel.

${ }^{16}$ This purge entails omitting all contract observations below 10,000 dollars prior to FY 1984 and all contract dollars below 25,000 after 1984. For the period from FY 2005 to FY 2012, discerning which observations below 25,000 account for a below threshold observation and which account for a modification to an above threshold observation is impossible. While purging all observations below these two thresholds attenuates the aggregate totals for the periods prior to FY 2005, it provides a consistent view of the data across time.
} 
consistency even holds true for the later years, where the greatest amount of the affected observations lie. The result of filtering low dollars is expected for aggregate spending though, again being reminded of the data in table 1.5, where a great deal of the total spending is derived from a relatively small pool of the largest observations, and the below threshold contracts historically count for about ten percent or less of all total contracting dollars. Also removing below threshold observations does not seem to affect the annual standard deviations, only slightly reducing them for the filtered data.

The post filter consistency is not the case however for the micro oriented statistics however, particularly contract frequency, and mean and median dollar obligation. To illustrate the lack of consistency, figure 1.5 lists these three graphs for deflated data, before and after omitting below threshold observations. After performing the filter, the micro-oriented statistics in the graphs experience a significant and visible change compared with the non-filtered data. With the unfiltered data, casual observation of the graphs would accurately suggest a significant structural change in the data beginning roughly around 2004. After filtering the data however, the evidence of structural break around the end of the time period is not so clear. The amount of information loss resulting from omitting below threshold contracts is not insignificant however, with the result of a purge of roughly 43 percent of the original data.

Next to the results from figure 1.5 and the visible impact of the threshold cut, the much smaller purge of the outer tails of our contract distribution described in section 1.3.2 suggests a more nuanced impact on our summary statistics. Results of these outlier purges are shown in figure 1.6. The displayed statistics are from the dataset cut as presented in table 1.8, beginning with the outer most 1 percent and dropping less observations in subsequent frames. Consistent with the impacts described in 1.3.2, changes resulting from these outlier omissions in this figure appear mostly to 
be nominal. It is clear that the totals in each year, and the range of those totals, are reduced when compared with the entire dataset but the shape and general trends remains generally unchanged after any of these outlier cuts. To further illustrate the impacts of this outlier filter on the distribution of the data, figure 1.7 duplicates the statistics presented in figure 1.5, after omitting the outer .01 percentile. Unlike the obvious and striking impact seen in figure 1.5, omitting the outer .01 percentile seems to retain the structural shift in the statistics that is present in the unfiltered data.

The question of whether to use the threshold filter which results in a large scale reduction of observations, or the outlier-tail omission which retains the majority of observations but does not address the structural changes in data collection, is answered by the goal of the research at hand. Deploying defense contracting in aggregate, macroeconomic research would benefit most from the smallest purge of data; dropping only the outer 0.01 percentiles. The parsimonious outlier filter retains the scale of aggregate totals that are necessary in macro studies while addressing the possibility of errant contract mistakes present in the most severe outliers. Furthermore if the study has a microeconomic bent that utilizes individual contracts as the population of interest, pooling contract data across the structural breaks described here presents the possibility of biased results. Using the threshold filter described above could help to address these changes in contract reporting methods helping to increase sample size and estimation precision instead of simply splitting the data across these periods.

\section{Seasonality}

Turning now to focus more on a seasonal perspective, figure 1.8 plots the frequency of contracts during the year, at a monthly and weekly frequency ${ }^{17}$. The most notable

\footnotetext{
${ }^{17}$ The use of both time frequencies is necessary, as only the month of the contract is recorded in data prior to the CICA in 1984.
} 
feature of this image is the year end rush to sign contracts. ? cites this characteristic of all federal contracts for the fiscal years 2004 through 2009, describing a frequency during the last week of the fiscal year that is more than 4 times higher than through the rest of the year. The end of year rush is also evident in this longer dataset, particularly in the weekly frequency data. ? suggests that this is in large part the result of "use it or lose it" type budgets, where unspent funds in one year may prove more difficult to garner the following year.

To better analyze the seasonality in contracts, observations prior to fiscal year 1984 are omitted to display the data in figure 1.9 in a weekly frequency. Here several statistics beyond the frequency are displayed, with several notable patterns in the data. When inspecting the weekly frequency from figure 1.8 and the total, mean and median values across weeks in figure 1.9, a large spike in both dollar value and number of contracts signed at the end of each quarter is clear, and to a lesser extent at the end of each month. While the end of the fiscal calendar yields the largest spike across statistics and is most likely driven by the contracting offices, the smaller spikes in quarter and month end spending are most likely driven by the individual contractors and standard business practices. These constraints most likely include the delivery of earnings reports, accounting deadlines, and project timetables, all of which traditionally exhibit the periodicity exemplified here, which results from operating on a monthly or quarterly planning horizon. Many government contractors are small private firms solely devoted to governmental work where quarterly earnings reports and third party commercial interests are not as much a concern. However a great deal of government contract work is performed by large, publicly traded firms with a great deal of commercial work outside of contracts, such as Boeing or General Electric. It is likely that various project teams at these firms work on timetables dictated by 
corporate policy, and these timetables would drive the quarter and month end spike in both contract size and frequency.

The seasonality is an important aspect of the data, which could help motivate sub-annual dynamic aspects of the data. In certain applications it could also be a source of spurious results, particularly in microeconomic studies. The estimations in the present study will directly control for the year end rush of contract signing and estimate the impact that this timing has on contract dollars.

\section{Duration Analysis}

The duration of a contract is another time dimension which can impact subsequent analysis. Consider a research problem that is looking at the economic impact of a shock resulting from a quick shift in DoD mission. By including long-term contracts that do not include financing options means that the contractor is paid long after the contract signing, and the actual impact of those dollars may not directly correspond to the sign date which could conflate one's results. Alternatively including long term contracts and accounting for the duration of these contracts in the presence of short ones can help elucidate the relationship that length of time plays with contract dollar awards.

The bulk of these observations contain both the initial and terminal dates of each contract ${ }^{18}$. Table 1.9 contains statistics for various levels of contract length. Contracts with a negative duration account for modifications to past contracts, where the final date of the contract may precede the signed date of the modifying action by many years. Also, contracts that extend for multiple years can be for goods or services and are typically large enough to find major cost benefits from economies of scale.

\footnotetext{
${ }^{18}$ By bulk we mean excluding the observations from the FY 1984 - FY 1988 files, where the information is largely missing
} 
A simple one way ANOVA test confirms that there is a highly significant, statistical difference in the mean spending across these levels of contract duration, suggesting that considerations should be taken to account for duration of those contracts.

\subsubsection{Defense Contracting Across States}

Military contracting exhibits significant geographic concentration for a number of political and economic reasons. To provide context to this statement see figure 1.10, which illustrates this geographic concentration as averaged across each of four different decades. As illustrated here, very few states experience sustained concentration of contract awards, namely California and for more recent years and to a lesser extent Texas and Virginia. Figure 1.11 offers more granular exposition of this trend across all states, and tells a similar story; relatively few states receive a large amount of spending compared to most of the others.

Considering the sheer dollar amount of many of these contracts and the substantial skills involved in manufacture of major systems used by the DoD, this concentration can be expected as the outcome of rational decision making by contractors. Many large contractors are able to take advantage of both economies of scale and extensive procedural knowledge, attributable to a long running history of repeated contract awards. These large contractors are very likely able to employ their size and expertise to effectively outbid competitors and garner successive awards.

Beyond the level of competitive pressure exacted by large contractors are industrial spillovers that can lead to significant agglomeration of smaller defense contractors. Billions of dollars on an annual basis is more than sufficient market volume to bolster a significant infrastructural network devoted to military procurements. Considering the complexity of many of these major systems, the levels of technical skills required for their development and production would necessitate a labor force of highly trained 
STEM professionals. Concentration of labor in this manner would suggest that subcontracting firms would also locate near these areas, who are devoted to serving prime contractors, and possibly bidding on prime contracts directly as well.

Spillovers could also be manifested through regional concentration of professional services designed to serve smaller contractors. These smaller firms may outsource legal, clerical and accounting duties which may require significant specialization geared to federal contracting ${ }^{19}$.

Another component of the geographic concentration may be derived from political variation across states. It is common practice for regional governments to tailor their tax policies and regulation to court industries, directly competing with other states for the benefits of increased business activity and jobs. One can imagine that as part of a contractor's optimization decision, regional variations in tax expenses and the severity of red tape are among the factors considered. A possible example of changes in political climate is seen in figure 1.11, where it may very well be the case that in New York the business climate grew inhospitable for contractors, while the opposite happened in Virginia. However without delving deep into the regional legislative actions of individual states any political changes will be difficult to fully detail.

National politics play into the geographic dispersion as well. Long serving congressional politicians typically hold committee seats that are responsible for directing a larger share of federal funding to various projects. Politicians that channel funds to their home districts in the form of increased federal contracts can gain significant financial support from their constituencies (??). This channel would further strengthen the degree of regional concentration.

\footnotetext{
${ }^{19}$ For example, consider cost type contracts typically used on research and development. Firms must have sufficiently detailed accounting techniques to be awarded such contracts.
} 
There is a great deal of military procurement that is not subject to these pressures of regional concentration. Typically work such as construction or building maintenance services aimed at non-specialized infrastructure, and food or medical supplies for military bases would fall under this category. There is also the possibility of a multitude of unobservable geographic effects that may play a role. Consider that perhaps a large contractor is located on the coasts for access to sea ports for their involvement in non-governmental contracts, or a contractor is located in North Dakota or Texas for proximity to petroleum resources. The dataset provides the location for the vast majority of contracts, which allows estimations to employ regional fixed effects which would control for these long term geographic idiosyncrasies which would otherwise be inestimable. The impact of regional fixed effects will be included in the estimations in section 1.4 .

\subsubsection{Defense Contracting Across Goods and Services}

As the largest federal purchaser of goods and services, and because of the sheer size of the US military and its global missions, the variety of goods and services it procures is quite large. Some ways to quantify the depth and breadth of this variety is conveniently supplied in the data. Each contract observation contains a four digit Federal Supply Classification (FSC) code, used by the federal government to categorize that contract into a subset of services or goods. Inspection of these categories however suggests that some care should be taken to distinguish between good contracts and service contracts. The current subsection will present the argument that service categories are too ambiguous and vast to appropriately control for dollar variation across contracts, by describing these categories in detail.

Distinction between goods and services is common in the field of international trade since services display unique characteristics, mainly that of task customization 
for each contract ${ }^{20}$. Firstly consider the significant customization required for most service contracts. Unlike goods, a service entails a level of specificity to any single job that is often not directly translatable to a separate service contract. Service customization makes categorization of services inherently difficult and somewhat broad based. Consider FSC category R425, engineering technical services, and the scope of professional services that may fall under this umbrella. Each contract under the engineering technical services classification will require some specialized tailoring of skills, expertise, resources and most importantly cost, that is unique to the job at hand. The same thought experiment can be made for most, if not all of the various FSC categories, from custodial services (S201) to demolition of buildings (P400). The extent of specific customization is especially true for various research and development projects, where even a single FSC designation fails to provide a great deal of insights into the cost and final values of a contract from the uncertainties inherent in research. Certainly analogous arguments can be made for various goods categories but in terms of degrees, services are far more precisely tailored to task at hand and far less fungible across contracts than are goods.

To better quantify this, the data are split into goods contracts and service contracts, and ANOVA results are listed in table 1.10. This table provides the estimation results from different subsets of the data; pooled FSC codes, then services alone and finally goods alone. After the implementation of the CICA the FSC codes for services were drastically changed while codes for goods were not, therefore the first three groupings contain data post 1984 eliminating this structural inconsistency, and as a comparison results for the full time dataset only containing goods contracts is listed

\footnotetext{
${ }^{20}$ Specifically ? and ? both speak to how customization for each recipient can provide a wedge between modeling services trade and goods trade which typically do not require the degree of specificity.
} 
in the last grouping ${ }^{21}$. It is not possible to compare the goods and services directly in the traditional ANOVA model building framework since they represent different samples of data. However the inclusion of the pooled sample provides a reference to judge the fit of either subset. When we consider the one-way ANOVA results of utilizing only the FSC fixed effects on contract dollars, we see that there is a modest fit for each model, with the strongest fit via $\bar{R}^{2}$ captured by the pooled regression. However when accounting for time and State effects as well, the fit of the model using goods only data is markedly improved, yielding the highest $\bar{R}^{2}$. Furthermore when compared with the pooled data, isolating only service contracts yields a relative reduction in model fit. Furthermore, when comparing subsets, goods contracts provide the smallest root mean squared error when comparing similar model structures.

It is in the context of service customization that it would be advisable to make the distinction between which set of contracts are analyzed. In all of these regressions, the unrestricted ANOVA suggests that the major portion of the explanatory power of the model is derived from the annual-time effects. While obviously accounting for aggregate level effects such as federal fiscal and monetary policy, these annual-time effects are also capturing changes in the goals and mission of the DoD, which in turn impacts the types of contracts sought. In the absence of time fixed effects, the explanatory power derived from changes in mission policy on contract prices may be incorrectly attributed to a contract FSC group attribute.

For example consider a policy shifting from large scale ground incursions to targeted air strikes. Such a change to policy may result in a shift in the procurement of fixed wing piloted aircraft towards smaller unmanned drones. Or consider a shift

\footnotetext{
${ }^{21}$ In 1984 there are around 1100 service code categories that were either recategorized or dropped, and the mapping of codes across this year is unknown. If we included the earlier time points and count them as entirely separate groups in the first two ANOVA sets the results are relatively unchanged, with the $\bar{R}^{2}$ values only slightly higher and the other results relatively static.
} 
from research and development on fossil energy to renewable energies, in order to reduce vulnerability to energy shocks. In either of these scenarios, if time effects are excluded, reduced demand for any given set of goods will decrease the price and this channel will not be captured, but good effects will errantly explain more variation of the model which is actually attributable to mission changes. Ignoring annual shifts in policy (captured by time effects) will emphasize the effect that contract categories (captured FSC effects) have on contract dollars.

While all variables in the models listed in table 1.10 are significant ${ }^{22}$ use of the unrestricted model with all three fixed effects groups shows to a large extent different impacts to the overall model fit depending on the subset of FSC codes used. In the goods subset, it appears that the time effects have the largest impact on model fit, capturing these aggregate level shifts in policy and mission goals. Beyond the time effects, the goods specific FSC codes seems to improve the fit even more. The improved fit of goods effects suggests that FSC categories for goods more accurately account for differences in the prices across contracts.

The opposite is true for services however. Here the changes to various mission goals and other aggregate level effects produce a reduction in model fit of an impact on contract dollars, while the type of job or services rendered captures more variation towards the final contract obligation, when compared with goods. Again this inability for time effects to explain as large a portion of the variation most likely follows from the original suggestions of the customization necessary for each service contract. Overall however it is clear that the fit is significantly worse among these contracts.

Another explanation for this gap between the model fit of goods versus service contracts can be determined by the connection between price and the unobserved

\footnotetext{
${ }^{22} \mathrm{An}$ F-test shows that each factor variable is highly significant at the 0.1 percent level, across all regressions.
} 
quantity. One of the limitations of this dataset is the lack of information on specific quantities contracted. The impact that quantity can play on the resulting contract price for goods is obvious, while it is a bit more ambiguous for services. Considering that we do not directly observe the quantity of contracted goods, including time fixed effects helps to control for the aggregate shifts in prices, affording the model better fit and less variance accountable to the unobservable elements in the error term. In an observation where the contract is for fixed wing aircraft in the year 1989 and the final contract price is known, the number of fixed wing aircrafts can be more easily inferred.

When considering service contracts, the notion of quantity is not as translatable. Quantity for service contracts encompasses a range of details that affect the final contract price; from labor hours, contractor expertise, size of the job, etc. It is this multitude of factors that yields time effects that are not as powerful in explaining the variation in the model when compared with goods contracts. In an analogous example, a contract for engineering technical services in the year 1989 and having access to the price and location of the contract, the unobservable quantity variable is not as easily inferred. These unobservable aspects imply a lack of clarity on a host of details that are fundamental in explaining the final price, and will leave a much larger piece of the puzzle hidden. The inability to directly observe quantity in this sense will therefore impact models of goods contracts less so than models of service contracts.

To provide more illumination of the FSC categories, table 1.11 lists the top five goods and top five services by three different measures. Glancing across these categories it is evident that service categories are inherently more ambiguous than the goods categories. The ambiguity is typical across all FSC codes, beyond the few categories listed here. Looking at goods alone, this dataset contains upwards of 684 
different goods classification while service categories take up almost three times as many groupings, with 2376 different classification categories. Beyond this difference in the variety of categories, consider also that more than half of all listed service codes designate research and development (RDTE) activities. Further splitting the services into RDTE and other services allows no improvement in model fit, where the RTDE only subset provides the poorest fit yet ${ }^{23}$.

It is this ambiguity coupled with the relative vastness of service FSC codes which makes service fixed effects rather poor at capturing the variation in contract dollars. The remaining estimations in this study will use only the goods FSC codes as a control for unobservable effects. There are practical benefits to the restriction to goods contracts beyond the improved model estimation fit and theoretical issues. Unlike service codes, FSC goods codes are aggregable from their native four digit identifier up to a two digit identifier. The ability to aggregate the codes proves extremely beneficial to this study by providing tractability, allowing the use of fixed effect interactions between these aggregated codes in a manner that can still be computed. As stated above there are more than 600 different categories for analysis, when coupled with State or year interaction terms, the estimation can have upwards of 30,000 variables. At the two digit level, our goods codes are restricted to just over 80 categories, greatly improving the tractability of computations and resulting estimates on interaction terms. The estimations in the next section will actively address this difference in identification. There is certainly room for inspection of service contracts in a more direct way, but that analysis is outside the scope of this study.

${ }^{23}$ While omitted from table 1.10 for brevity, the model $\bar{R}^{2}$ is as low as .14 or .16 for only RDTE coded contracts, for the analogous restricted and unrestricted models as listed in table 1.10. 


\subsection{Estimation Analysis}

The variables and fixed effects included in the estimates in this section are largely motivated through the distributional analysis in the preceding one. Considering the multiplicity of unobservable factors that affect the dollar obligation of a single contract, this study will employ a variety of fixed effects with the hope of controlling a significant proportion of the variation; specifically time, state, and good level fixed

effects and various interactions of these terms. These regressions will be variations on the following models:

$$
\begin{gathered}
c_{g, s, t, i}=\gamma_{g}+\sigma_{s}+\tau_{t}+\mathbf{x}_{\mathbf{i}}^{\prime} \beta+\epsilon_{i} \\
c_{g, s, t, i}=\gamma_{g}+\sigma_{s}+\tau_{t}+\left(\sigma_{s} \times \tau_{t}\right)+\mathbf{x}_{\mathbf{i}}^{\prime} \beta+\epsilon_{i} \\
c_{g, s, t, i}=\gamma_{g}+\sigma_{s}+\tau_{t}+\left(\gamma_{g} \times \tau_{t}\right)+\mathbf{x}_{\mathbf{i}}^{\prime} \beta+\epsilon_{i} \\
c_{g, s, t, i}=\gamma_{g}+\sigma_{s}+\tau_{t}+\left(\gamma_{g} \times \sigma_{s}\right)+\mathbf{x}_{\mathbf{i}}^{\prime} \beta+\epsilon_{i}
\end{gathered}
$$

Here $c_{g, s, t, i}$ represents the natural $\log$ transformed dollar obligation for the $i^{\text {th }}$ contract belonging to the $g^{\text {th }}$ FSC demarcated goods category, procured in the $s^{\text {th }}$ State during the $t^{t h}$ calendar year. $\mathbf{x}_{\mathbf{i}}$ is a vector of covariates describing contract characteristics. These covariates will provide telling results, and shed some light on the influence of the contracting process on dollar obligation. Among the included variables is: information about the financing, type, competition extent, and duration, among other factors. The estimated effects of these characteristics on contract dollars suggest aspects of the process to look towards for cost reduction and efficiency gains. At 
the very least these estimates provide more elucidation of the contributing factors to dollar obligations ${ }^{24}$.

Each of these regressions has fixed effects that capture different unobservable phenomenon. Equation 1.1 captures only fixed effects for goods, states and years separately with no interaction terms. Equation 1.2 adds interaction at the state-year fixed point which can capture idiosyncratic changes in State laws and fluctuations in State specific prices. Equation 1.3 captures good-year effects which can account for technological innovations in a specific product line's production across time and mission shifts that asymmetrically affect different procurement categories. Finally equation 1.4 captures good-State fixed effects, which can include any regional effects on goods caused by regional resources or localized trade concerns.

As mentioned in the preceding section, to improve the tractability of the computation the aggregated two digit product id FSC codes are used for equation 1.3 and 1.4, while the untransformed four digit codes are used for models 1.1 and 1.2 as these models yield relatively low variable counts. For consistency of comparisons however, models 1.1 and 1.2 are additionally estimated with the two digit codes, and listed in the table as model (1-2) and (2-2) respectively, resulting in six distinct estimates. Therefore the differences across each of these model specifications lies first in the choice of which unobservable fixed effects interaction terms are included, and second in the level of aggregation of the product identification codes.

These estimations will be carried out on the subset of data that corresponds to goods contracts only. From the analysis in the previous sections, there are clear distinctions between contracted goods and services. Solely estimating goods allows

\footnotetext{
${ }^{24}$ These variables are mostly factor variables, and precisely describe: the type of contract, type of financing if applicable, extent of pre-award competition, whether the contract was for a weapon, whether cost or pricing data was required by the contracting officer, if it was a multi-year contract, if it was signed in the last month of the fiscal year, and finally a natural log transformed count of the months of contract duration.
} 
us to focus on several benefits. First service customization described in the previous section does not lend itself readily to a discussion of prescriptive goals for improving contract costs. As a result of this customization, the streamlining of services must be dealt with on a case-by-case basis unlike that of goods. There are also more practical benefits of higher degrees of freedom and a more parsimonious model than if all FSC codes were included. Finally focusing on goods contracts alone yields estimates with a better model fit compared with the unrestricted model, which helps to strengthen the following arguments.

From the information in the previous sections, it should be no surprise that the nature of these data are unbalanced, where some good-state-year units contain many more observations relative to others. Fortunately the goal of including the fixed effects is not to utilize point estimates for the analysis of any particular sub-group, but to control for the otherwise unobservable influences, allowing more focus on regressors that belong in vector $\mathbf{x}_{\mathbf{i}}$.

Finally several model specification decisions will further subset the data. By log transforming the data we eliminate any of the negative dollar observations, which originally resulted from contract modifications or deobligations. This transformation provides more estimate consistency across various specifications and better comparability of the resulting estimates. Furthermore some covariates contained within the vector $\mathbf{x}_{\mathbf{i}}$ are not recorded for the entire 45 years of the time span. Many of these characteristic regressors are not recorded until the CICA act and following few years, such as financing information. Also the modernization that was completed in the fiscal year 2007 data files drops the weapon identifier in records. These specification decisions result in estimates over the time span of 1987-2006.

Fortunately many of the structural issues discussed in section 1.3, such as changes in record keeping and legislation that alter the nature of the data, occur predomi- 
nantly outside this timespan, which renders an otherwise important estimation issue moot. This is a significant benefit of the given model specification.

\subsubsection{Baseline estimates}

The results from the estimations described above are contained in tables 1.12 - 1.16. Each of these tables represents estimates from the same six model specifications; 1.1 - 1.4 plus the aggregate good code versions of 1.1 and 1.2 (listed as 1-2 and 22 in these tables). Looking across these results, It quickly becomes clear that the estimates are relatively robust to changes in the model specifications: the estimates typically produce a coefficient of determination around between .51 and .48 , with

similar decomposition of variance measures across models, and comparable $\hat{\beta}$ point estimates for the observable covariates.

In order to see the collective influence of various groups of fixed effects and regressors in these estimations, a series of decompositions of variances are calculated on the estimated coefficients, as employed in ?. A decomposition of variance in this regard will inform us to the proportion of variation attributed to each set of regressors, suggesting which components are most powerful in explaining dollar variations across contracts. Furthermore, as described above, the unbalanced nature of data with respect to the fixed effects makes inference from individual fixed effect estimates difficult in the least, and suspect at best. However grouping all fixed effects into their respective categories and measuring the variance contribution of each group provides information about the general impact of these groups.

The results of this calculation are listed in table 1.12, with the covariance listed in the first row for each model specification and the respective percent of overall variance listed underneath. It is clear that regardless of the model specification, the bulk of the variation in contract dollar obligations is accounted for by annual time 
fixed effects. As previously mentioned, these effects capture annual global shocks that impact contract spending. Among the multitude of shocks that may influence contracts in this regard, national political shifts and changes in the Defense Department's mission are likely causes of much of this influence. Furthermore, State fixed effects seem to capture the least amount of variation in dollar obligations, suggesting that individual State idiosyncrasies, as well as general agglomeration effects has the least influence on contract dollar as far as can be estimated here. These results should be rather intuitive, primarily since it is the federal government who is choosing what to contract and with whom to do it, while States have at best a tertiary influence on these award decisions, after the decisions of the government and contractors are made. While there may be some benefit provided of a geographic critical mass of contractors, it is evident that these effects are greatly smaller than any direct change in national politics that would impact foreign policy, defense policy, or otherwise.

Goods fixed effects and interaction effects also seem to explain relatively little contract dollar variation. Using the less aggregated (4-digit) version of the FSC goods codes increases the proportion of variation captured in the regression, effectively doubling the proportion of explained variation by these effects, however at 8.3 percent, it is still relatively low. The low level of explained variation suggests that unobservable factors across goods categories do not play a substantial role in the determination of prices. The relatively low value is likely a consequence of the lack of information in this data set on quantities ordered of these goods categories. If information on quantity was coupled with the price data we have, the result may be an increase the variance captured by goods fixed effects. If one solely focuses on the interaction of fixed effects, good-year effects seem to capture the greatest amount of variation in dollar obligations. These effects most directly capture the changes over time in one good category versus another. These shifts can arise from annual changes that affect 
only individual categories like reduction or increases in the reliance of ground forces and the kit they require. It also captures good specific price shocks, or sub-aggregate inflation changes. In total however, all interaction terms seem to at best explain only very little of the variation across contract obligations, with good-State interactions accounting for just over 2 percent being the high end.

After annual fixed effects, the second best group of variables that captures contract dollar variation are the observable characteristics for each contract, specifically the variables in vector $\mathbf{x}_{\mathbf{i}}$. Across all model specifications, collectively these characteristic variables explain around 15 percent of the total variation in contract price. The next subsections will look at these variables in more depth. It should also be noted that across all model specifications, the estimated effects of these characteristics are generally highly consistent, with typically large and significant effects on average

contract prices. Furthermore these factors are the most controllable by individual contracting officers and offer the most direct way to alter the procurement process for the better.

\subsubsection{Contract Structures and Cost Types}

As earlier stated, contracts can fall into one of two broad based categories, fixedprice type or cost type, and the general distinction between the two is the burden of risk across parties. Table 1.13 displays the point estimates from all six model specifications. These estimates are produced by comparing various types with the base type: firm-fixed price contracts. Firm-fixed price contracts account for the vast majority of contracts signed by the federal government, and are perhaps also the "safest" for the taxpayer, as they effectively shift all risk onto the contractor. Any variation on these fixed price contracts include some room for risk-sharing, displacing some level of risk back to taxpayers through various sub-types to redetermine final 
payment or incentivize contractor performance. Intuition would dictate that this risk translates directly to higher prices for contracts, and this logic is borne out in the results, where all of the the riskier (from the perspective of the taxpayer) contracts increase the average price of the resulting contract to some degree.

Economic adjustment clauses to fixed-price contracts listed under the categories A and $\mathrm{K}$ in table 1.13 do not seem to increase contract price dramatically over firm fixed price contracts, with redetermination leading typically to a contract cost increase of 5 percent or so, while escalations leading to somewhere between a 16 and 22 percent rise in the average cost. It is likely that these contracts have a significant pool of information at the time of the contract award and these adjustments are minimal at most. Inclusion of performance and award fees however has significantly more upward pressure on the price of a contract. Performance incentives increase price somewhere between 55 and 72 percent, while award fees more than double costs over the basic firm-fixed price option, with estimates between 108 and 145 percent average increase. The increase in cost is the direct consequence of the option for fee payment above and beyond the contracted items, and most likely is capturing the typical cost of the fee itself.

Cost type contracts shift the bulk of the risk over to taxpayers, and we should expect that these contracts may cost even more than fixed price type contracts. The increase in average dollar obligation is apparent, as cost contracts can increase the average price of the contract anywhere from 120-145 percent for cost type plus a fixed fee, to between 380-470 percent for cost type plus incentive fee contract. Remember that these types of contracts are not the preference of the government as there is less incentive for contractors to keep costs down when compared with fixed price contracts. Also as a subset of cost contracts, time and materials and labor hour contracts do not seem to follow this pattern of displaying a many fold increase in price above our 
base group. These two subcategories are targeted at two direct types of costs, and only present an increase over firm fixed price contracts of 29 to 42 percent for either category. The relative inexpensive of these two cost contracts is most likely the result of transparent monitoring of these types of costs, which are typically easy to account for.

Cost contracts are typically used as a second best option for the government. They are a tool for bringing in increased diversity of sources or improved quality of procurement for projects that would otherwise be deemed too risky by smaller contractors. These typically can involve significant research for a specific new systems or long term horizons with volatile inputs. As stated in section 1.3.1, cost type contracts are not the norm, but far from uncommon and require heightened scrutiny to the accounting practices of the contractor engaged in such a contract. The required accounting transparency is aimed at reducing the inherent moral hazard with cost contracts. Award fees are used to provide additional incentives to contractors to keep costs down and maintain efficiency, by providing them a payment above and beyond the costs of the project and promote quality effort.

In order to evaluate the effectiveness of these types of contracts however additional information is needed. It is clear that firm-fixed price contracts are by far the least expensive option for the government. Whether there should be moves to increase fixed price contracts over cost type contracts is where the balance between mission objectives and economic efficiency must be weighed. Of particular interest would be some measure of contract outcomes, be that quality or otherwise, where some more empirical judgment calls could be made with this trade off.

One can draw a few suggestions from these estimates however. Additional fees written into contracts, be they award, incentive, or performance fees, seem to drastically increase the contract obligation, regardless of whether that contract is fixed 
price type or cost type. There is undoubtedly room for further inspection of these fees, both their stated purposes and measured effectiveness, to help quantify the net benefits to these higher prices. The relatively low increase in costs associated with labor or material costs contracts may provide insights that translate to other cost contracts. There may be room within cost contracts generally to have a narrower definition of covered costs in aims to reduce the overall price gap between cost and fixed price contracts. Overall, while the sign of these effects is intuitive, the magnitude should give readers pause. To better evaluate and quantify efficacy of the tools that the government uses to promote diversity and contract quality, data on the outcomes of these contracts would greatly benefit future studies.

\subsubsection{Finance options available for Contracts}

Contract financing is a tool available to the contracting officer to promote high quality contracts and competition, making competitive bids by smaller contractors possible by providing them some degree of prepayment for the contract. As with all tools, if its goal is to increase competition and quality then its efficacy should be quantified and measured. The coefficient estimates for different finance levels are listed in table 1.14. For comparison, the base level that these coefficients are measured against are contracts with no financing. Therefore these estimates directly compute the average cost of different forms of financing. The most notable finding is that regardless of the form it takes, financing seems to increase contract price.

When contract financing is used, the preferred method is performance based financing where disbursements are predicated on a set of clear, objective and quantifiable goals for the contractor to meet. Performance based financing is perceived to be the least risky to enter into from the government's perspective, where the key is

the completion of these goals, unlike other financing terms which rely on less tangible 
benchmarks for payment disbursements. Progress payments determined by costs (A in table 1.14) or a percentage of contract completion ( $\mathrm{C}$ in table 1.14) are next in the government's preference hierarchy. Least preferred are advanced payments or otherwise unusual progress payment, and the FAR has rather strong language to dissuade contracting officers from writing contracts with such financing terms ${ }^{25}$, as an effort to reduce risk exposure to the government.

Unusually however, the ranking of most to least expensive estimated average cost of financing listed in table 1.14 is the reverse of this preference ordering. Starting with the most expensive category, performance-based contracts account for an average increase in contract prices in the range of 280 to 390 percent over non-financed contracts $^{26}$. The pattern continues with progress payments and percentage of completion progress payments, presenting increases in contract dollars in the range of 100 to 115 percent and 74 to 96 percent respectively. Finally, unusual progress payments/advanced payments account for the least expensive set of traditional financing, yielding an increase in the range of 62-111 percent.

So while there is greater risk involved in advanced-payment or unusual-progresspayment financing they tend to produce cheaper contracts than their relatively less risky counterparts. Perhaps the reduction in average costs is associated with the increased scrutiny these least preferred contracts receive; where greater pressure on the terms of these financing yields lower average dollar obligations. Another cause may be the general reluctance of contracting officers to write higher priced contracts with

\footnotetext{
${ }^{25}$ The FAR states that progress payments must be up to and less than 80 percent (85 percent for small business concerns) of the total cost of performing the contract. Financing outside of these terms would constitute an unusual progress payment (FAR 32.501-1).

${ }^{26}$ It should be noted that the two estimates at the low end of this range are derived from the two models that utilize the four digit FSC code, translating to greater refinement of the good fixed effects and most likely attenuating the estimate a significant amount. With that in mind however the effects are still far from what one would consider small.
} 
these risky forms of finance in the first place. If in fact the driving force in the price disparity is the increased government pressure and scrutiny, then there is the potential for benefit in translating these practices to other types of financing. Alternatively if the source of this cost wedge is reluctance on the part of the contracting officer, the scope for application of similar protocol is significantly less. Which of these two cases is the driving force is unobservable from the data and FAR protocol alone, where quantifiable data on competition outcomes would greatly help to understand the forces driving this pattern. Information on outcomes is unfortunately outside the scope of this study, but it suggests fruitful places to search for more prescriptive recommendations to contracting efficiency gains.

Another noteworthy result from these findings is the relatively low increase from commercial financing. Commercial financing is specifically financing provided by the government for commercial goods, and occurs in industries where some level of financing provided by the buyer is common. The increase in contract price associated with this form of financing relative to no financing is estimated at between 11 and 19 percent. The very fact that these items are provided in a commercial market, where the federal government is entering as an (albeit potentially large) buyer, provides a framework of price competition in terms of market pressures and infrastructures outside the typical federal contracting parameters. Existing market structures allow clearly defined rates and competitive pressures to facilitate lower prices over all. The majority of contracts with financing terms are for non-commercial items, which do not have a market outside of government monopsony and limited competition to help put downward pressure on costs. Commercial items however experience market forces that are more competitive than their non-commercial counterparts. Also in industries where buyer financing is a common practice, the terms of financing are more standardized and also receive competitive pressures by the market forces. Contracting 
officers are instructed to incorporate market-competitive terms into the contract on the basis of market research, and when financing is practiced outside federal contracting research is easily gathered. These factors combine to yield significantly less expensive contracts when commercial financing is deployed when compared with the standard financing described in the preceding paragraphs.

\subsubsection{Extent of Competition in Contract Bidding}

The entire contracting process is predicated on the notion that the award of contracts is determined by a competitive process of either sealed-bidding or open proposals. Suboptimal procedures based on less than full and open competition may be pursued for any number of reasons, ranging from national security risks to a lack of reliable contractors for any given contract. The entire FAR is written in a tone directed at increasing competition for all circumstances, particularly when a contract bidding is less than fully competitive. Therefore as stated in section 1.3.1, the bulk of the FAR and associated legislation on contracting is written to guide less than fully competitive situations in an effort towards increased fairness.

The information in the estimation window on extent of competition for each contract is somewhat imprecise, yielding only four levels of competition. Full and open competition corresponds to our base level, while follow on competition corresponds to a continuing action that, while not competed in its particular signing, follows a previous contract that was awarded under competitive procedures. "Not available for

competition" represents a subset of the "not competed" category, where the availability for competition is dictated by federal law (10 U.S.C §2034).

One would expect that reduced competition should increase prices, which is generally the story told in table 1.15. The impact on prices is an increase in the range of under one and up to 16 percent in average price over full and open competition. 
It is worth noting that the two model specification types that use the native 4 digit FSC product codes produce negative coefficient estimates for the not available and follow on competition classifications. The existence of a specification inconsistency does not occur for the larger, more general category of not competed, where the estimates are consistently positive across the board. As all estimates are significant, the change in sign depending on model specification should cause concern, particularly when compared the the strong and reinforcing results associated with financing and contract type. The notion that more competition will reduce costs is a fundamental notion in economics. The relatively small impact of these results is surprising, and coupled with the specification issues makes uncertain how influential competition is in determining the final contract dollar amount.

As previously mentioned the President and various policy makers have stressed the promotion of competition as the sole best method for reducing federal contracting costs. It is often the sole method mentioned among politicians and the media for reducing costs. These estimates suggest that perhaps increasing competition is not as powerful a tool in lowering contract costs as those politicians would have us believe. There is something to say for the political draw of promoting competition. Average constituents easily identify with the principles of competition as it is clear and intuitive. The estimates in this section suggest that slight alterations on the administrative end of procurement through bureaucratic process modifications may be more powerful to reduce costs than competition alone.

\subsubsection{Role of Signing Date and Duration}

As previously stated, the timing of a contract can significantly influence its price. The annual fixed effects in each regression have already been shown to capture a 
large portion of the variation in each regression. Listed in table 1.16 are the effects various time dimensions have on contract dollar amount.

\section{Multi-Year Contracts}

Multi year contracts are contracts written with an expectation on the outset for the government to procure and the contractor to produce a good beyond one year. The FAR advises against writing multi-year contracts, in favor of single year contracts, with options to extend the original contract. As with the majority of the FAR, the reasoning behind advising against these contracts is to protect the government against the possibility of unforeseen volatility in future years and other unknown risks, which can lead to increases in costs. If however signing a multi-year contract improves supply chains for future needs, produces long term cost savings, has expectations that the needs and budgets for the product extend into the foreseeable future, and has a low expectation of risk, then it is considered a useful tool for contracting officers.

Unfortunately little can be said from the estimates in this study, as the effects of multi-year contracts on dollar obligations seems to be strongly influenced by the model specification. While some estimates suggest a cost savings of around 11 percent through the use of multi-year contracts, other models suggest between a 6 and 12 percent increase in average contract $\operatorname{cost}^{27}$. These inconclusive results make it difficult to draw conclusive results about the relative expense of multi-year options or its effectiveness as a tool for the government.

\footnotetext{
${ }^{27}$ Again the estimates seem dependent upon whether two digit or four digit goods fixed effects are used, and as such unreliable for inference.
} 


\section{Year End Rush}

A symptom of the annual budgeting process at any institution is a reluctance to spend early followed by a rush to spend towards the end of the budget cycle, in order to consume all appropriated funds. The reasoning behind this is a fear of the loss of unused funds for the next budget cycle. The fear of lost funds is understandable when the parties involved in setting budgets are not those directly involved in awarding funds and administering projects, which is the case for the DoD and congressionally approved budgets. Often times the year end rush to spend results in less efficiently allocated dollars and wasteful spending on projects that would otherwise be considered unnecessary or of low quality. ? describe both the increase in cost and the drop in quality involved in contracts signed in this regard, using federal I.T. projects.

Displayed in table 1.16 is the dollar impact of a contract that was signed in the last month of the fiscal year, which for the estimation period is September. Regardless of model specification, there is a very clear increase in average contract price of around 12 percent over contracts that are signed in any other month of the year. These findings are in line with those of ?, and also consistent with the trend indicated in table 1.8. One reasonable and demonstrably effective solution to this problem is to allow a portion of remaining budgets to rollover into the next fiscal year ${ }^{28}$. However as with most solutions that make economic sense, they may appear counterintuitive with only cursory analysis, and subject to significant political pressures in search of budgetary savings. It is hard to convince policy makers that allowing institutions to keep unused budgets will actually lead to better outcomes and long run savings. If these budget policies are enacted safeguards must couple them to stand against political whims.

${ }^{28}$ This scenario is described in ?, where the Department of Justice is allowed to keep a portion of unused budgets at years end to roll over to the next, which the authors describe as a successful project at reversing this phenomenon. 


\section{Duration of Contracts}

The final column of table 1.16 lists the effects of contract duration on the price of a contract, and enters the estimates as the natural log transformed measure of duration months. Right away one can see that regardless of model specification, the estimates for effects on all very precisely estimated and also very consistent. All estimates generally suggest that for a ten percent increase in a contracts duration, we can expect about 4 percent rise in the cost of that contract.

Typical contracts are executed in a relatively short span of time, namely fixed price contracts to purchase commercial goods where existing supply is present and no need for an extended manufacturing process. However it is natural to assume that projects needing longer time projections for completion are very likely complex in nature. For example, the expectation of contract completion for office supplies for a administrative needs is quite different than the expectation when contracting for fighter jets. In this context that duration may be a suitable proxy for measures of contract complexity. Typically larger programs such as major systems and development of new weapon technology will require both longer time commitments and greater dollar amounts to fund them over the contract duration. Looking back to table 1.9 it is clear that the highest mean contract value occurs in contracts which take two years to complete. Inspecting the report ?, all major systems listed require significant amounts of time to completion, which can be compounded by delays in implementation and delays delivery of capabilities ${ }^{29}$.

Unfortunately determining the source of causality is impossible in the estimation of this effect. It is intuitive that one would expect that a longer contract would most likely lead to larger expenses, but whether to use restriction of contract duration

\footnotetext{
${ }^{29}$ In ?, the ten largest programs with cost overruns are all still in the production phase. At the reports publication, the newest program was two years old, while the oldest was 18 years old.
} 
as a prescription for reducing contract costs seems unwise. Currently the FAR and federal legislation dictate that multi-year contracts not extend beyond 5 years, of course with exceptions. There are situations that would benefit longer contracts, particularly those requiring study and analysis for the overall best implementation of certain systems and projects. More analysis is required before knowing if suggestions to curb contract duration with the aim of reducing costs would actually be effective and not counter productive. As has been a common refrain throughout this section, there is no question that information on contract outcomes that could be coupled with this data would be necessary to even begin to answer this question.

\subsection{Concluding Remarks}

For many decades, military spending has accounted for a very large share of the U.S. federal government budget appropriations. Furthermore if one only considers federal contracting, the portion accounted for by the DoD is by far the largest. Scholars have used total military spending by the government to estimate a variety of fiscal policy

questions, with only cursory scrutiny of procurement spending. In depth analysis of contracting the was the very goal of the current essay, using a vast pool of data on individual contracts as the source of this information, instead of relying on aggregated data and anecdotal reports. These preceding analyses were all in the hope of providing some insight into which aspects of the procurement process provide the driving force behind ultimate contract dollar obligations, and to what extent. In addition to studying aspects of the contracting process that drive costs, the present study attempts to paint a vignette of the history of contracting for the past five decades, looking at contracting across the dimensions of time, geography, and sectors.

In the present political-economic environment surrounding defense spending, better understanding of which factors may contribute to the costs associated with con- 
tracting may provide insight into how to squeeze efficiency out of procurements that would otherwise remain unseen. One interesting finding counters conventional wisdom regarding promoting competition, which is typically described as a great equalizer. Recent directives from the President to increase competition added to the forced budgetary cuts from sequestration have further increased the push for greater competition in contracting. The results in this study show that while increasing competition seems to reduce the actual contract cost, the impact is relatively small and not always guaranteed. Furthermore, other aspects of the contracting process may be vastly more promising to reduce dollar obligations, appearing to be significantly more influential on contract cost competition. The current study raises the issues that a more holistic and nuanced approach, with a combination of competition promotion and addressing contract signing procedures may provide the most benefit. At the very least it suggests that aspects of the process, outside of competition alone, need more attention and analysis. Alterations in the application of contract financing and assignment of contract type assignment may hold the key to significant cost savings.

Furthermore, it has been shown that the single largest source of variation in contract dollars comes from annual aggregate shocks, embodied by political shifts, military actions, and geopolitical events. These shocks account for roughly 20-25 percent of variation in an individual contract's dollar obligation. This suggests that the BCA of 2011 will have profound effects on the dollars that individual contracts receive. Since the sequestration is intentionally ham-fisted in its cutting approach, there is no scope for changing allocations across departments and programs in the DoD's portfolio, making these cuts even more painful. With no repeal of the BCA in sight, studies such as this one are even more valuable. Since the DoD cannot control the dispersion of cuts, perhaps changing the way contracts are written can provide some room to alleviate the impact on the DoD's mission. This study has shown 
which tools are relatively expensive in the procurement process, highlighting areas that should be further analyzed.

As was clear throughout section 1.4, a primary goal of future work should be aims at isolating and quantifying the outcomes of contracts. One aspect missing in this study is a direct measure of outcomes, be they quality of contracts, costs overruns, or delays in delivery. Here it is clear that cost contracts and financing of contracts are associated with higher costs, but if these costs provide better quality contracts ultimately these tools may be worth the cost. Incorporating some measure of a contract outcomes could provide the piece of information to prescribe more direct and effective solutions for improving the contracting process. 
Sample Form DD-350

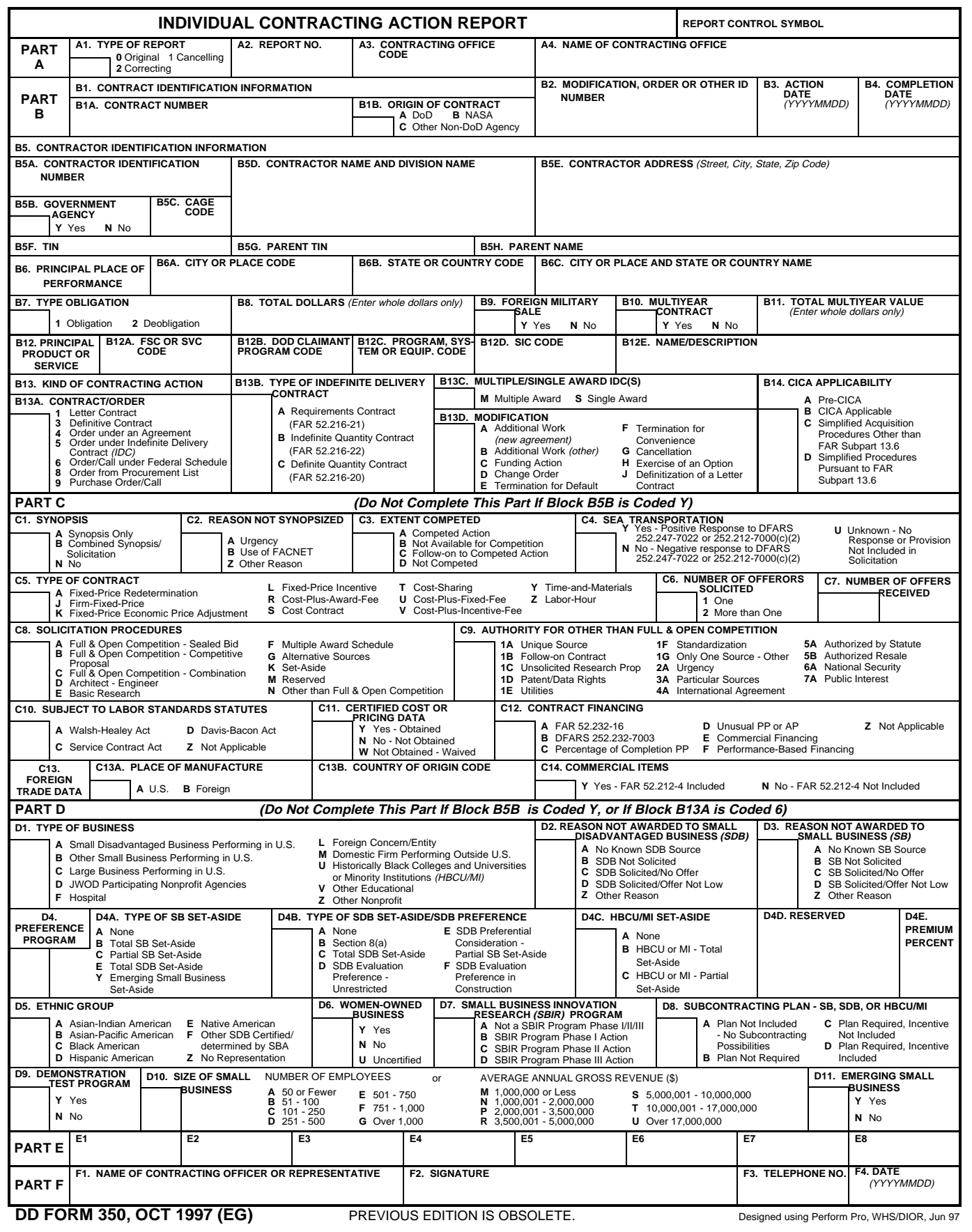

Figure 1.1: This form is used for summarizing individual contract actions above the threshold, for this FY it is 25,000 dollars. This is the contract issued for fiscal year 1998, and differs slightly from previous and future forms, depending on changes in legislation and procurement protocol. This copy was chosen for its clarity and compactness; previous years photo copies lack legibility, and beginning in fiscal year 2001 the form moves to 4 pages. Written forms for all years can be found at http://siadapp.dmdc.osd.mil/procurement/ Procurement.html. 


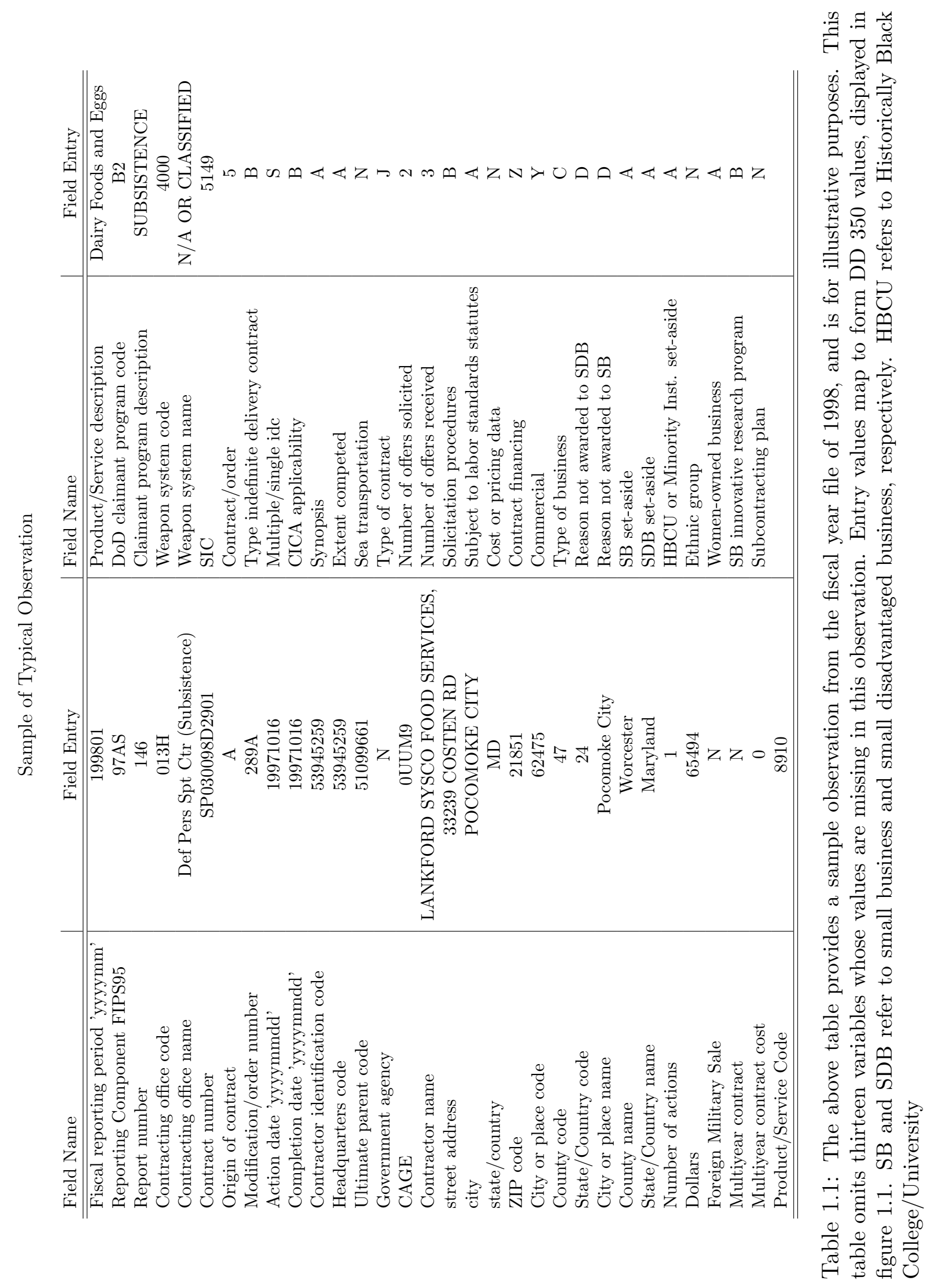




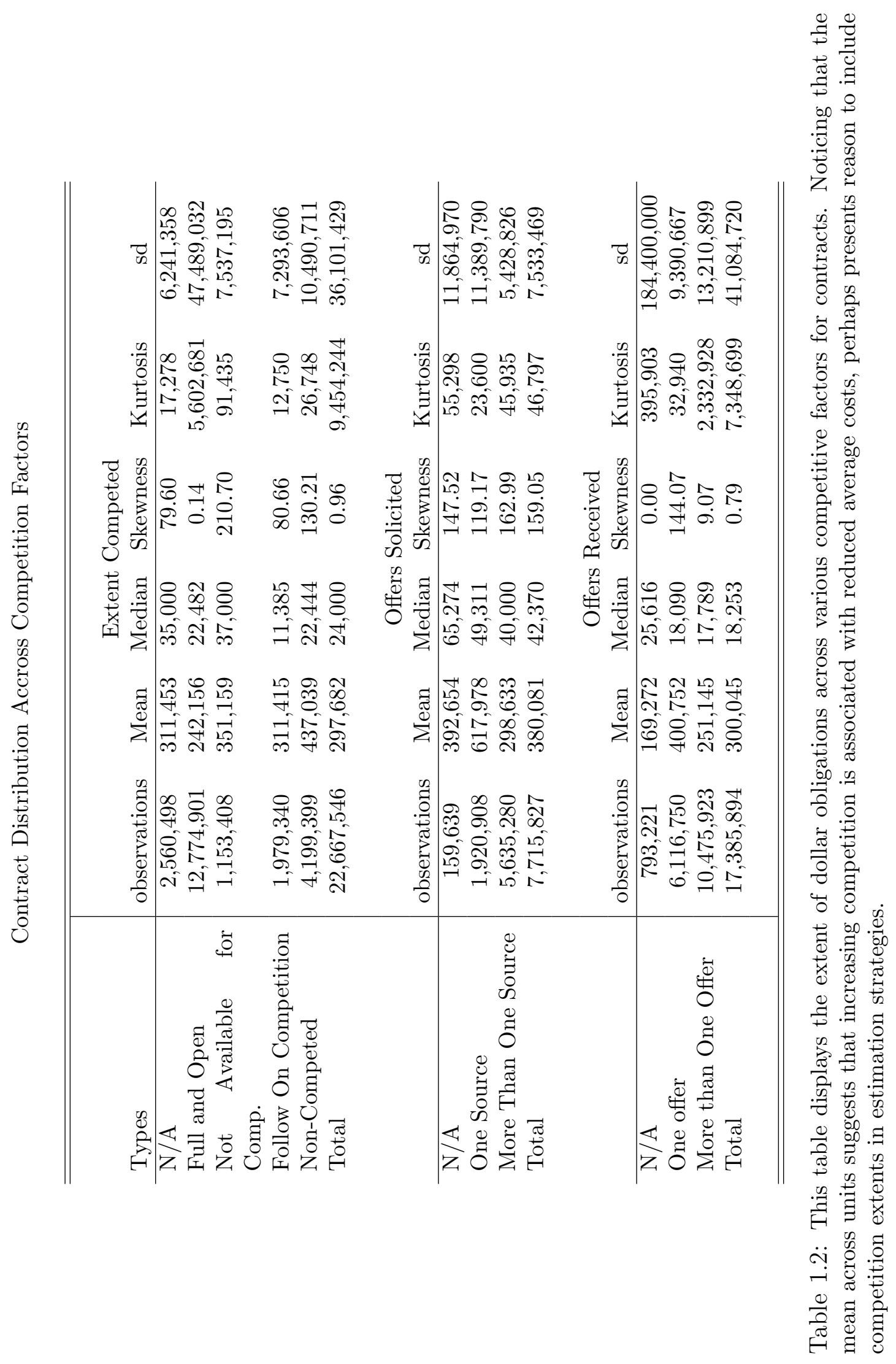




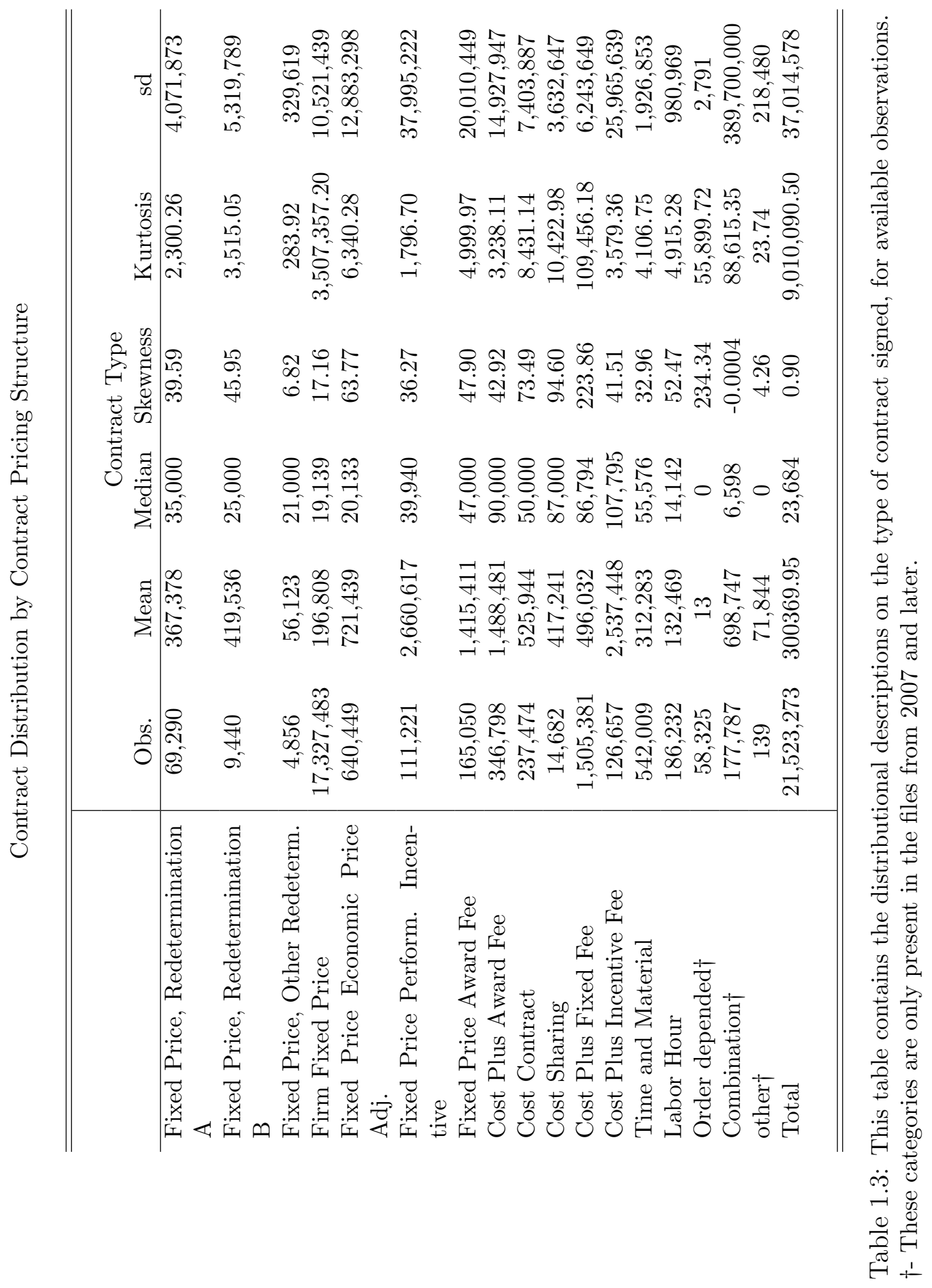




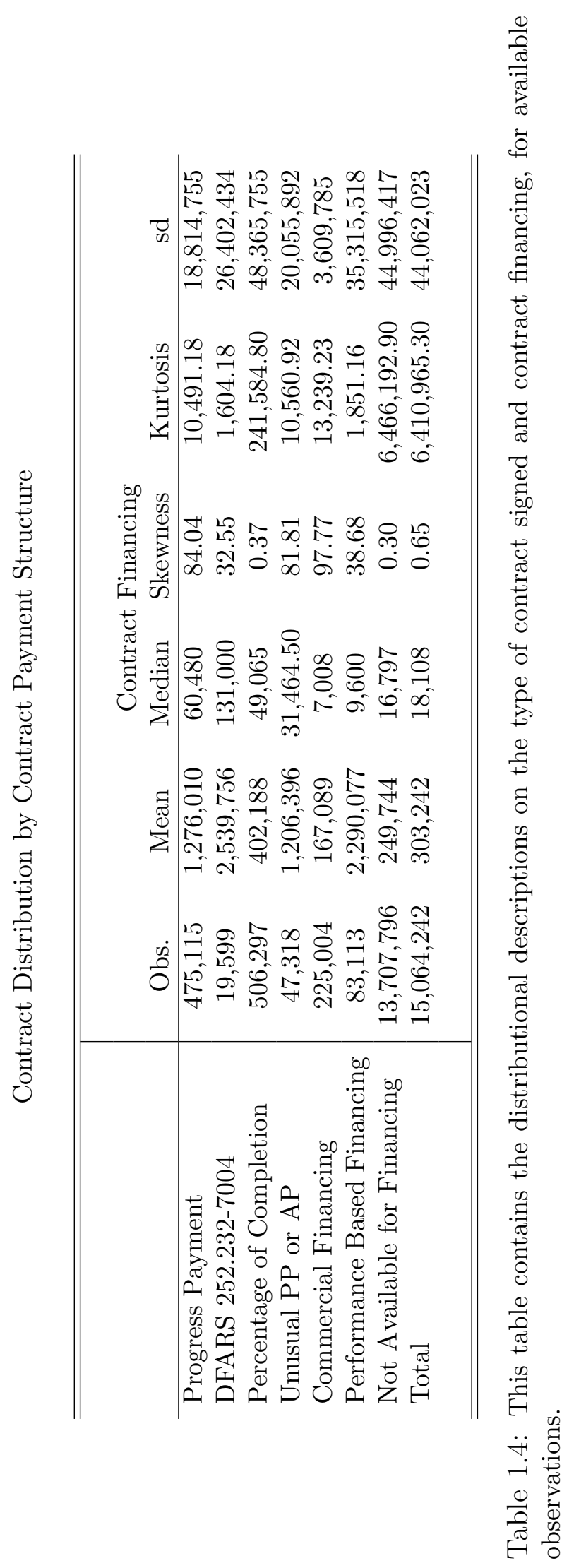


U.S. Federal Contracting

\begin{tabular}{|c|c|c|c|c|c|}
\hline \multirow[b]{2}{*}{ Fiscal Year } & \multicolumn{2}{|c|}{ All Contracts } & \multicolumn{3}{|c|}{ Contracts Above Individual Summary Threshold $\dagger$} \\
\hline & $\begin{array}{l}\text { Dollars } \\
(000 \mathrm{~s})\end{array}$ & $\begin{array}{c}\% \text { of Tot. } \\
\text { Federal Dollars }\end{array}$ & $\begin{array}{c}\% \text { of DoD } \\
\text { Actions }\end{array}$ & $\begin{array}{c}\% \text { of DoD } \\
\text { Dollars }\end{array}$ & $\begin{array}{l}\% \text { of Tot. } \\
\text { Federal Dollars }\end{array}$ \\
\hline 1982 & $125,082,843$ & 78.69 & 3.15 & 93.55 & 73.61 \\
\hline 1983 & $135,462,268$ & 80.54 & 1.61 & 90.96 & 73.26 \\
\hline 1984 & $145,673,741$ & 79.65 & 1.58 & 91.45 & 72.83 \\
\hline 1985 & $163,644,190$ & 81.92 & 1.69 & 92.02 & 75.38 \\
\hline 1986 & $158,983,888$ & 79.51 & 1.77 & 91.77 & 72.96 \\
\hline 1987 & $155,384,596$ & 78.77 & 1.66 & 90.97 & 71.66 \\
\hline 1988 & $149,227,088$ & 76.58 & 1.63 & 90.41 & 69.24 \\
\hline 1989 & $137,039,220$ & 74.41 & 2.28 & 92.42 & 68.77 \\
\hline 1990 & $142,210,430$ & 74.38 & 1.84 & 90.22 & 67.10 \\
\hline 1991 & $149,016,250$ & 70.73 & 2.18 & 90.49 & 64.00 \\
\hline 1992 & $135,236,112$ & 67.71 & 2.19 & 89.02 & 60.27 \\
\hline 1993 & $136,022,346$ & 67.75 & 1.92 & 89.27 & 60.48 \\
\hline 1994 & $131,907,204$ & 67.16 & 2.00 & 89.31 & 59.98 \\
\hline 1995 & $132,349,622$ & 65.42 & 2.17 & 89.48 & 58.54 \\
\hline 1996 & $135,303,363$ & 68.48 & 2.93 & 90.67 & 62.09 \\
\hline 1997 & $126,802,192$ & 66.76 & 3.57 & 91.03 & 60.77 \\
\hline 1998 & $126,953,050$ & 64.35 & 4.02 & 91.67 & 58.99 \\
\hline 1999 & $133,315,113$ & 67.08 & 4.64 & 92.40 & 61.98 \\
\hline 2000 & $142,047,609$ & 64.91 & 5.61 & 93.00 & 60.36 \\
\hline 2001 & $156,456,002$ & 66.61 & 4.32 & 91.01 & 60.62 \\
\hline 2002 & $164,688,843$ & 65.83 & 7.10 & 93.73 & 61.70 \\
\hline 2003 & $208,658,211$ & 68.30 & 9.73 & 94.97 & 64.87 \\
\hline 2004 & $238,126,937$ & 69.74 & 10.96 & 96.14 & 67.05 \\
\hline 2005 & $268,425,648$ & 70.94 & 100.00 & 100.00 & 70.94 \\
\hline 2006 & $295,624,557$ & 71.23 & 100.00 & 100.00 & 71.23 \\
\hline 2007 & $330,757,977$ & 71.90 & 0.00 & & \\
\hline
\end{tabular}

Table 1.5: This table illustrates the size of defense contract spending versus total federal contract-procurement spending, coming from the Federal Procurement Data System annual reports, at https://www.fpds.gov/fpdsng_cms/index.php/reports.

$\dagger$-The summary threshold is the dollar amount above which individual contracting actions must be reported, and below which all contract actions are collectively summarized. For FY 1982 and FY 1983, this threshold was 10,000 dollars. For FY 1984 - FY 2004 this threshold was 25,000, with the threshold elimination in FY 2004- FY 2007. 
Individual Reported Contracts Share of Total

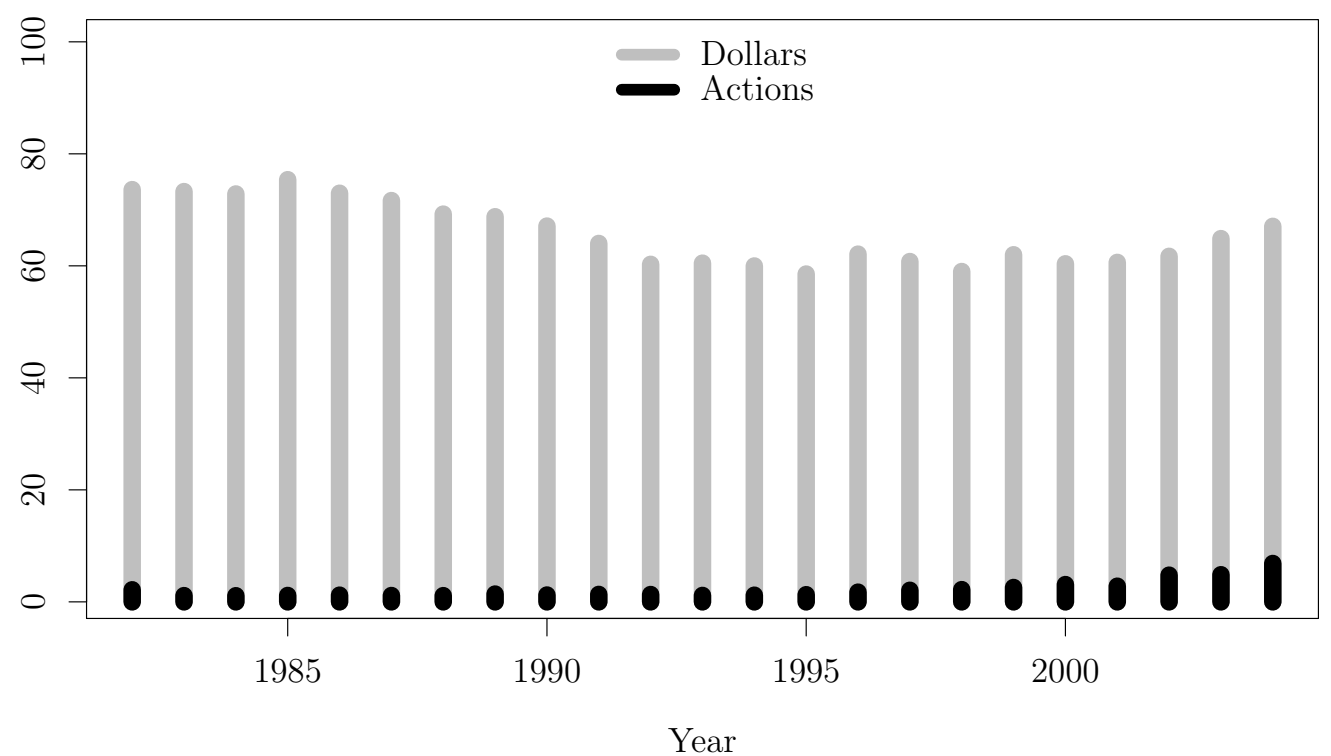

Figure 1.2: This figure captures the relative size of defense procurements for contracts above the summarized reporting threshold for fiscal years 1982 through 2004, compared against all federal contracts. The summarized reporting threshold prior to FY 1984 is for contracts above 10,000 dollars and FY 1984 and later above 25,000 dollars. It illustrates the relatively small number of contract actions contrasted against the fact that these few contracts account for a large majority of all federal procurement. 


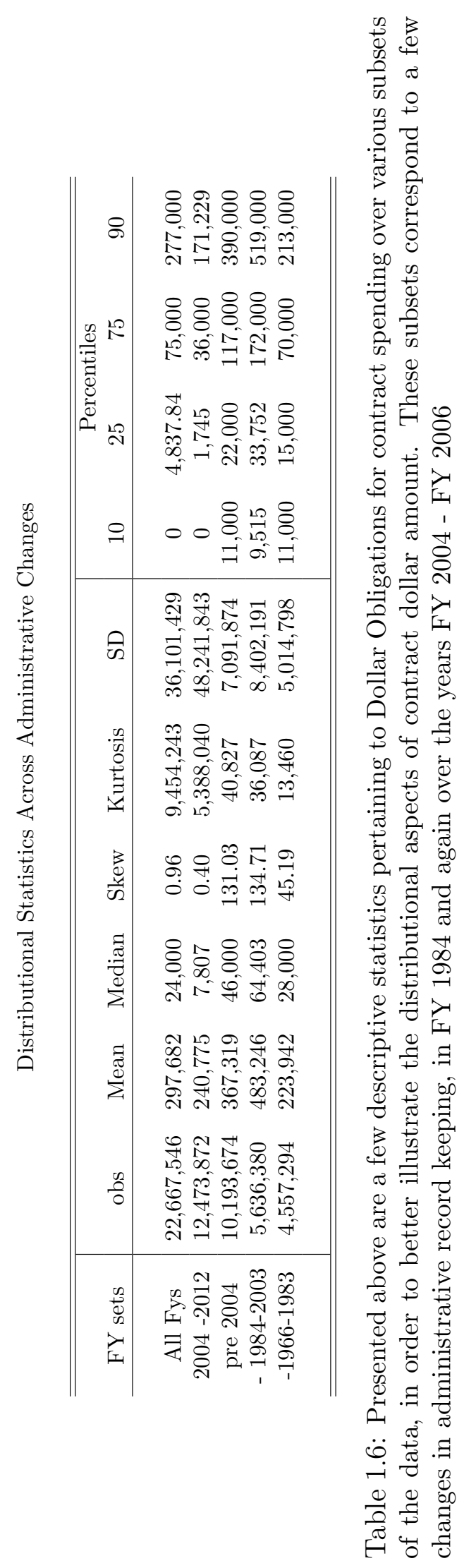




\section{Dollar Density Estimates}
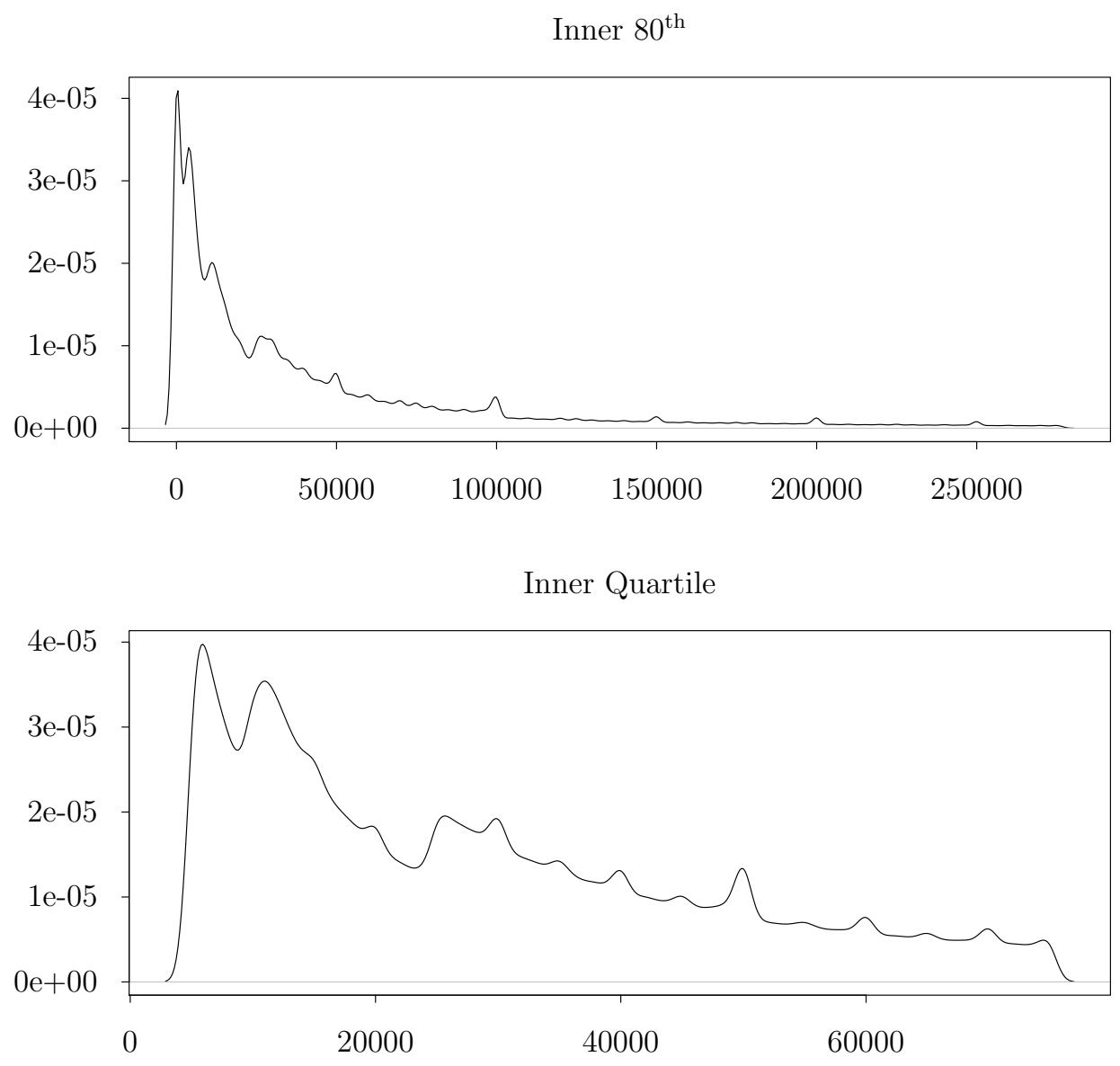

Contract Dollar Amount

Figure 1.3: The above two charts display two kernel density estimates of individual contract dollars, with outer tails stripped to better visualize the data. The Top graph displays observations of the $10^{\text {th }}$ up to and including the $90^{\text {th }}$ percentile and is estimate using a bandwidth of 1141 and a total of 18,976,286 observations. The lower graph displays the inner quartile of spending observations, estimated with a bandwidth of 654.5 and 11,345,720 observations. 


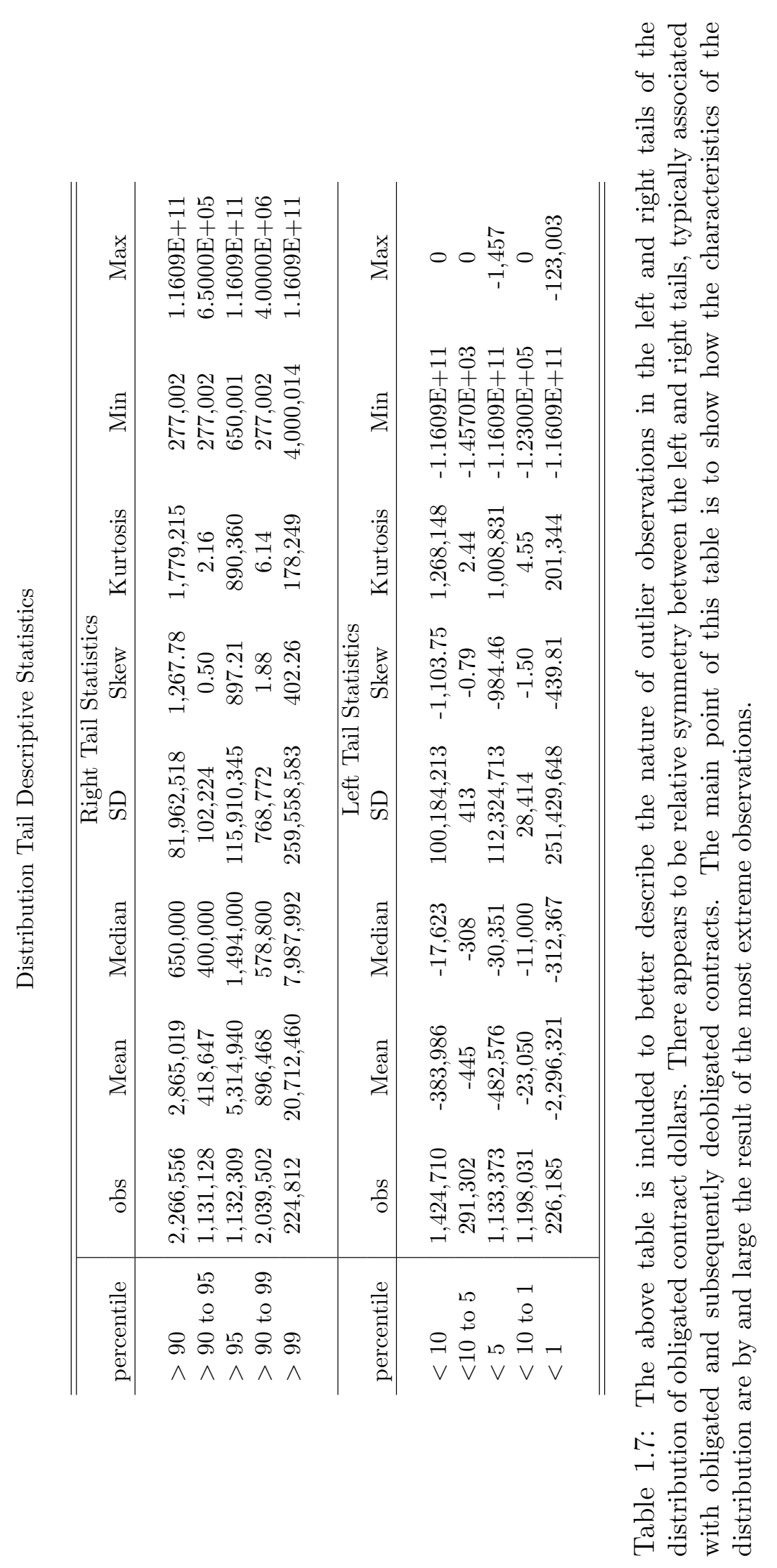




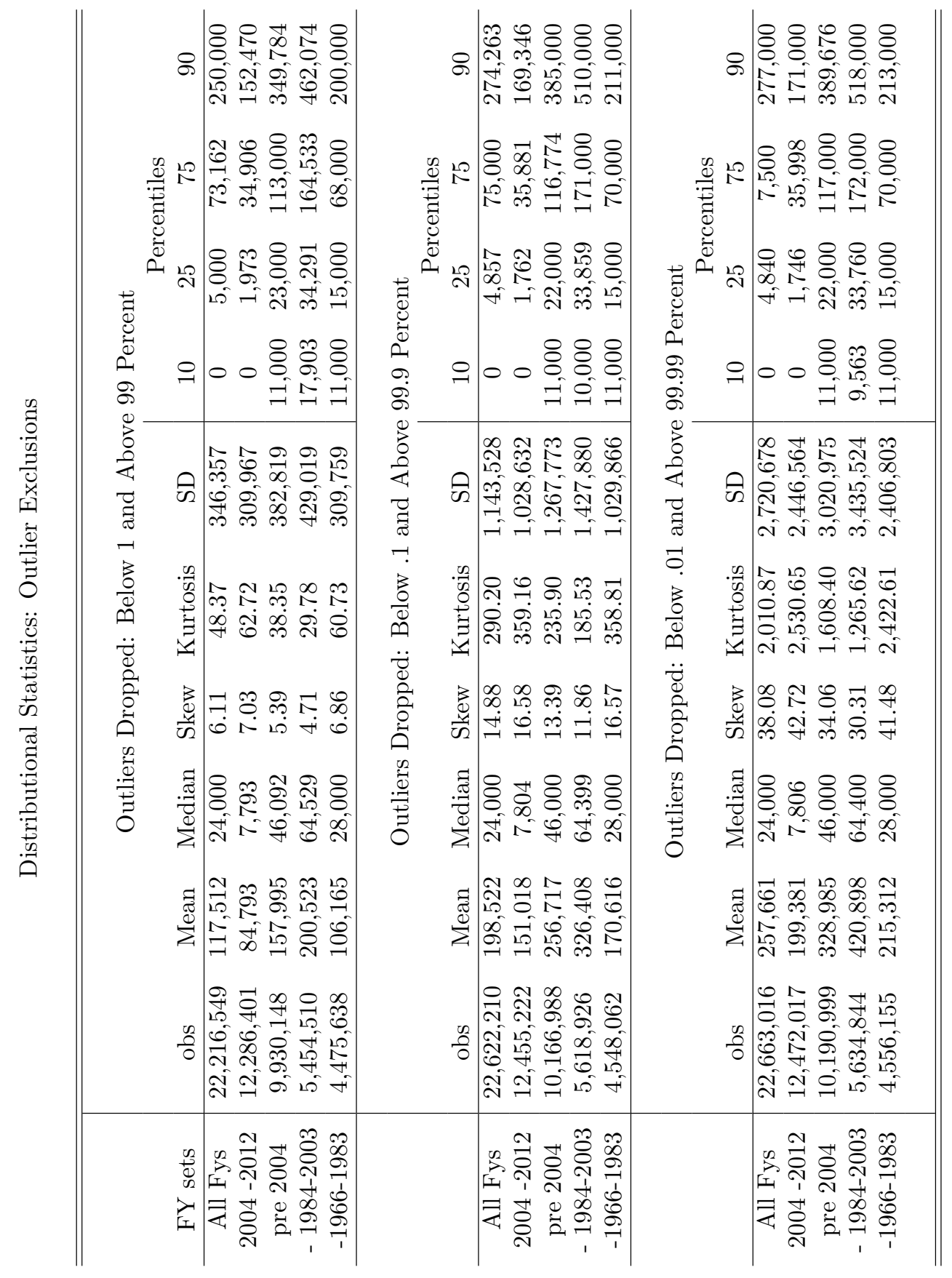

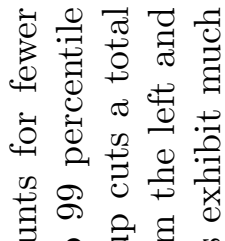

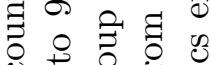

选 -50

官

60 is 0 की

궁

证

论

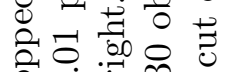

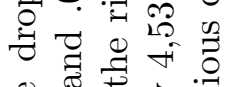

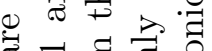

की

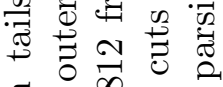

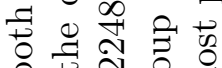

$\therefore+\underset{0}{0}$

$\exists$ \&

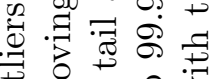

范进

पे $\overrightarrow{0}$ o

के

0 : व्न

- च

$\exists \div$

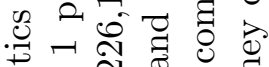

.

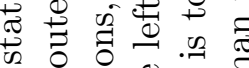

0 若

I

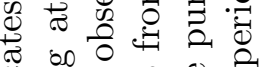

.

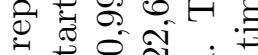

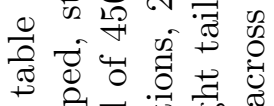

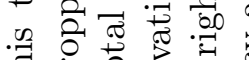

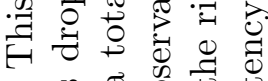

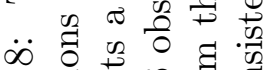

- 荧 节

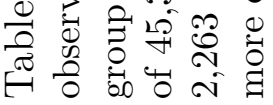



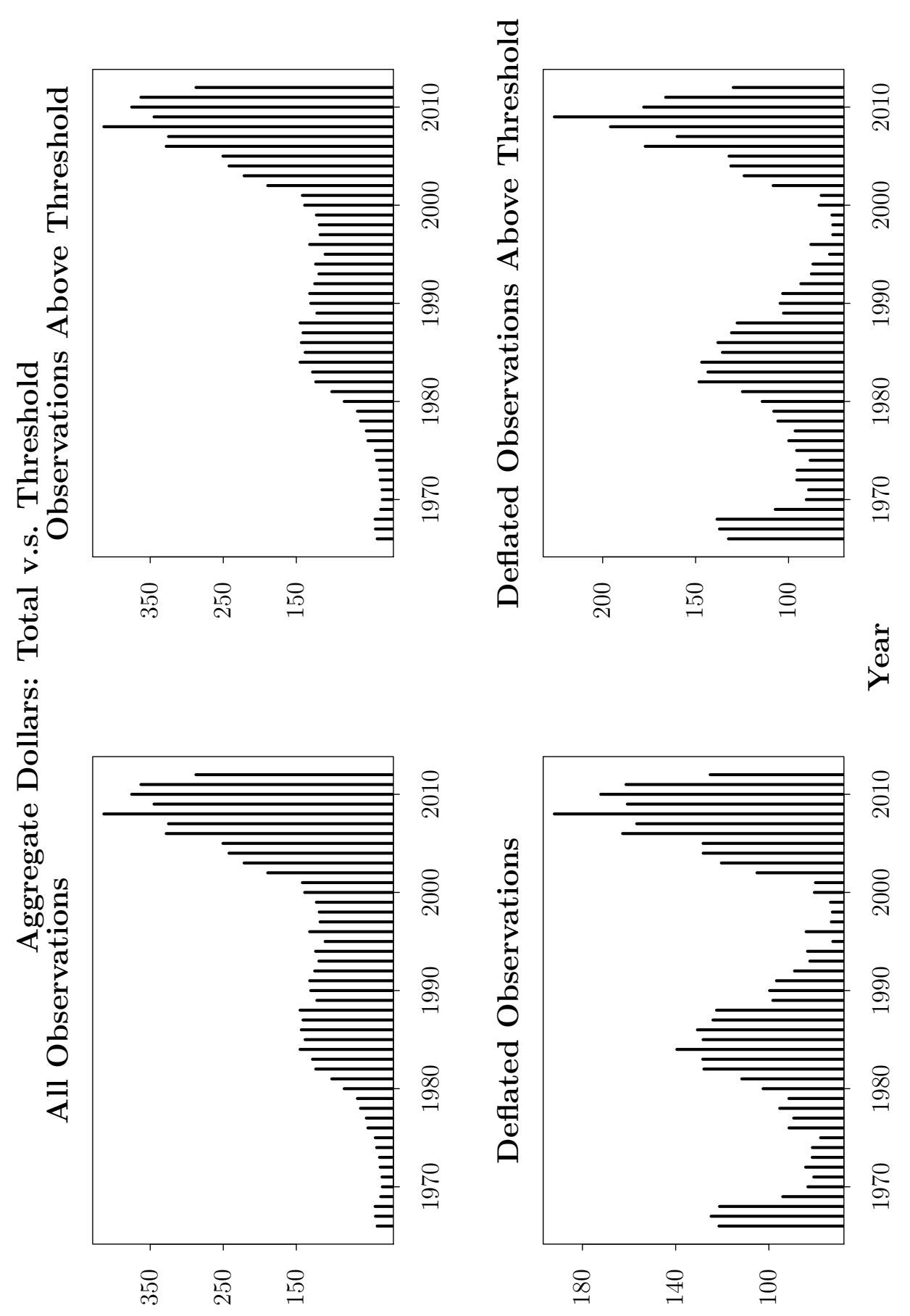

告0

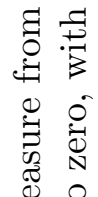

需

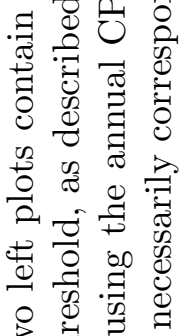

$+70$

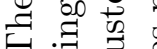

. : تृ

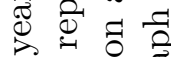

สี సี

룰

ชี

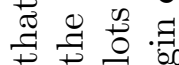

$\exists \approx \overrightarrow{0}$

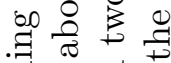

类

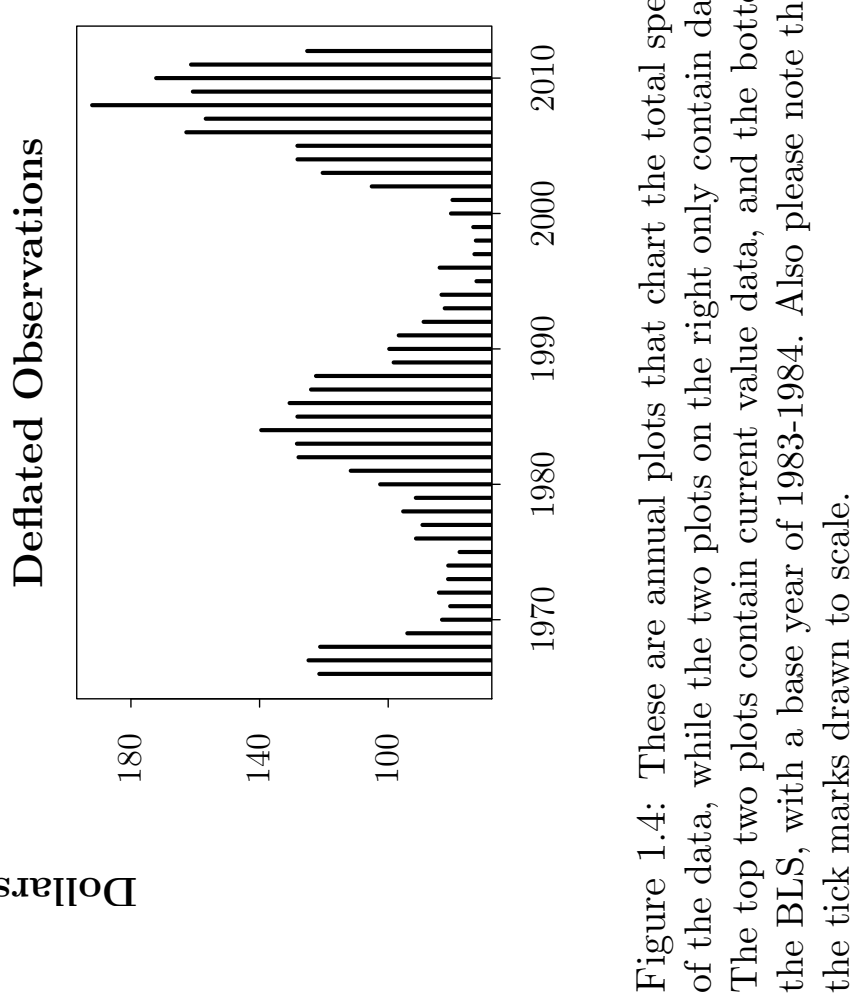

(suotıI!q U!̣) s.JeIIOC 
Annual Spending Statistics:

Total v.s. Threshold

Frequency Total
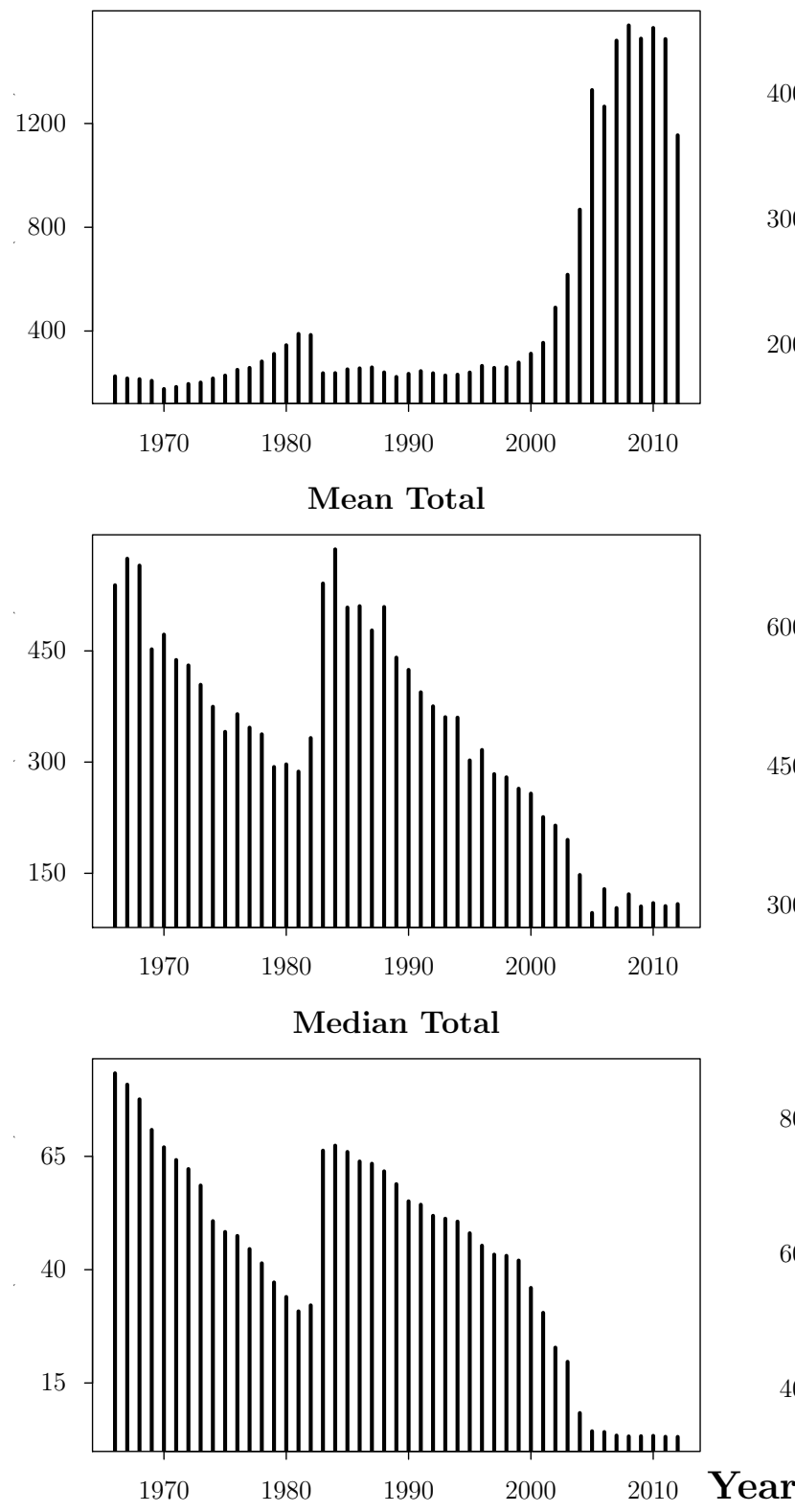

Frequency Above Threshold
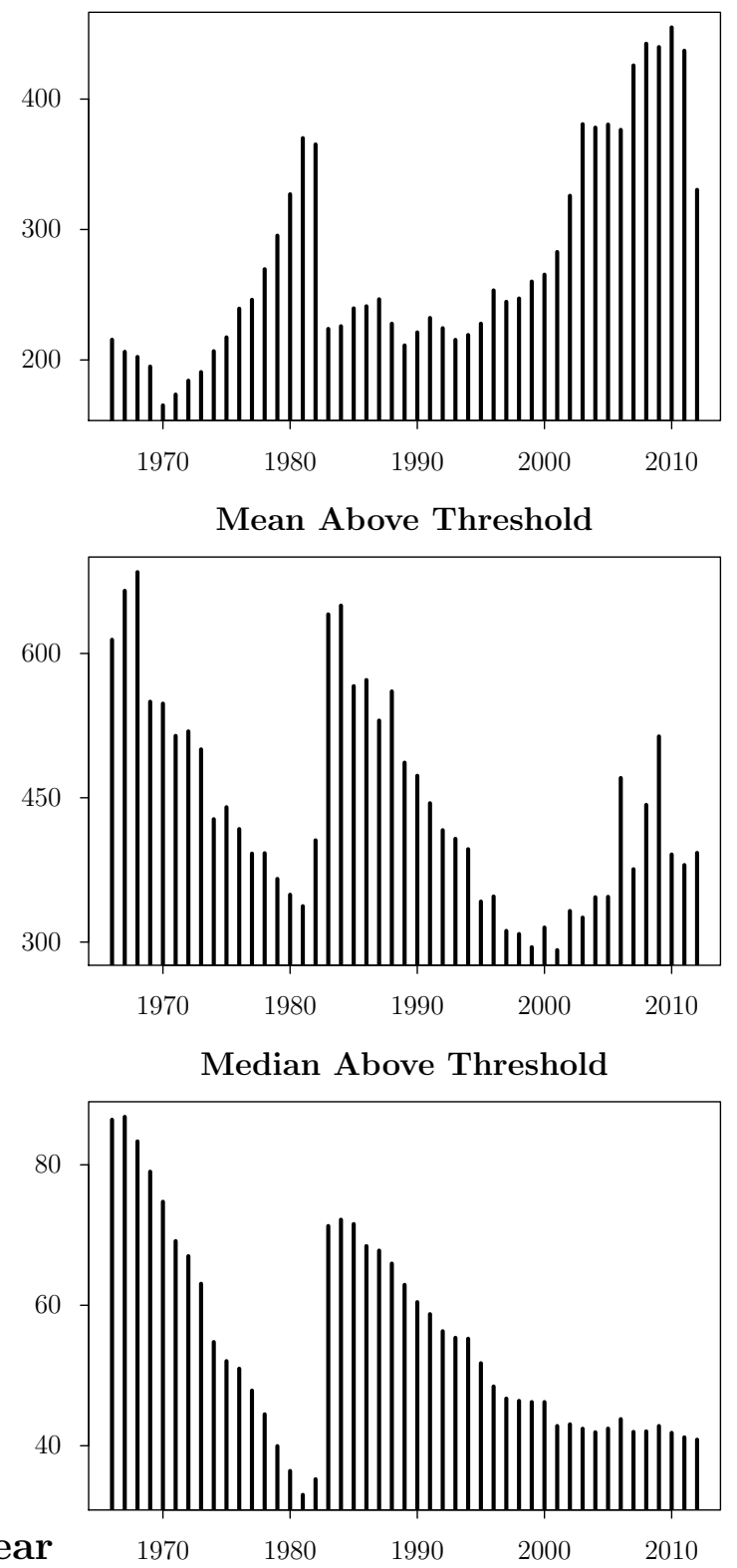

Figure 1.5: The above charts are made using the the contract data from 1966 to 2012 calendar years, with contract dollars deflated using the annual CPI from the BLS, vertical scales are in thousands. Charts on the left contain all data observations, charts on the right are made with observations above the the individual reporting threshold, as described in footnote 16. Also please note that the origin of each graph does not correspond to zero, and tick marks are drawn to scale. 


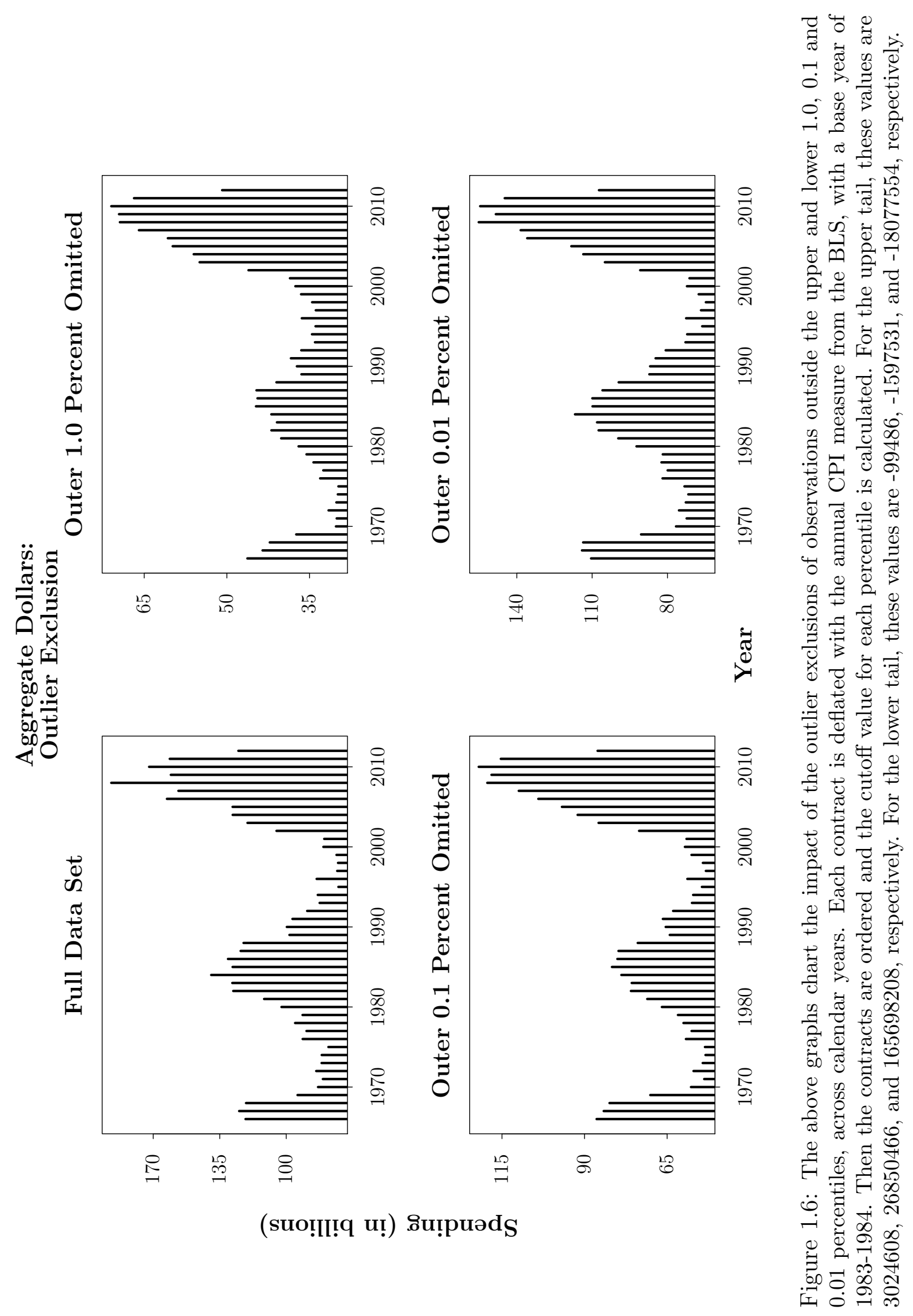




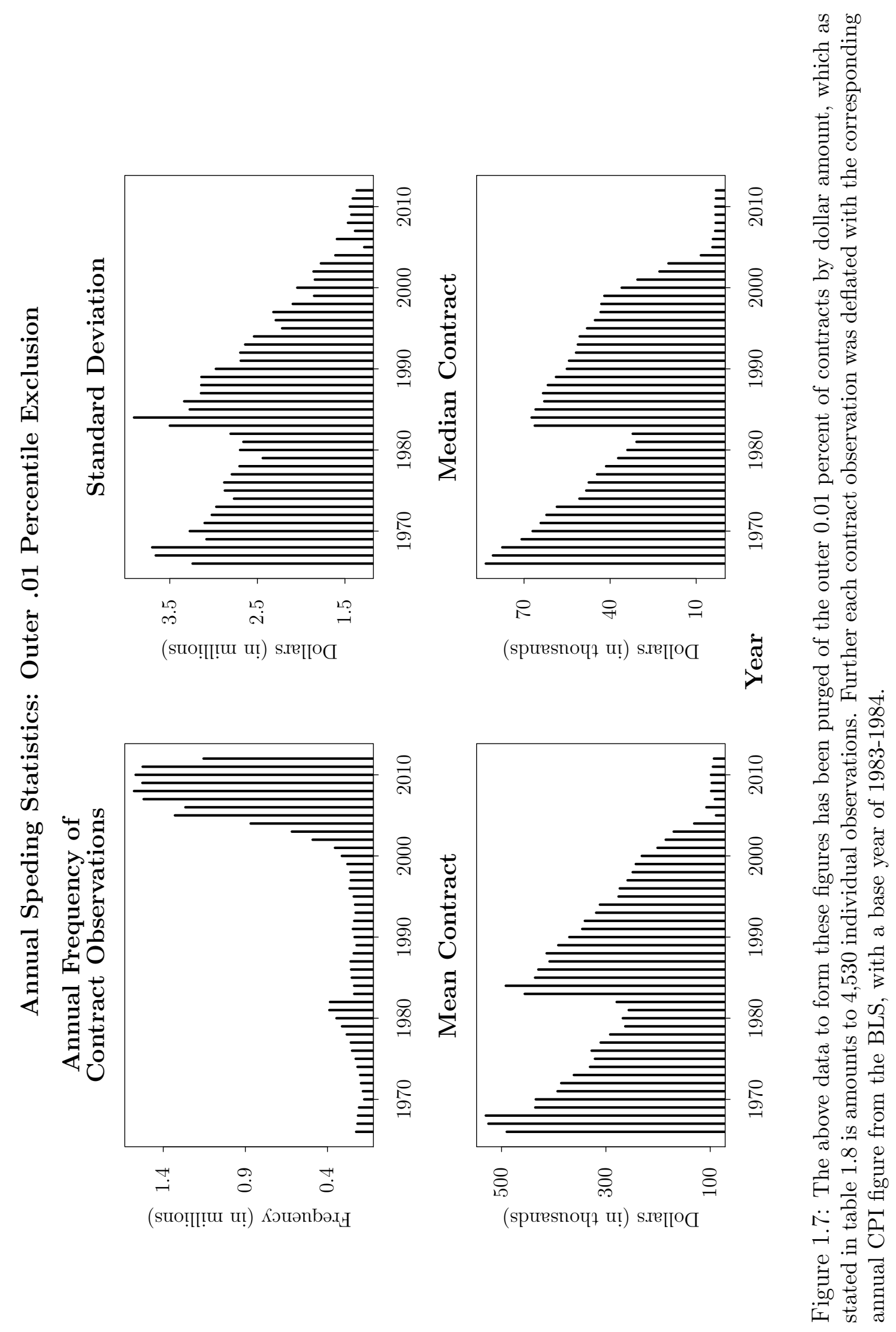


Seasonal Frequency of Contract Obligation

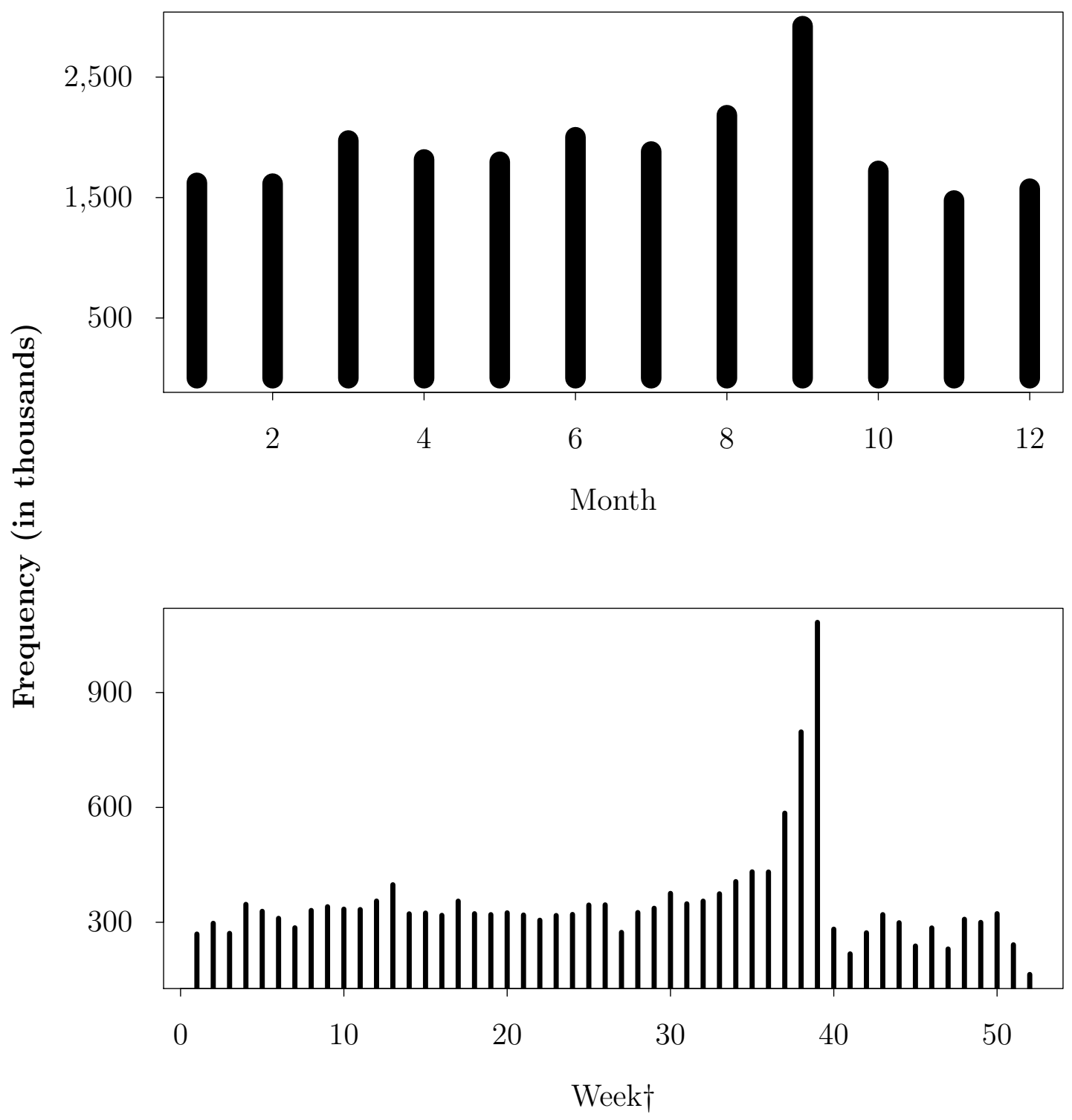

Figure 1.8: This chart displays the seasonal frequency of individual contracts, in months and weeks. The end of the federal fiscal year is September 30, which is reflected in the above graphs with a year-end rush to sign contracts.

$\dagger$ Denotes Weekly observations are only available from FY 1984 and on, as the observations prior to this point only contain information at the monthly frequency. 


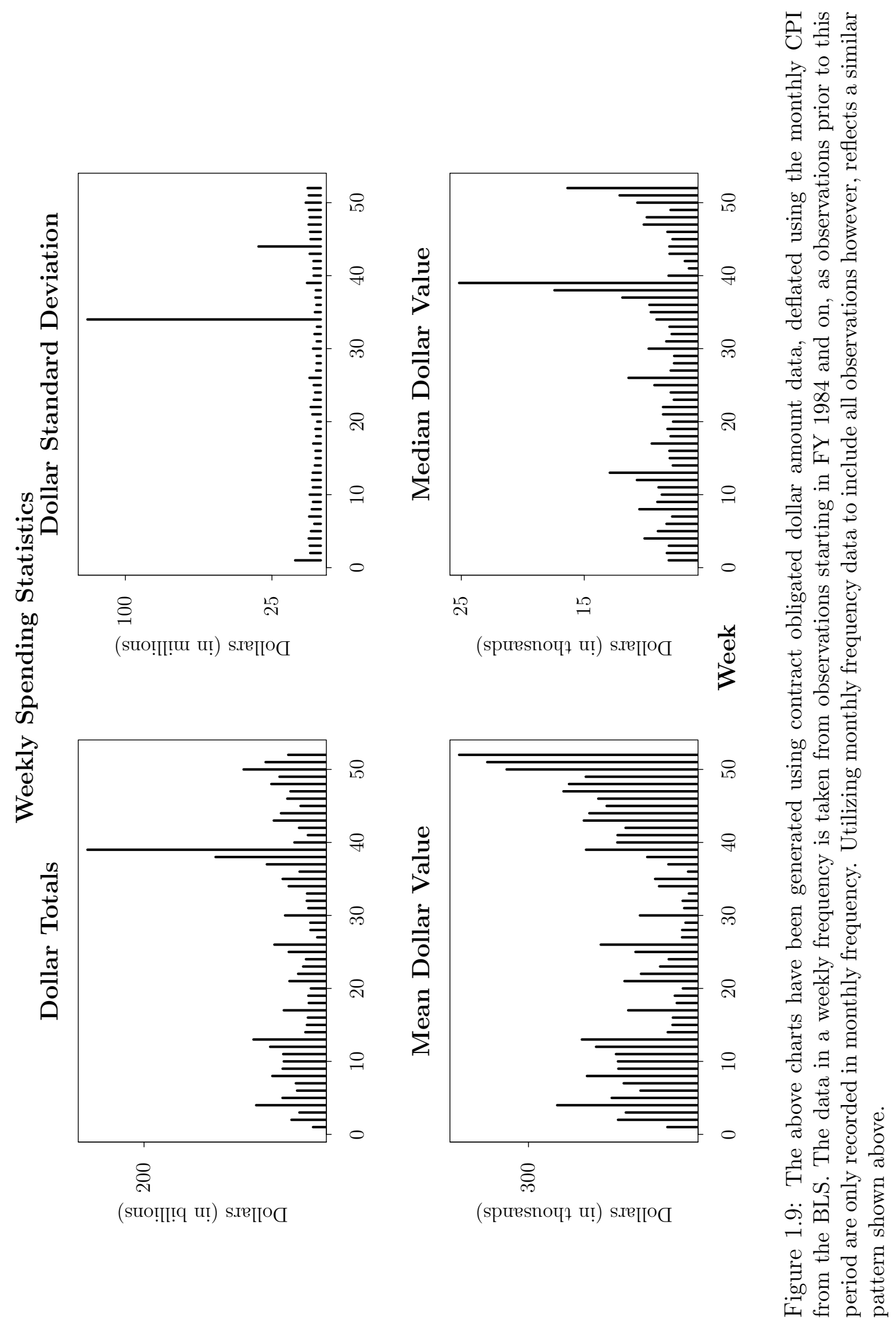



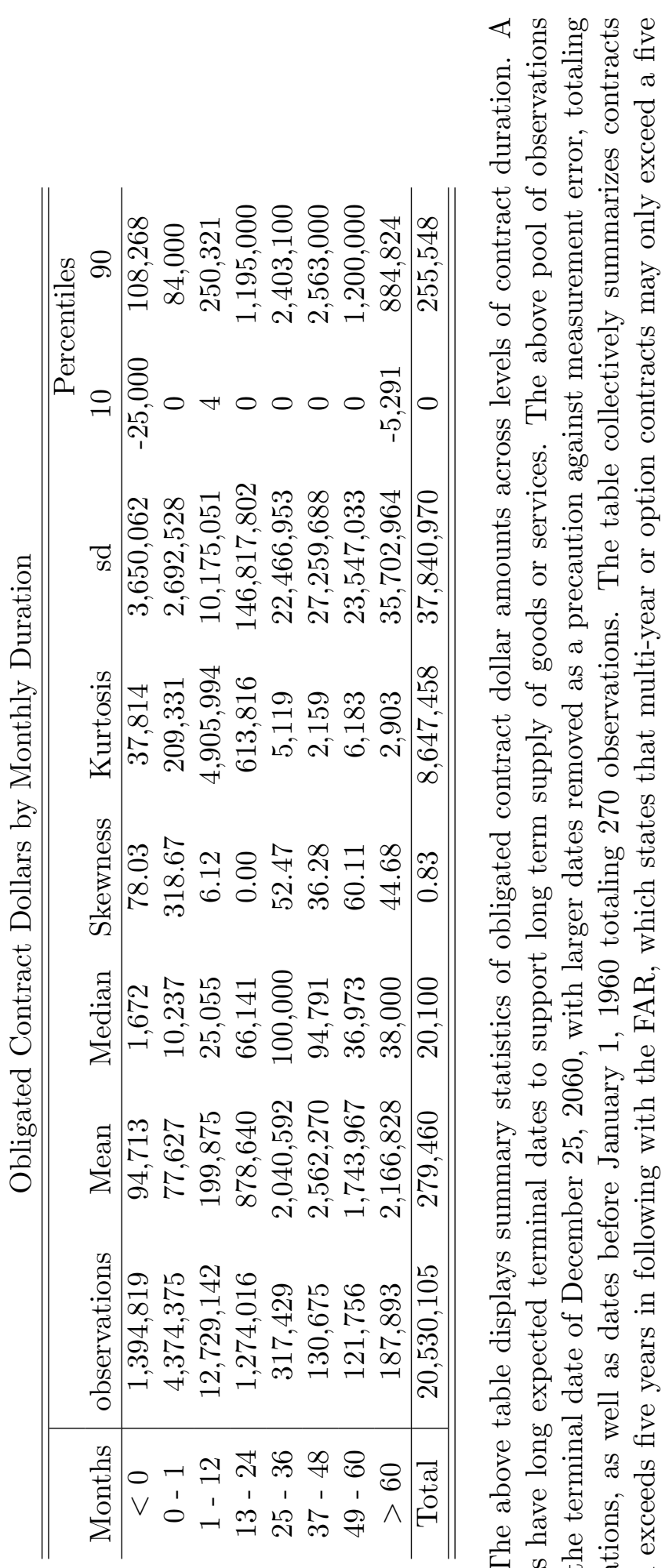

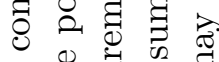

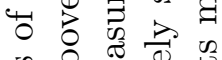

क $\pi$ \&

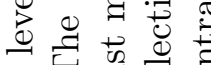

क

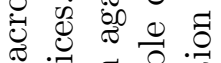

क :

寻范

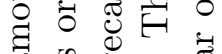

ส

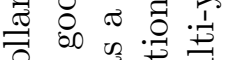

낭

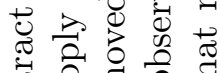

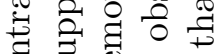

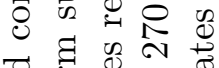

可

$\because 0$ 年

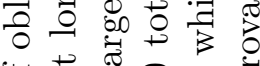

प艹

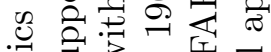

ज证 $\overrightarrow{0}$

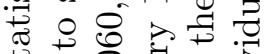

का कू ते

ㄴ.

घ $\rightarrow$ o

छ ज

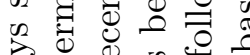

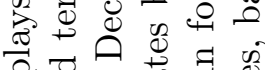

त्ञ

0

त्र

0

。으.

के क्षे की

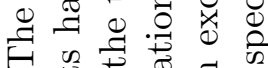

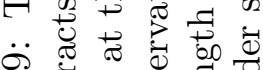

के

0000

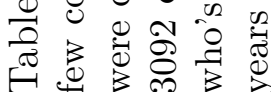




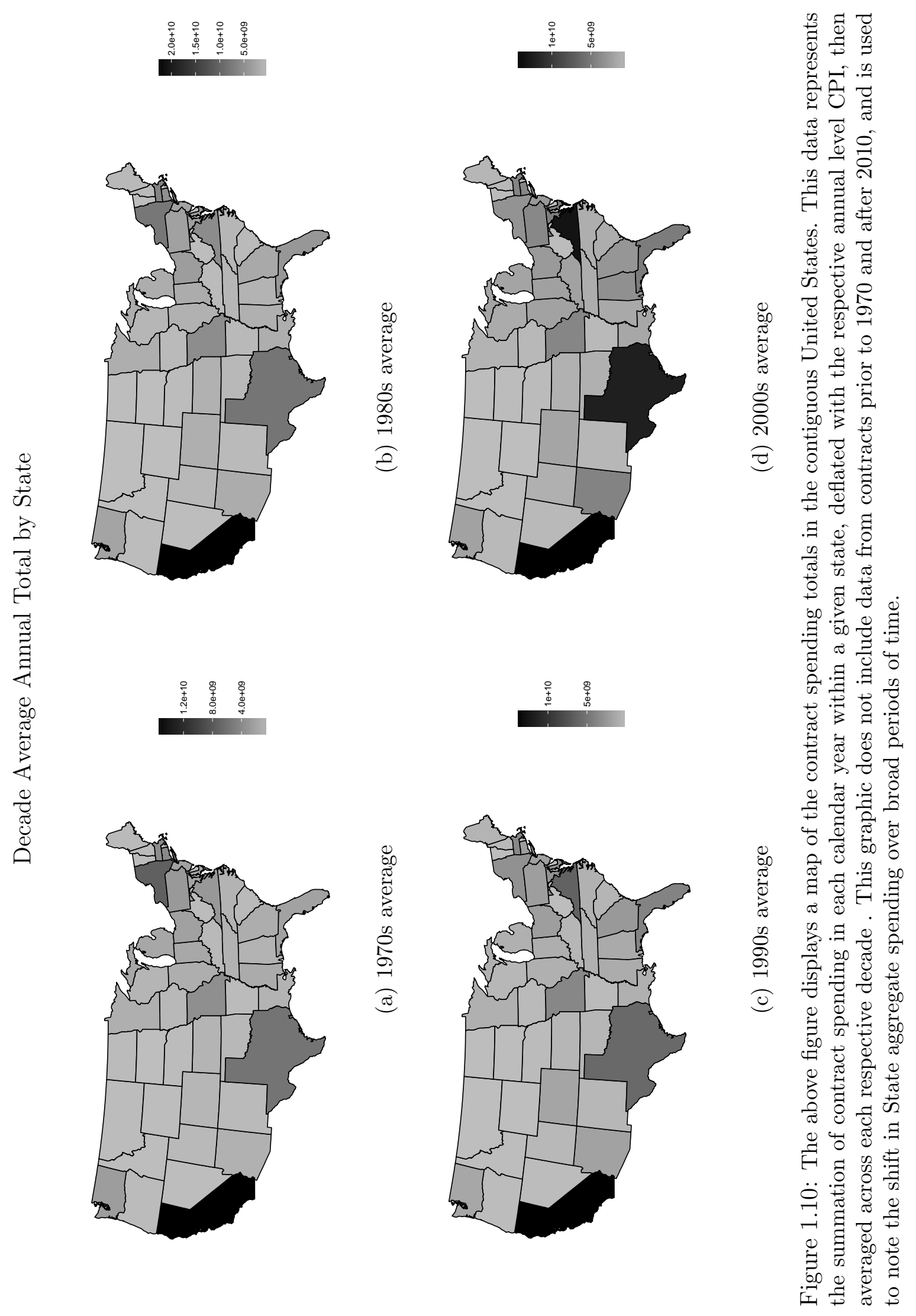




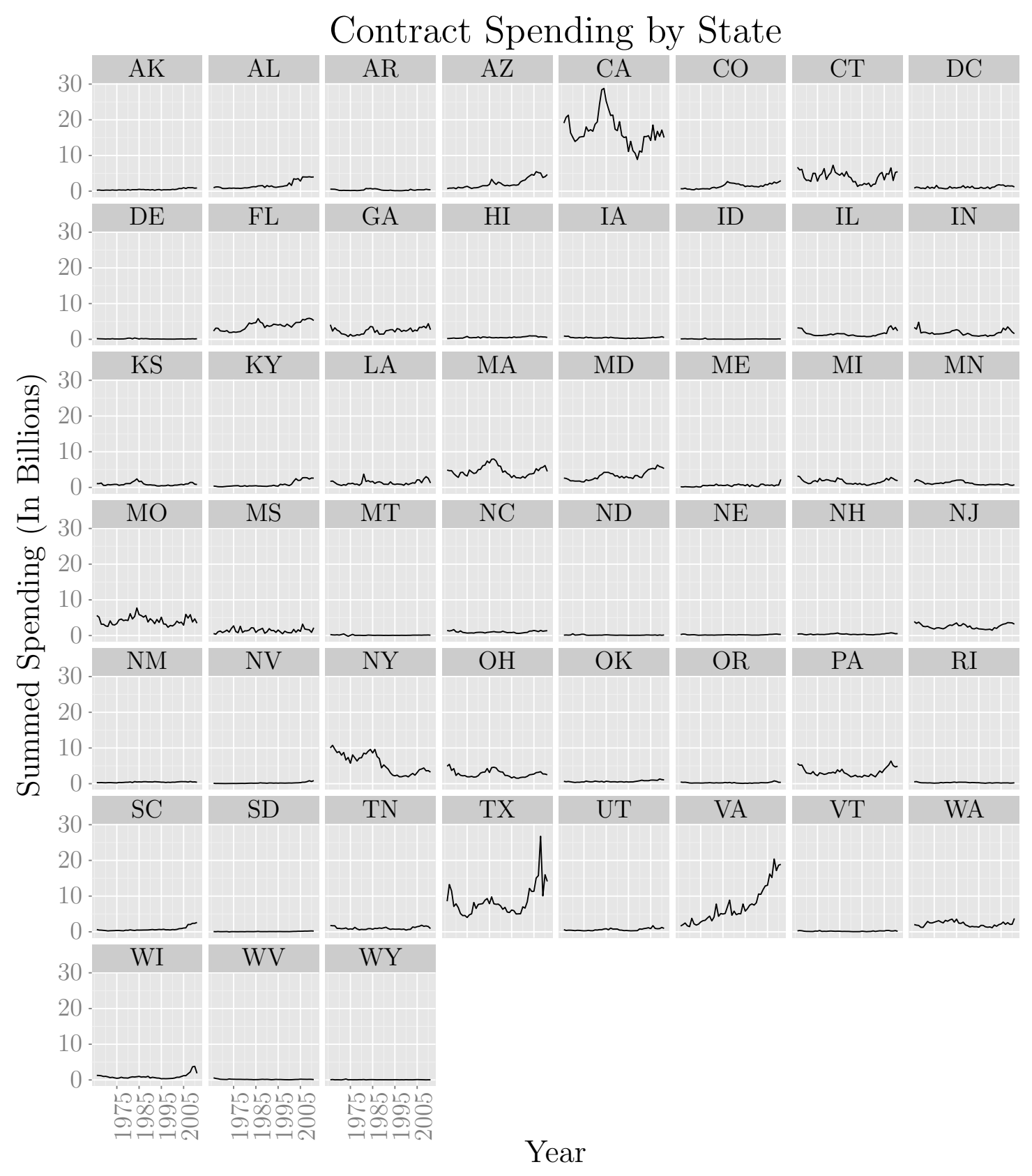

Figure 1.11: This figure displays time series plots for the annual summed spending for all 50 United States. The data reflected here is deflated with the annual, national CPI 


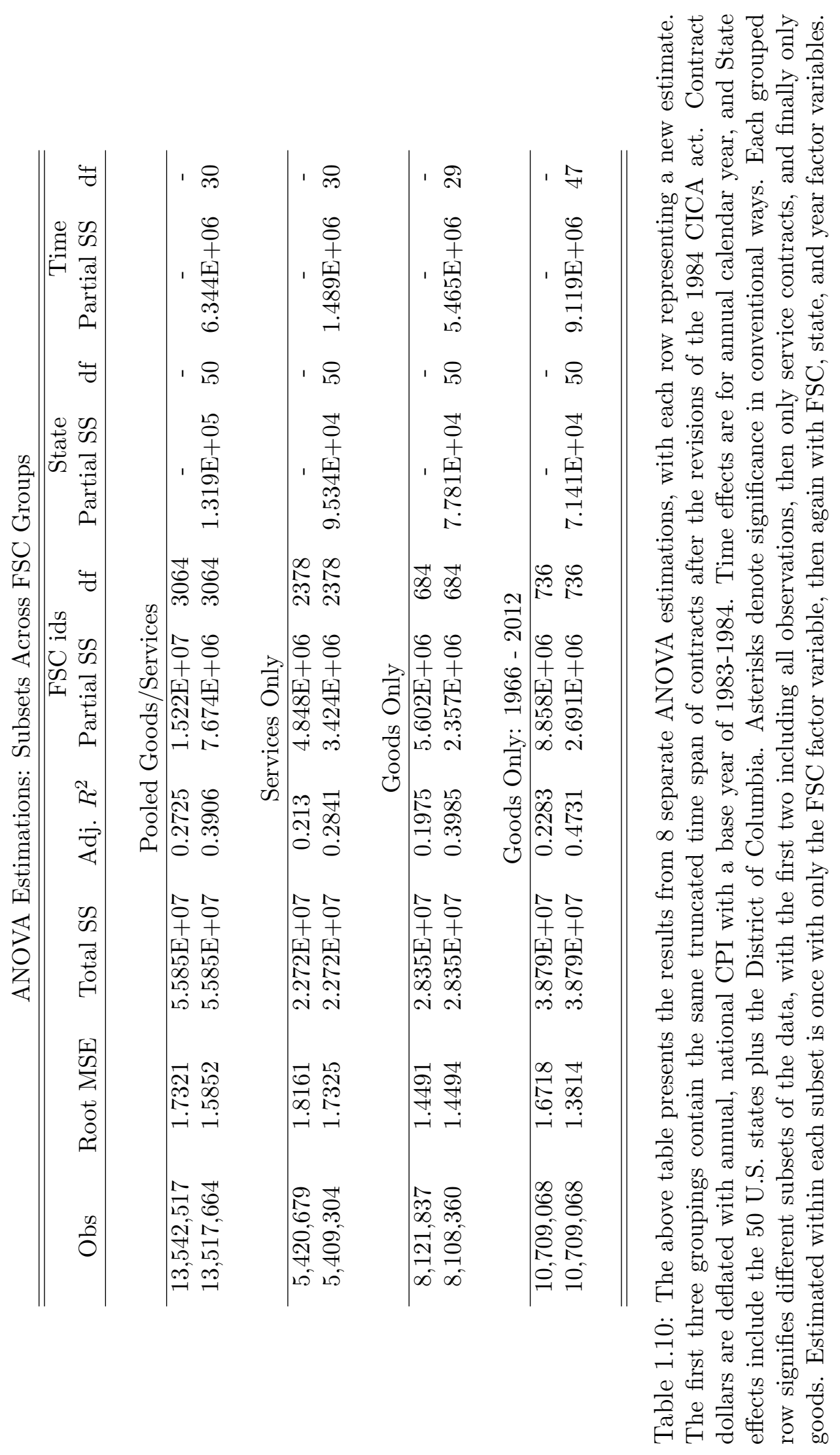




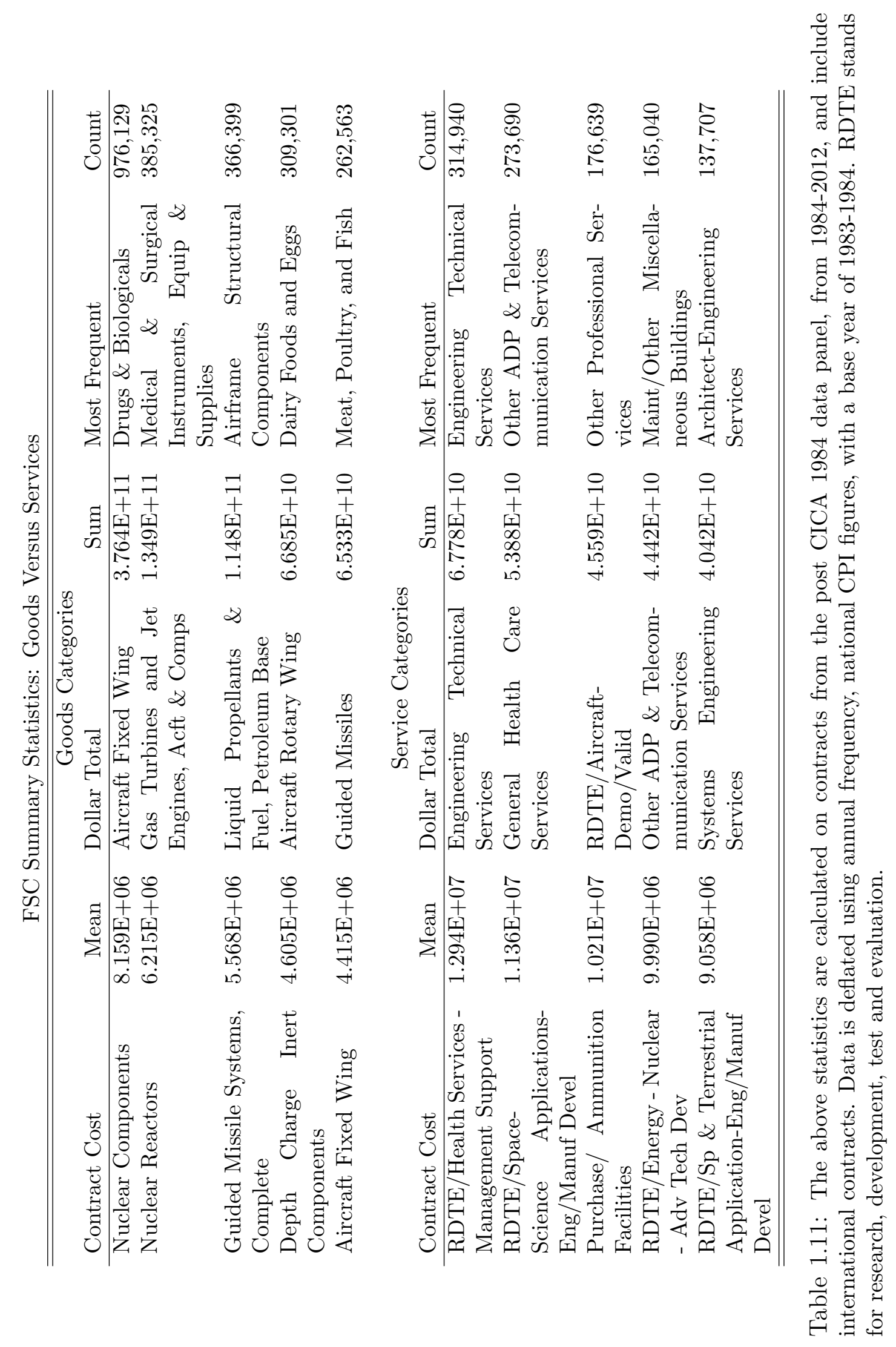


Decomposition of Regression Variance

\begin{tabular}{lcc|ccccc}
\hline \hline \multirow{2}{*}{ Model } & $\bar{R}^{2}$ & Total & Product & State & Year & Conteraction & Covariate \\
& & Variance & Effects & Effects & Effects & Effects & Effects \\
\hline & & & & & & & \\
$(1)$ & 0.5058 & 3.4165 & 0.2863 & 0.0094 & 0.8384 & & 0.5051 \\
& & 100 & 8.3804 & 0.2743 & 24.5386 & & 14.7830 \\
$(1-2)$ & 0.4833 & 3.4165 & 0.1645 & 0.0080 & 0.8667 & & 0.5130 \\
& & 100 & 4.8139 & 0.2342 & 25.3690 & & 15.0162 \\
$(2)$ & 0.409 & 3.4165 & 0.2846 & 0.0187 & 0.8000 & 0.0400 & 0.5047 \\
& & 100 & 8.3309 & 0.5477 & 23.4146 & 1.1706 & 14.7726 \\
$(2-1)$ & 0.4868 & 3.4165 & 0.1642 & 0.0190 & 0.8035 & 0.0628 & 0.5130 \\
& & 100 & 4.8047 & 0.5573 & 23.5173 & 1.8387 & 15.0147 \\
$(3)$ & 0.4948 & 3.4165 & 0.1626 & 0.0146 & 0.8371 & 0.0834 & 0.5180 \\
& & 100 & 4.7588 & 0.4287 & 24.5012 & 2.4408 & 15.1608 \\
$(4)$ & 0.5031 & 3.4165 & 0.2374 & 0.0079 & 0.8705 & 0.0153 & 0.5156 \\
& & 100 & 6.9494 & 0.2312 & 25.4806 & 0.4470 & 15.0910 \\
\hline \hline
\end{tabular}

Table 1.12: This table lists the computed decomposition of variance for model 1.1 through model 1.4 with model (1-2) and (2-2) indicating that an aggregated 2 digit product id variable was used instead of the 4 digit variable, using log measured, CPI deflated spending. The listed percentages denote the proportion of variance captured by the various groups of regressors. Note that the variances/covariances are calculated on the estimation sample for that particular regression, and each regression consists of 2,022,483 obser. 


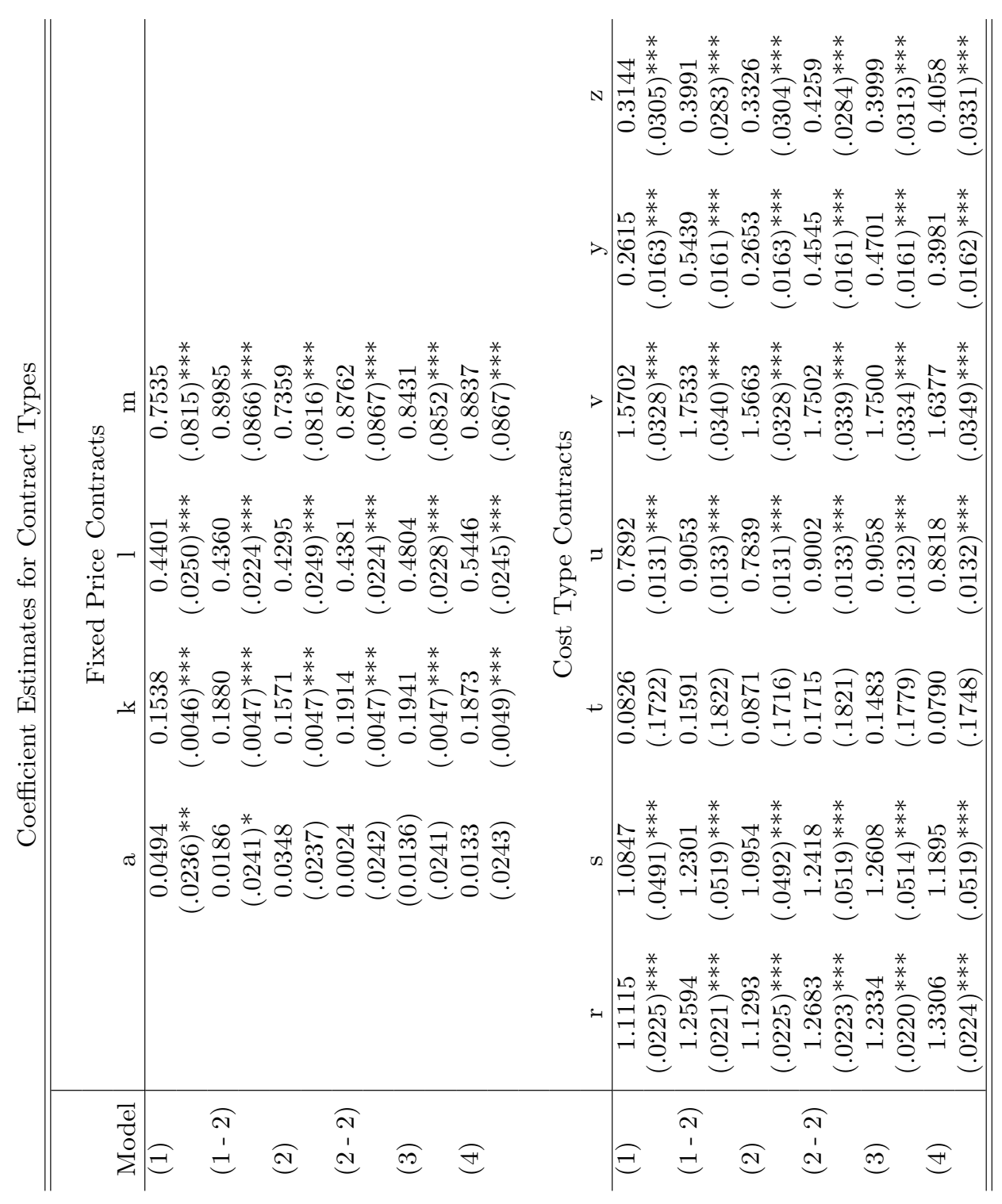


Coefficient Estimates for Finance Types

\begin{tabular}{c|ccccc}
\hline \hline \multirow{3}{*}{ Model } & $\mathrm{A}$ & $\mathrm{C}$ & $\mathrm{D}$ & $\mathrm{E}$ & $\mathrm{F}$ \\
\hline$(1)$ & 0.6974 & 0.6413 & 0.4854 & 0.1123 & 1.3396 \\
& $(.0050)^{* * *}$ & $(.0273)^{* * *}$ & $(.0383)^{* * *}$ & $(.0098)^{* * *}$ & $(.0311)^{* * *}$ \\
$(1-2)$ & 0.7429 & 0.5584 & 0.7400 & 0.1470 & 1.5924 \\
& $(.0050)^{* * *}$ & $(.0238)^{* * *}$ & $(.0394)^{* * *}$ & $(.0100)^{* * *}$ & $(.0314)^{* * *}$ \\
$(2)$ & 0.7001 & 0.6564 & 0.4860 & 0.1045 & 1.3415 \\
& $(.0050)^{* * *}$ & $(.0274)^{* * *}$ & $(.0385)^{* * *}$ & $(.0098)^{* * *}$ & $(.0311)^{* * *}$ \\
$(2-2)$ & 0.7450 & 0.5789 & 0.7342 & 0.1376 & 1.5921 \\
& $(.0050)^{* * *}$ & $(.0243)^{* * *}$ & $(.0396)^{* * *}$ & $(.0101)^{* * *}$ & $(.0314)^{* * *}$ \\
$(3)$ & 0.7619 & 0.5686 & 0.7484 & 0.1780 & 1.5491 \\
& $(.0050)^{* * *}$ & $(.0240)^{* * *}$ & $(.0390)^{* * *}$ & $(.0101)^{* * *}$ & $(.0309)^{* * *}$ \\
$(4)$ & 0.7435 & 0.6730 & 0.6913 & 0.1049 & 1.5092 \\
& $(.0051)^{* * *}$ & $(.0247)^{* * *}$ & $(.0395)^{* * *}$ & $(.0100)^{* * *}$ & $(.0314)^{* * *}$ \\
\hline \hline
\end{tabular}

Table 1.14: The figures above are produced from the same estimations listed in table 1.12. These coefficients represent the effects of various financing options for individual contracts, with no financing as the base level to compare with. Standard errors are displayed in parenthesis below each point estimate with asterisks indicating significance in the standard fashion. The financing options listed above correspond to the following options: A Progress Payments, C - Percentage of Completion, D - Unusual Progress Payment or Advanced Payment, E - Commercial Financing, and F - Performance Based Financing. Models correspond to equations 1.1 - 1.4, with model (1-2) and (2-2) indicating that an aggregated 2 digit product id variable was used instead of the 4 digit variable. 
Coefficient Estimates for Extent of Competition

\begin{tabular}{c|ccc}
\hline \hline \multirow{3}{*}{ Model } & \multicolumn{3}{|c}{ Levels of Competition } \\
\hline$(1)$ & Not Available for Comp & Follow On Competition & Not Competed \\
\hline \multirow{3}{*}{$(1-2)$} & -0.0144 & -0.0742 & 0.0326 \\
& $(.0055)^{* * *}$ & $(.0101)^{* * *}$ & $(.0026)^{* * *}$ \\
$(2)$ & 0.1454 & 0.0190 & 0.0412 \\
& $(.0056)^{* * *}$ & $(.0103)^{*}$ & $(.0026)^{* * *}$ \\
$(2-2)$ & -0.0106 & -0.0896 & 0.0346 \\
& $(.0055)^{* *}$ & $(.0102)^{* * *}$ & $(.0026)^{* * *}$ \\
$(3)$ & 0.1509 & 0.0002 & 0.0447 \\
& $(.0056)^{* * *}$ & $(.0104)^{* * *}$ & $(.0026)^{* * *}$ \\
$(4)$ & 0.0968 & 0.0191 & 0.0382 \\
& $(.0056)^{* * *}$ & $(.0103)^{*}$ & $(.0026)^{* * *}$ \\
& 0.1252 & 0.0264 & 0.0567 \\
\hline \hline
\end{tabular}

Table 1.15: The figures above are produced from the same estimations listed in table 1.12. These coefficients represent the effects of various restraints on competition, where the base level is full and open competition. Standard errors are displayed in parenthesis below each point estimate with asterisks indicating significance in the standard fashion. Models correspond to equations 1.1 - 1.4, with model (1-2) and (2-2) indicating that an aggregated 2 digit product id variable was used instead of the 4 digit variable. 
Coefficient Estimates for Time Dimension Covariates

\begin{tabular}{c|ccc}
\hline \hline Model & multi-year-contract & last month & $\log ($ duration) \\
\hline$(1)$ & -0.1167 & 0.1119 & 0.4310 \\
& $(.0334)^{* * *}$ & $(.0027)^{* * *}$ & $(.0014)^{* * *}$ \\
$(1-2)$ & 0.3102 & 0.1126 & 0.4341 \\
& $(.0260)^{* * *}$ & $(.0028)^{* * *}$ & $(.0013)^{* * *}$ \\
$(2)$ & -0.1162 & 0.1127 & 0.4306 \\
& $(.0337)^{* * *}$ & $(.0027)^{* * *}$ & $(.0014)^{* * *}$ \\
$(2-2)$ & 0.3075 & 0.1135 & 0.4340 \\
& $(.0261)$ & $(.0028)^{* * *}$ & $(.0014)^{* * *}$ \\
$(3)$ & 0.3595 & 0.1156 & 0.4360 \\
& $(.0270)^{* * *}$ & $(.0027)^{* * *}$ & $(.0014)^{* * *}$ \\
$(4)$ & 0.3744 & 0.1100 & 0.4328 \\
& $(.0272)^{* * *}$ & $(.0027)^{* * *}$ & $(.0014)^{* * *}$ \\
\hline \hline
\end{tabular}

Table 1.16: The figures above are produced from the same estimations listed in table 1.12. These coefficients represent the effects of various measures of individual contract length and timing. multi-year-contract indicates whether the original signed contract was for more than a one year term, last month indicates whether the contract was signed in September, and $\log$ (duration) is a natural $\log$ transformed measure of the months from the sign date to the end of a contract. Standard errors are displayed in parenthesis below each point estimate with asterisks indicating significance in the standard fashion. Models correspond to equations 1.1 - 1.4, with model (1-2) and (2-2) indicating that an aggregated 2 digit product id variable was used instead of the 4 digit variable. 


\section{CHAPTER 2}

\section{ESTIMATING A STATE FISCAL MULTIPLIER}

\section{$2.1 \quad$ Introduction}

Views on the role of government spending have long been split across political and ideological lines. These divisions are perhaps no more obvious than in the current political climate, with partisanship predominantly focused on the government's fiscal responsibility. This study will attempt describe of effectiveness of fiscal policy by estimating a fiscal multiplier across States. Using a panel study natural experiment framework, I will deploy defense contracting data to isolate the short-run, immediate effects of an increase in federal spending on state output.

Arguments about fiscal multipliers are typically centered around whether they are larger or smaller than unity. The fiscal policy multiplier measures the rate at which government spending boosts output, and if it is greater than one there is significant justification for it's use to correct economic woes. If the true multiplier is lower than one however, this justification quickly dries up and then the arguments for stimulus are much more difficult to defend.

Perhaps the gulf between these opposing ideologies could be bridged if there was more consensus on estimates of a multiplier. Predictions about aggregate economic indicators are typically linked to the underlying theoretical framework being used. The typical neoclassical framework has suggested multipliers from as low as 0.02 as in ? to slightly over unity (?). These models emphasize a perfectly competitive market structure with flexible prices (?), where fiscal shocks correspond to a positive movement in output and labor supply and a decrease in consumption, depending on the the financing of the spending (?) . The most typical criticisms of this class of 
models is the failure to reconcile predictions with stylized facts about the movements of aggregate consumption, wages and productivity (?).

New Keynesian models can generate higher fiscal multipliers, such as 1.6 estimated by ? and 1.7 estimated by ?. Where these models typically rely on various market imperfections and price rigidities in their specification ${ }^{1}$.

Likewise there is a dearth of consensus in the empirical multiplier estimates. A great deal of research is conducted through SVAR analysis, where the timing of government spending is typically assumed to precede other macroeconomic variables as in ?, ?, ?, and ?, which justify their estimates in a theoretical new Keynesian, sticky price framework. The timing of spending shocks is of serious concern with these models however, as estimates distinguishing between anticipated and unanticipated spending shocks can yield effects of opposite sign (?).

Alternatively, estimation utilizing the narrative approach first illustrated by ? attempts to address the issue of timing by isolating the news of a military spending shock. The narrative approach method uses the dates of news reports about military buildups in conjunction with military spending data to isolate the exogenous effects of government spending, and typically produces estimates of multipliers consistent with neoclassical models, as in ?, ? and ?. While exogeneity of military spending is the typical assumption in the literature ${ }^{2}$, military expenditure decisions are highly political and as such have the potential to be economically driven. ? highlights the use of military spending as an instrument of fiscal policy. While some may say this

\footnotetext{
${ }^{1}$ ? note that their estimates are made with a slight reversion of assumptions from forward looking (?) to rule-of-thumb consumers, among other special features made in their analysis

${ }^{2}$ Not only is it assumed, it is the main justification for using military spending data in these estimates, see?
} 
is a cynical view of U.S. foreign policy, turning a blind eye on these issues could seriously bias any resulting estimates.

The present analysis attempts to address this possibility of endogeneity by taking advantage of the natural experiment environment afforded by the United States. This analysis looks at military contract spending at the State level, and its effects on GSP and employment. The methods in the current chapter is perhaps most similar to ?, who utilize State level military contract data to construct an instrument and estimate spending effects through 2SLS estimation. Their main identification assumption is that the federal government does not embark on aggregate level military buildups on the basis of the economic conditions of any one individual State. The variance among interstate economic idiosyncrasies is used to estimate an "open economy relative multiplier" of 1.5 .

The following analysis will utilize a continuous difference-in-differences (henceforth DD) estimation across States, as the method of guarding against endogeneity bias. Difference-in-differences estimation techniques utilize a treatment and control framework to take advantage of "natural experiment" scenarios across various groups. The primary assumption for DD estimation is that the groups are similar enough that, in the counter-factual state without "treatment," the average difference between groups would be unchanged. Typical DD experiments use a binary treatment effect, however the experiment in the current study will utilize defense contract spending as a continuous treatment variable. The strategy deployed here will produce a short-run, continuous measure of the effect of spending on GSP, or a State level fiscal multiplier. Combined with standard fixed effects estimators, the differences in agglomeration of defense contracting across States provides enough variation to produce multiplier estimates in the range common to the literature, while State characteristics are similar enough to provide a check against endogeneity bias described above. 
Although DD estimation has been widely used in microeconometric analysis (specifically labor economics and wage studies) it has received little implementation in macroeconomic study. ? use DD analysis to study the effects of trade openness on economic growth at an international scale. ? also use DD to study the link between improved nutrition and the rapid urbanization experienced between the eighteenth and nineteenth centuries. Care must be taken to ensure a well designed DD macroeconomic experiment (?). If an exogenous shock is isolated, resulting analyses can yield relatively insightful findings, which are not as vulnerable to endogeneity bias.

As ? point out, two important advantages result from analysis at the State level. First, using a panel of State level data implies that monetary policy is constant across groups, through constant nominal interest and exchange rates. Holding these aggregate effects constant eliminates any estimation errors possible in macro studies, which arise when one does not control for reactionary monetary policy as a result of spending shocks enacted through congress. The current experiment puts primary focus on the defense spending shock that occurs in 1982 as will be outlined in the following sections. Considering the severe monetary policy shocks introduced by Volcker during this time, an experiment of this nature is particularly useful.

Second, the treatment is directly financed through federal taxation and borrowing which is also constant across regions. Therefore, relative changes in procurement spending across groups does not translate to relative changes in federal taxes across those groups. By fixing the effects of monetary and fiscal policy, we can get a more direct picture of the effects on output.

To preview these results, our short-run, DD analysis produces a State-level relative fiscal multiplier of 1.19, with alternate regression specifications yielding multipliers in the range of $1.17-1.21$. This multiplier is in the lower range of many New Keynesian models but higher than the typical neoclassical models would suggest. 
The rest of the chapter will proceed as follows. Section two will describe the sources and transformations of the data used in this analysis. Section three will briefly describe the aggregate and State level trends in military procurement spending. Section four will outline the experimental design, where the construction of the regressions will be described, as well as selection and justification of the timing and also discussion of the results. Section five concludes.

\section{$2.2 \quad$ Data Sources}

The data employed in the analysis is compiled from a variety of sources, including the Bureau of Economic Analysis, the Bureau of Labor Statistics, the United States Census Bureau and the Department of Defense. The data gathered from the department of defense form DD 350 as described in the first chapter is the foundation of this study. These figures are aggregated to the total dollar value for each State, for each calender year.

The GSP data are gathered from the Bureau of Economic Analysis. Unfortunately, real GSP is only published back to 1987. However, using the same method employed by the BEA, real GSP is reconstructed back to 1977 using the State quantity index and nominal GSP series, both publicly available from the BEA. Because of the reporting structure of the BEA, all real figures are presented in 1997 dollars.

Historical data on State level prices is also difficult to come by, where the BLS only publishes CPI data at national and regional level ${ }^{3}$. To control for prices I use the constructed real GSP series to create a GSP deflator. Use of this deflator allows the analysis of real changes as a result of government spending changes. As with the

\footnotetext{
${ }^{3}$ These regions are also somewhat broad; Northeast, Midwest, South and West. One can easily imagine large variation of prices within these regions, say between Montana and California, both in the Western region.
} 
real GSP series, the deflator is also presented in 1997 dollars $^{4}$. We use this deflator to adjust for military spending prices.

State level population data are derived from the U.S. Census. Since the census is conducted once every decade, the inter-survey years are population interpolations generated by the Census Bureau. We utilize this series to control for population flows between States and potential effects this may have on the estimations, by transforming the aggregate level data to per-capita terms. Employment data are compiled from the Bureau of Labor Statistics. Each State series is collected from the total count of nonfarm State employees, annually from 1965 through 2010. Unfortunately total hours or average weekly hours worked at the State level are only available from 2007 and on, so the count of actual employment must be used. Data on State level consumption are not readily available, and therefore out of the scope of this analysis.

\subsection{Trends in Military Procurement: 1977-2006}

United States military excursions since 1977 have palled in comparison to those of previous decades. The largest two buildups within the boundaries of the panel both began with the Carter-Regan buildup and with the events of September 11, 2001 as described in great detail in ? and ?. These episodes of high spending are much smaller than those seen during of course World War II, but also the Korean War, and even the Vietnam War (??). The DD estimation requires that the shock be carefully selected to be able to be able to capture its effects. Therefore the work of ? and ? will be expanded upon in this section to better justify the focus this study places on these time periods.

\footnotetext{
${ }^{4}$ The BEA changed its reporting regime from the SIC to the NAICS, where both series present data in 1997. While the BEA warns against appending the two datasets outright, the deflator was separately constructed and properly transformed, then joined smoothly
} 
To provide some visual context with figure 2.1, procurement spending as a fraction of aggregate U.S. GDP was relatively much greater in the early eighties than even during the first part of this century. This indicator provides a frame of reference, connecting output to procurement spending. It is similar in construction to the indicator used by ? and other national level multiplier studies, and as such this measure of spending will also be deployed in the next section in a DD framework. It should be noted here too that while ? identifies the period after 2001 as another buildup in this timespan, the size of spending in relative terms shown in figure 2.1 is much less substantial when compared with the buildup in the early eighties ${ }^{5}$.

While the aggregate trends in military procurement have shifted significantly between 1977 and 2006, the relative percent of spending received by States has changed little over that same time span. California has consistently been the largest recipient of procurement dollars receiving as much as $20 \%$ of total procurement spending at times and often the only State with double digit percent of receipts. Meanwhile some States that typically receive little spending such as Wyoming garner well less than one tenth of one percent of the total ${ }^{6}$. It is also useful to note that while California consistently receives the largest percentage of contract spending (except for in 2005 when Virginia received more), most States in the high percentage group receive more than ten times the amounts received by the lowest group.

\footnotetext{
${ }^{5}$ While Virginia has experienced a substantial buildup of relative spending for some time, the other states in this figure have really only one shock, at 1982, which is more typical for most states in the panel.

${ }^{6}$ The raw procurement data is inclusive of military contracting procured both domestically and abroad. Domestic spending typically accounts for the vast majority of contracting; typically $90 \%$ or more of the total procurement spending
} 
Also the top and bottom ten States have changed position relatively little, as is clearly evident in table $2.1^{7}$. The fact that there is little change in the relative position of State's rankings is useful for DD analysis, which can be biased if there is significant change in group designation during the course of the experiment $(?)^{8}$.

To better understand the impact of this spending, again see figure 2.1. The figure visualizes the trends of two States each from the highest and lowest proportion groups compared with the national aggregate trend, where the difference between the two groups is clear. Groups that tend to get large proportions of spending experience a greater degree of volatility of this indicator when compared with low proportion groups. Table 2.2 lists the standard deviations for the five series listed in figure 2.1, where the two low proportion groups have much lower standard deviations than do the large proportion groups.

To further the understanding of the trend in U.S. aggregate, relative procurement spending see figure 2.2 , which displays the percentage change in aggregate domestic contract spending on the previous year relative to U.S. GDP, both nominal and deflated with the GDP deflator ${ }^{9}$. Most notable is the large shocks in the early eighties and around 2002. The difference in the United States aggregate trend between figures 2.2 and 2.1 around 2002 is striking, but it is a direct result of the growth of real U.S. output which is captured in 2.1. Clearly the difference is a direct result of the construction of this relative spending indicator. The spending shocks associated with the 2001-2002 period when compared with local observations may be significantly

\footnotetext{
${ }^{7}$ Looking at this snapshot of years, most States jump fewer than 10 places, only 30 percent of all States changed more than 10 spaces, and only Kentucky jumped more than 20 spaces

${ }^{8}$ The DD analysis performed here is not as subject to this bias since a group is created for each State instead of arbitrary designations.

${ }^{9}$ This plot is a trend of the main indicator used in the regression estimation, namely $\tilde{G}_{i t}$ described in section 2.4
} 
large, when compared with historical data they are much smaller. This is principally the result of steady GDP growth over the entire panel, ostensibly reducing the level size of the shock at the aggregate. Since this study will be deploying the relative spending measure as our source of shock, we will focus on the earlier period of spending

which has a much more substantial spending shock. This shock should provide a more substantial impact on state economic output, as its size relative to output is much larger.

Therefore this analysis will proceed by attempting to estimate the State level multiplier using a DD framework, by focusing on the timing of our spending shock. With the carter/Reagan buildup described in ? and ?, and analysis of our relative spending index the clear spike in spending is in 1982, providing the shock timing for the subsequent analysis.

\subsection{Estimation}

The main estimation technique used in this analysis is Difference-in-Differences. Using DD analysis is attractive to researchers for its intuitive approachability and its power to potentially avoid omitted variable bias. However as ? illustrate, the need for careful experimental design is paramount in arriving at a meaningful estimate of causal effects . What follows is a description of the experiment design, and how this analysis will take steps in its identification strategy to ensure sound and unbiased estimators are produced.

The two crucial identification issues with DD analyses are group selection and treatment timing. Traditional DD estimations attempt to capture differences in averages across two groups, one treated and one the control. The assumption is made that in the counter-factual absence of treatment, the difference between groups would be unchanged over time. 
An essential part of any successful DD analysis is that the differences between treatment and control groups be as small as possible, to reduce the potential for omitted variable bias (?). The intuition in this result is that among similar groups, the effect of treatment will be most clearly estimated, and not clouded by unobservable effects. Greater degrees of similarity across groups will reduce the pool of possible unobservable effects, producing a clean estimate of causal effects.

The United States are very often the laboratories for this literature; where subjects across states are largely homogeneous relative to cross-country group studies. States' relative homogeneity is characterized by a great deal of features, such as laws, culture, language, and federal policy. In this landscape of relative homogeneity, heterogeneous treatments across states provides a test, or a "natural experiment". Resulting interstate studies of policy typically yield interesting and intuitive results ${ }^{10}$.

Analysis using DD is scant in macroeconometric modeling, probably because of the lack of data availability of comparable groups and more complicated experimental design required. In the studies mentioned above, group selections are obvious, such as injured workers for workers compensation insurance, or low wage earners for minimum wage legislation, etc. For this study the treatment is military procurement spending, and its dollar amount relative to other states. The subsequent decision of any state's group membership then becomes an arbitrary decision to the researcher, resulting in a binary treatment variable to signal whether the group member received high or low spending. Arbitrarily determining a spending threshold for high spending states and low spending states would raise serious doubts about this analysis. The difficulty is particularly at issue here as all states receive some contract dollars, even if they are orders of magnitude smaller than top contracting states.

\footnotetext{
${ }^{10}$ For examples of interstate microeconomic studies see ?, ?, ?, ?, ?, and ?
} 
Fortunately a framework exists that both solves this group selection problem and provides a more intuitive estimate in the state level multiplier that has been discussed thus far. Instead of using military spending as a binary variable to distinguish between high and low groups, this study will estimate spending as a continuous treatment (??). As a result of this construction, each State belongs to its own group, and the treatment is an individual level of procurement spending. Thinking of the DD framework in a continuous sense is analogous to studying a controlled experiment for medication: the binary case being a selection of treated and placebo groups, and the continuous case a question of dosing rate. In this construction the estimator will be measuring the effect of spending on State output, instead of the difference between effects in States with higher levels of spending versus States that receive lower levels. Also when deploying a continuous treatment variable, the regression coefficient produced is interpreted as a fiscal multiplier, a convenient result of the construction of the relative spending indicator which will be discussed shortly.

This addresses the first of the two main aspects of a DD study, group identification. To isolate a meaningful shock in this study we start at the description of large scale military buildups in the 21 century. A natural starting point is the buildup in the early 1980 described by suggested by ?. An inspection of our data shows that the spending buildup beginning in 1980 first peaks in 1982. Figure 2.2 shows that while the change in spending begins in 1980, after deflating the data the, 1982 yields an even larger spike in the change in spending, producing the peak in 1982 seen in figure 2.1. Therefore 1982 will provide the timing for the impact of the spending shock. Furthermore, the DD framework's power lies in the basis of a truly exogenous shock. The following experiment will borrow the assumption employed by ?, that the federal government does not embark on any large scale buildups for the benefit of any state relative to other states. Combining this with the body of work around the use of 
military spending for its exogeneity, one can be fairly confident on the ability of this experiment to guard against endogeneity bias.

Finally, the regression will use a subset of the data constrained to two time periods, before and after the spending shock. Constraining the time is necessary to eliminate any possibility of autocorrelation bias in the residuals, as suggested by $?^{11}$. The resulting framework yields a regression with data from two periods, a pre-shock and post-shock year of 1982. As such the experiment outline captures a purely shortrun state multiplier, where the effect is only the immediate impact of the spending shock. The estimation will follow standard panel estimation strategy for the control of unobservable errors. The econometric DD model used in this analysis is as follows:

$$
\widehat{Y}_{i t}=\beta_{0}+\beta_{1} \gamma_{\text {treat }}+\beta_{2} \gamma_{\text {treat }} \tilde{G}_{i t}+\sum_{i=1}^{51} \alpha_{i} \lambda_{i}+\epsilon_{i t}
$$

where, $\widehat{Y}_{i t}=Y_{i t}-Y_{i t-1} / Y_{i t-1}$ and $\tilde{G}_{i t}=G_{i t}-G_{i t-1} / Y_{i t-1}$, and $Y_{i t}$ and $G_{i t}$ are real, per-capita GSP and real per-capita military procurement spending, respectively, for State $i$ in year $t$. This construction is the continuous "treatment" DD regression, where $\gamma_{\text {treat }}$ is the treatment year dummy, and $\lambda_{i}$ represents State fixed effect for state $i$. The coefficient of interest in this study is $\beta_{2}$, which captures the direct effect of government spending on GSP embodied in the multiplier. In keeping with the literature, the indicator here is analogous to that used in ? and ?, albeit with varying time intervals ${ }^{12}$. We also study the effects of government spending in a similar fashion for employment, by replacing the left hand side with $E_{t}-E_{t-1} / E_{t-1}$.

\footnotetext{
${ }^{11}$ ? goes through great lengths to show, through Monte Carlo analysis, that DD estimations with more than two periods have a strong likelihood of overstating the significance and committing type I error, if they do not explicitly account for this possible bias.

${ }^{12}$ ? use the indicator $G_{t}-G_{t-2} / Y_{t-2}$, suggesting that it is a parsimonious, albeit crude way to capture the dynamics between spending and output
} 


\subsubsection{Results and discussion}

The regression results are listed in 2.3. First thing to note is that the coefficient estimate for $\beta_{2}$ is in the expected range at 1.19. The estimate is generally smaller however than the main effect reported by ?, which is in the neighborhood of 1.5. It is important to note that this is likely due to the very short-run nature of this effect. Considering that there is considerable length to any shock of this size, it is reasonable to figure that the effects will be drawn out for several years. In experiments such as?, one can view the multipliers as long run averages, capturing extended expansions (and contractions) of military expenditures. If all of the spillover effects of these shocks are accounted for it is reasonable to consider that the resulting multiplier would be larger than estimated here.

The results of the current experiment are closely aligned with the existing literature of New Keynesian frameworks based on sticky prices. Note that this literature describes the bulk effects of any spending shock being felt right after the impact and slowly decaying to the trend over the following years. This further reinforces the notion that the estimated coefficient in this paper are expected to be smaller in size than those estimated in long run frameworks, such as ? and others.

Another thing to note is that these results are significantly different from those exemplified by neoclassical models and alternative econometric models employing defense data (??). Consider the important notion of unity again, where multiplier coefficients greater than unity versus less than unity imply that the effects of spending will be beneficial or wasteful, respectively. While not as large as other New Keynesian studies, this estimate provide further evidence into the school of thought that fiscal spending is beneficial instead of wasteful, particularly if the goal is a short run boost to output as is captured here. 
The impact on employment is not nearly in the comparable range as reported by ?, with the estimates for their employment multiplier are in the range of 1.3 to 1.8 , and the estimate in the study here is .29. The vast gap between these estimates provides significantly more emphasis on the notion that this study explicitly focuses on the short-run impact. The lower multiplier on employment growth suggests a more sluggish response by labor markets to this spike in spending. Considering the typical story regarding sticky prices and accounting for annually based labor contracts, significant lagged labor response to a sizable spending shock should not be entirely unexpected. Therefore this short-run impact multiplier estimate would be expected to be relatively lower than analogous long run studies. The effect is still substantial here however, providing an on impact boost to employment of .3 percent for a 1 percent spike in relative spending.

As a check against the per-capita, real data employed in the baseline results, the regressions are replicated using level real and level nominal data series as well. The results for these regressions are also listed in table 2.3. Note that the results are largely unchanged by deflating the data, or adjusting for population flows via percapita transformations, with estimates and their respective standard errors within .03 points of the baseline coefficient estimate.

Going back to the periods of defense buildup suggested by ? and ?, we can test a second spending shock contained in the bounds of this panel, specifically the shock originating from the War on Terror beginning on 9/11. Looking at our data in the span of this military buildup, again considering figures 2.1 and 2.2 an alternative possible spending shock could be 2002. Replicating the analysis with consideration of this as a point of defense spending shock however does not yield a coefficient that is statistically different from zero. The insignificant result is suggestive of the presence of a threshold, one that spending shocks must first reach before their magnitude (as 
measured relative to output) is substantial enough to impact GSP. It is quite possible that either the relatively lower spike in spending for 2002 is not effective at moving output growth, or that the relatively lower shock does not yield enough variation to provide statistical precision ${ }^{13}$. The question of the existence of a threshold, above which spending provides an effective tool to impact state level output and below which there is no measurable effect on output, is a fruitful topic for further research.

\subsection{Concluding Remarks}

The goal of this study was to estimate a State level, short-run relative fiscal multiplier through the use of DD estimation and a rich set of data on military procurements across the United States. By focusing on the spending shock in 1982, multiplier estimates produced are between 1.17 and 1.21, which is in the lower range of studies like ? and many New Keynesian studies, but critically larger than typical neoclassical models suggest.

Furthermore these estimates are directly within the range described by ? who broadly surveys the literature on these estimation attempts. The resulting set of estimates strengthen the notion that the true fiscal multiplier is perhaps in the range of slightly larger than unity, which helps temper some of the more extreme views of very large or virtually non existent estimates, and builds confidence in the power of

\footnotetext{
13? and ? suggest that the news announcement of the buildup should encapsulate the timing of the shock, emphasizing forward looking rational expectations. They suggest a timing of 1980 and 2001 as spending shock years, even though the peak shock in relative spending is clearly in 1982 and 2002. Replication of the experiments above with these suggested shock timings yields coefficients that are not statistically different from zero, again suggesting that the power of a shock is embodied in exceeding a certain threshold. Setting the timing in this framework at 1980 or 2001 may capture the news shock, but does not measure the impact of the spending shock itself.
} 
fiscal policy. Also,since these estimates are inherently focused on the short run, they may understate the full, multi-year effect of fiscal policy on state output.

The present study's estimation of the effects on employment is however significantly lower than those found in ?. The most likely reasoning for this is once again the short-run nature of this experiment. Labor contracts are typically sluggish to adjust and based on year long terms. Also, the lag between spending shocks and contractors actions on these new dollars, then leading to employers reactions to the new economic environment and ultimately their hiring decisions may be substantially longer than a single year's time. A 0.3 percent increase in employment growth is far from insubstantial, but it is possible that this estimate understates the full impact of spending on employment when accounting for labor market sluggishness.

The primary benefit of the approach outlined here was to produce unbiased estimates, combining military spending, typically held up as a source of exogenous spending, with an estimation strategy to guard against endogeneity bias. Another benefit to this slightly disaggregated study is to hold fixed any fluctuations in monetary policy or federal tax policy that could mask the true estimates, allowing an even clearer picture of fiscal spending effects.

As this study is focused on the short-run impact of a spending shock, future work could be focused on expanding the time horizon of this study. The main benefit of a time extension would be to more fully capture the multiplier, combining the impact of the shock and subsequent spillovers throughout the state economies over time. Building a dynamic econometric model to capture the time path of a spending shock could provide a better idea of the longer run efficacy of fiscal spending.

Additionally, exploring the possible existence of a threshold of spending, above which fiscal policy is effective in impacting the economy and below which the impact is inconsequential, may be a fruitful avenue of research. If the fiscal multiplier behaves 
in a variable, non-linear fashion, the non-linear nature may go a long way in explaining the historical difficulty in pinning down multiplier estimates. 


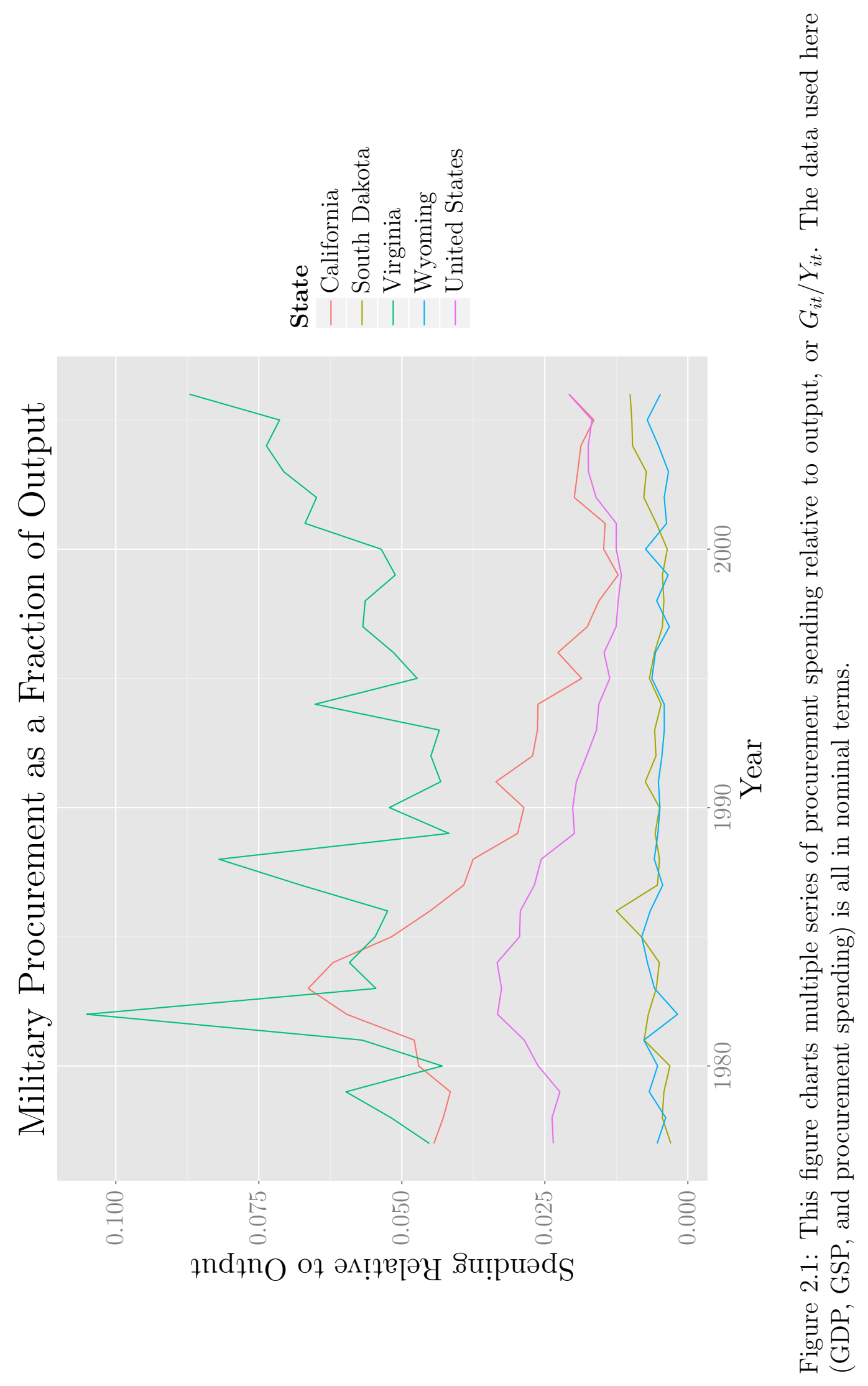




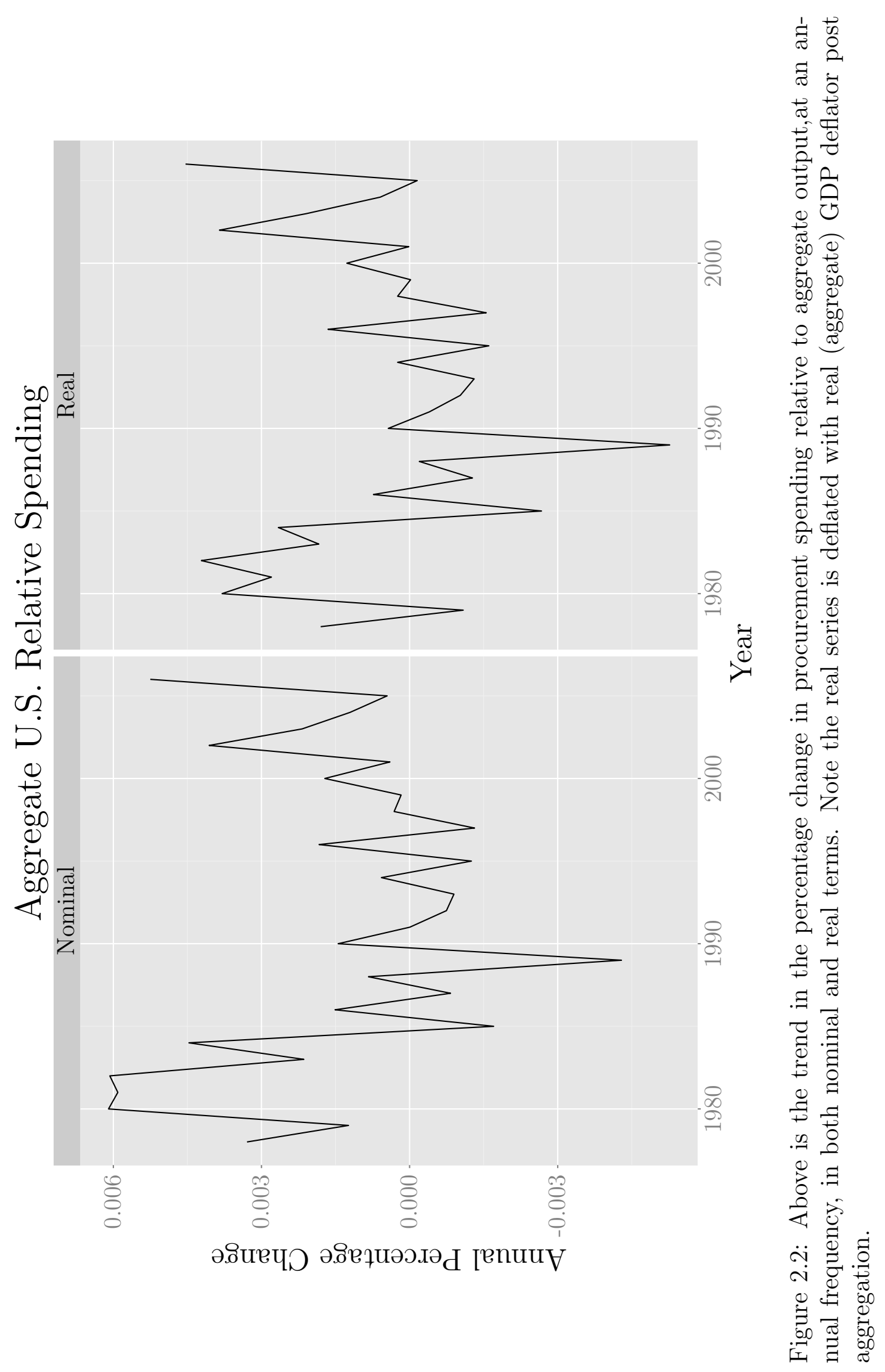




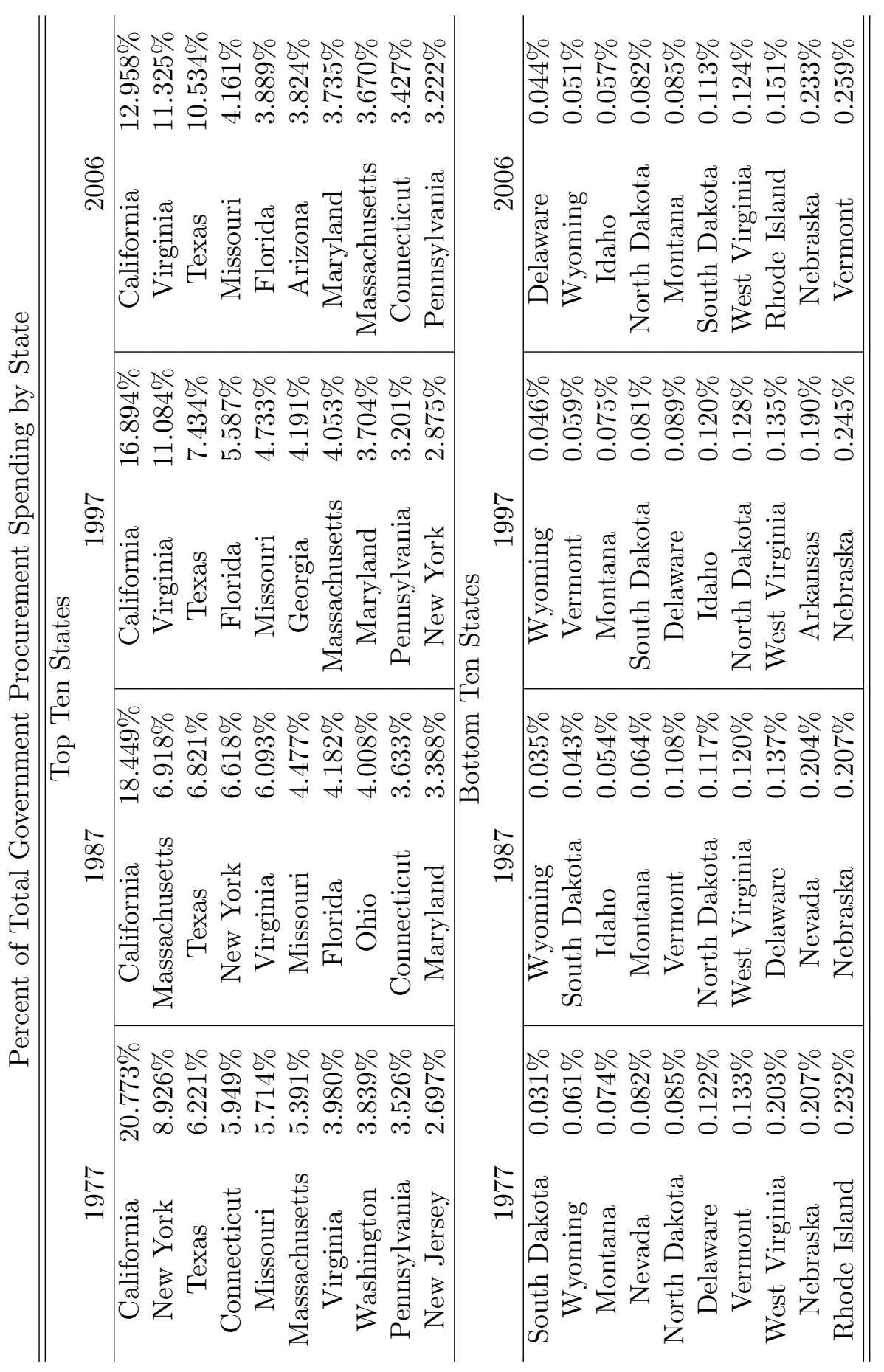

윰 శ్రేี

$\stackrel{g}{\square}$

呟

㣢

究

공

.

궁

흥

ㅎ․

률 द्व

잉

: .

画

$+50$

营菏

㻤

웅 음

施

过

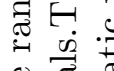

政䨔

능. ․․

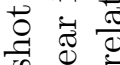

空

ตี

क त्]

.

눌

은

要要

承焉.

$\therefore$ 명

त

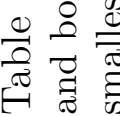




\begin{tabular}{cc} 
Volatility of Spending Across States \\
\hline \hline \\
United States Aggregate & 0.006807 \\
California & 0.015574 \\
Virginia & 0.014469 \\
South Dakota & 0.002232 \\
Wyoming & 0.001479 \\
\hline
\end{tabular}

Table 2.2: This table displays the standard deviations relative military procurement spending from 1977-2006, for the countries listed in figure 2.1. Notice that Virginia and California have much higher standard deviations than do Delaware and Wyoming, and the United States on the aggregate.

Regression Coefficient Estimates

\begin{tabular}{|c|c|c|c|c|c|}
\hline \multicolumn{6}{|c|}{ Baseline Per Capita, Deflated } \\
\hline \multicolumn{3}{|c|}{ GSP } & \multicolumn{3}{|c|}{ Employment } \\
\hline$\beta_{1}$ & $\beta_{2}$ & $\bar{R}^{2}$ & $\beta_{1}$ & $\beta_{2}$ & $\bar{R}^{2}$ \\
\hline $\begin{array}{l}-0.0524719 \\
(.0087)^{* * *}\end{array}$ & $\begin{array}{l}1.1972425 \\
(.5746)^{* *}\end{array}$ & .2046 & $\begin{array}{l}-.0269562 \\
(.0021)^{* * *}\end{array}$ & $\begin{array}{l}.2928872 \\
(.1367)^{* *}\end{array}$ & .3740 \\
\hline \multicolumn{6}{|c|}{ Level Data, Deflated } \\
\hline & GSP & & \multicolumn{3}{|c|}{ Employment } \\
\hline$\beta_{1}$ & $\beta_{2}$ & $\bar{R}^{2}$ & $\beta_{1}$ & $\beta_{2}$ & $\bar{R}^{2}$ \\
\hline $\begin{array}{c}-0.0566153 \\
(.0085)^{* * *}\end{array}$ & $\begin{array}{l}1.1709775 \\
(.5579)^{* *}\end{array}$ & .2273 & $\begin{array}{c}-.027026 \\
(.0021)^{* * *}\end{array}$ & $\begin{array}{c}.290604 \\
(.1364)^{* *}\end{array}$ & .3740 \\
\hline \multicolumn{6}{|c|}{ Level Data, Nominal } \\
\hline & GSP & & En & ployment & \\
\hline$\beta_{1}$ & $\beta_{2}$ & $\bar{R}^{2}$ & $\beta_{1}$ & $\beta_{2}$ & $\bar{R}^{2}$ \\
\hline $\begin{array}{l}-0.096297 \\
(.0096) * * *\end{array}$ & $\begin{array}{l}1.212528 \\
(.5466)^{* *}\end{array}$ & .3279 & $\begin{array}{l}-.0274709 \\
(.0021)^{* * *}\end{array}$ & $\begin{array}{l}.2694835 \\
(.1229)^{* *}\end{array}$ & .3745 \\
\hline
\end{tabular}

Table 2.3: Standard errors appear beneath parameter estimates and stars indicate significance at the 10, 5 and 1 percent mark for one, two and three stars, respectively. This table contains six separate regressions, one for GSP and for employment as outlined in 2.4, with per-capita deflated as the baseline, then again for aggregated state level deflated data, and finally aggregated state level nominal data. Also only data on spending and output has been deflated or population adjusted. 


\section{CHAPTER 3}

\section{MILITARY PROCUREMENT AND INCOME INEQUALITY}

\subsection{Introduction}

A good deal of attention has been paid to the degree of income inequality in the United States of late. Developing alongside the growing income gap is the changing state of this nation's military industrial complex. Typically the two are viewed as separate issues in the political economic landscape, and few scholars ask about the possible impacts on income inequality from such a large source of fiscal spending. The current essay hopes to shed a bit of light on the relationship, by scrutinizing the impact of defense contracting dollars on income inequality at the State Level.

With the concentration of income at the top of the distribution higher than it has been since the 1920 's ${ }^{1}$, more and more politicians are finding it increasingly difficult to ignore growing public unrest. Also, discontent over the level of inequality has been exacerbated by the recent severe recession and real economic losses experienced by all strata of the population. The result of these recent events has pushed policy makers to directly address inequality.

The debate around income inequality has provided a stark foil against another contentious aspect of the federal budget, national defense spending. The past decade saw birth to the war on terror and two large-scale wars in The Middle East, whose compounded costs have not faded in the public consciousness. In general, the dynamics of the post World War II military experience in the U.S. has molded the defense budget into a bipartisan, political sacred cow. However since the recession, this status

\footnotetext{
${ }^{1} ?$ provide a succinct and accurate summary of the state of income inequality in the United States, using a variety of common sources. The income inequality disparity was at its recent peak just prior to the great recession for earners at the top one percent, after which the income share declined sharply but has again increased. As will be refereed to later, for more detailed analysis of income dynamics see ?
} 
quo is being questioned and it is not surprising that policy makers are scrutinizing all facets of the federal budget. In the face of these two policy flash-points, the signing of the Budget Control Act of 2011 (BCA) poses interesting questions about the state of income inequality. With the BCA enacting the first significant cuts to the defense budget in recent history, it is still unclear how these cuts may impact income inequality.

This study seeks to better quantify the relationship between income inequality and defense contracting directly by employing an extensive data series on military procurement and on income inequality at the state level. Typically studies of this sort are characterized in terms of a guns-versus-butter trade-off: more spending on defense related endeavors, the "guns", can lead to a reduction in available resources for public services, or "butter" (??). Historically, scholars have attempted to estimate the existence of this trade off between defense and social spending to varying degrees of success (???). Typically these studies use aggregate level spending on social programs and infer subsequent welfare implications, where this study directly looks at income inequality.

The following analysis finds that across model specifications the relationship between inequality and military spending is generally positive. In other words, increasing spending on military procurements leads to higher degrees of income inequality. The bulk of studies that have scrutinized this relationship find a similar result, with different measures of military spending or inequality indices (??). However these studies are often constrained by length and quality of the data deployed, where the time spans are typically about a decade at most and the time frequencies are often once every few years. Combining several sources this study capitalizes on the use of annual frequency data, for a time span of greater than 40 years. 
Another novel component of the present study is its use of panel techniques across the 50 states to help account for otherwise unobservable influences. Many of the previous studies focus on national level data often in cross country panel frameworks that focus on a wide group of countries (?) or focus on specific global regions (?). The benefits of using the United States as the cross sectional unit in panel studies is not entirely new, where the relatively homogeneity of these units is desirable. This conformity provides better control for unobservable effects by effectively reducing them or holding them constant, where the presence of differences in language, currency, culture, regulations, freedom of labor and capital flows, and laws can cloud cross country results. A specific benefit here is greater control of unobservable, country specific policy effects aimed at affecting inequality or military policy by holding these components fixed across groups.

It is crucial to understand the relationship between defense spending and inequality, as the landscape of military procurement, and government spending more generally, is poised to change significantly in the coming years. The BCA has ordered sequestration across the federal government budget, which impacts the department of defense to the tune of 470 billion dollars over the coming decade. While few would argue for the use of defense budgets as a tool for economic policy, it is impossible to ignore its effects on the greater economy. Larger than the size of the DoD budget relative to the total budget is defense contracting relative to overall contracting, which accounts for the vast majority of federal procurement dollars. As illustrated in 1.5, the department of defense typically accounts for 70 percent of all federal contracts, and in recent years this has amounted to between 170 and 360 billion dollars each year. Because defense procurement is such a large share of total procurement, one may be tempted to generalize the findings in this study to government procurement spending more broadly, however this would be a mistake. Studies have outlined how 
defense contracts are inherently different from other federal contracts, from the labor skill set they employ to the fact that their demand typically is partitioned from policy makers other economic decisions (??). Again however, the size of defense procurements in both relative and absolute terms necessitates greater understanding of it's varied impacts on the economy as a whole.

The outline of this essay is as follows. The next section will provide a brief literature review, followed by a detailed account of the data sources utilized in this study, and the potential problems presented by this data. Section four outlines the experimental methodology and presents the results. Section five provides concluding remarks.

\subsection{Defense and Inequality: Literature Review}

The discussion of income inequality in economic literature has come in waves, falling in and out of fashion usually corresponding to political and social current events. The work of $?^{2}$ has done a great deal to comprehensively catalog the state of income distributions in the United States at the national level for this past century. In their coverage the authors illustrate how the income share of the top decile of earners has experienced a U shape, decreasing after the Great Depression until it changed course in the 1970's and began to increase again. Piketty and Saez also describe how the nature of those incomes received by the top earners has changed. In the early part of the 20th century capital rental incomes accounted for the largest share, whereas more recently top earners income is mostly generated from wages and entrepreneurial work.

\footnotetext{
${ }^{2}$ The main contribution of this work is to generate a time-series measure of inequality that covers roughly the past century using tax return data, and has since been updated include more current estimates of inequality for the nation. Furthermore, ? describes the historical income dispersion from a global context.
} 
Taking a subnational approach, ? follows the methodology of ? and produces a similar series of inequality measures for each of the 50 states plus the District of Columbia. ? finds a similar U pattern over the past few decades for most states, where some states experience greater inequality while others do not see as dramatic changes. The data produced by ? is one key source of data for this analysis.

More in line with the current study are papers that attempt to estimate a tradeoff between defense spending and spending on social welfare programs. These guns versus butter arguments are focused on estimating the existence and direction of a relationship between federal spending on defense and federal spending on social programs. Many previous studies have encountered great difficulty in empirically demonstrating the existence of this trade-off, where attempts to estimate these effects directly provides little to no evidence (??). ? uses a disaggregated analysis on the subsets of the defense budget, and finds no existence of the effect prior to the Reagan defense build up, but a trade-off during the early 1980's. Also, ? find no suggestion of a direct link between military expenditures and social spending but find indirect, longer term effects of defense spending crowding out spending on education.

The majority of these earlier studies utilized measurements from a variety of sources for both defense spending and social spending. While the impact on social spending has implications for inequality, inequality is typically peripheral to these analyses. ? suggests that the existence of a trade-off would result in a positive relationship between income inequality and defense spending. His justification for this relationship lies in the composition of employment generated by defense contracts, which is concentrated in high skilled, engineering and science jobs and has relatively few lesser-skilled, "blue collar" jobs. The following analysis will depart from these earlier studies by directly using a variety of income inequality measures to estimate the relationship as directly as possible. 
One of the earliest studies to directly estimate inequality and defense spending is ?, who estimates a positive relationship while providing a description of the extent of pay differentials between defense and non-defense sectors. He postulates that the existence of sectoral pay differentials coupled with the concentration of defense related jobs to white males relative to women and minorities exacerbates inequality levels. The analysis in ? is based on national U.S. statistics and as such the most closely related study to the present one, albeit at a higher level of aggregation. Another key distinction here is our use of military procurements, when compared to Abell's use of overall military expenditures as the source of fiscal shock.

Since ?, several studies have inspected this relationship and found a similar positive effect for a variety of countries and regions of the globe. The majority of other studies that directly discuss this relationship suggest higher inequality is a result of increased military spending (?????). ? looks at a dynamic familiar to the economy more broadly; shifts towards higher capital intensity have caused displacement of lower skilled workers, which has exacerbated the positive relationship between inequality and defense spending in recent years.

There are a a few studies that find either no evidence, or slight evidence for the opposite effect of a reduction in income inequality. ? demonstrate the difficulty in empirically producing evidence to show the existence of a relationship between income dispersion and defense spending, while ? finds that the experience of Middle Eastern and North Africa actually displays a tendency for decreases in inequality from increases in military expenditures. In a related context, instead of focusing directly on expenditures, ? look at the military participation and find that increased conscription in the armed forces reduces the level of income inequality, suggesting that military service is a useful method to improve one's station in life, particularly for those who may have few economic alternatives. 
The following analysis aims to add to the body of literature in a few key ways. First many of these analyses use defense budgets or estimates of defense spending from third party sources such as the Stockholm International Peace Research institute (SIPRI), IMF or World Bank ${ }^{3}$. Ultimately these sources use official statistics when available but often times for non-OECD or lesser developed countries these statistics are based on estimates or survey results. The following analysis uses military procurement data directly observed from individual contracts and aggregated to the state level, instead of either using a proxy such as budgets or even estimated budgets when official statistics are unavailable ${ }^{4}$. Also many of these countries are limited by the availability of data, be that the time span of their data or the observed frequency, which in some cases occurs as infrequently as once every five years. Our study suffers from neither constraint, with data at an annual frequency from 1966 through 2011.

In addition to the benefits listed above, the following analysis will provide more precision by using a disaggregate, sub-national analysis of spending across states. Many of these panel level studies utilize cross-country experiments, with a broad global or regional focus. The benefits of panel data analysis, specifically controlling unobservable effects, are larger when the observational units exhibit more homogeneity or the potential set of unobservable effects is smaller. There is a vast array of unobservable effects that vary widely across countries and can impact both inequality and defense spending: federal policies such as taxation, monetary policy, civil rights regulation, social program spending, or supreme court rulings as well as cul-

\footnotetext{
${ }^{3}$ SIPRI uses published statistics when available, but also relies on budgets, and secondary sources to aggregate their statistics. Details in their methodology are located at http://www.sipri.org/.

${ }^{4}$ Budgets represent outlays that can take years to decide and may ultimately not reflect the actual dollar figure spent, although it is often the best replacement for direct expenditure data. Many of the estimates for countries expenditures are collected via surveys or from third parties financial analyses of the country in question and can be subject to measurement error inherent in this process.
} 
tural and societal norms. Using the fifty states (plus D.C.) as our sample set keeps all of these sources of variation fixed, and provides greater homogeneity in individual units, allowing more precise estimates of the parameters of interest.

\subsection{Data Sources}

The data employed in the analysis here are compiled from a variety of sources, including the Bureau of Economic Analysis, the Bureau of Labor Statistics, the United States Census Bureau and the Department of Defense. Additionally state level income inequality measures are sourced from ?. Combined, these data sources form a panel of state level data from 1966 - 2005, where a great deal of information is available.

The first main portion of data consist of DoD procurement spending, which comes from the DoD form DD 350. The form also includes information on location and signing date, allowing us to appropriately aggregate the data into a panel of state level aggregate contract dollars, at an annual frequency.

The second source of data at the core of the empirical study here is the state panel on income inequality produced by ?. The author compiles six long term measures of state level inequality using IRS data. As suggested by ?, I will focus my attention primarily on the two measures that the IRS data best captures, specifically the top decile and percentile shares of income ${ }^{5}$, but also test the remaining measures of income

\footnotetext{
${ }^{5}$ Here ? and ? explain that the IRS data is truncated at the lower end. Individuals earning below a varying threshold depending on years, age, and household composition, are not required to file with the IRS, essentially omitting these low earning households from typical measures. While this will not affect the top decile and percentile shares which use top household statistics and aggregate income data, it will affect other measures of inequality such as the GINI coefficient, Theil and Atkinson indices which include the lower levels of households in their calculations.
} 
inequality as a check for the baseline estimates. The series created by ? extends from 1945-2011, and is available for the same time window as procurement data.

In addition to the two main sources of information in this study is state gross domestic product, gathered from the Bureau of Economic Analysis. All GSP series are in current dollar measures available for a period of time encompassing both our measure of inequality and military spending. We will also use National Aggregate CPI data from the BLS as a check against inflation. We deflate both state procurement dollars, and GSP using the CPI. The base year for the CPI index used in this study is $1983-1984$.

State level population data is derived from the U.S. Census. Since the census is conducted once every decade, the inter-survey years are population interpolation estimates, also generated by the Census Bureau. We utilize all State population series to control for population flows between states and potential effects this may have on the estimations. Employment data is compiled from the Bureau of Labor Statistics. Each state series is collected from the total non-farm state employees, annually from 1965 through 2010. Unfortunately total hours or average weekly hours worked at the state level are only available from 2007 and on so we use the employment count in levels per state-year. The resulting dataset is a balanced panel from 1966-2011 for all our groups.

\subsection{Estimation and Analysis}

The main estimation strategy utilizes a panel data setup, containing annual observations for state level inequality, military contract spending as our main data series

of interest. Also included to help control for omitted variable bias are GSP, state employment rate as well as state population. We utilize the following regression to 
estimate the data:

$$
\begin{array}{r}
i_{i t}=\beta_{0}+\sum_{j=0}^{l} \beta_{1, j+1}\left(g_{i, t-j}\right)+\sum_{j=0}^{l} \beta_{2, j+1}\left(y_{i, t-j}\right)+ \\
\sum_{j=0}^{l} \beta_{3, j+1}\left(e_{i, t-j}\right)+\sum_{j=0}^{l} \beta_{4, j+1}\left(n_{i, t-j}\right)+\sigma_{i}+\epsilon_{i t}
\end{array}
$$

In the above equation, $i_{i t}$ represents the state level inequality measured by the share of income earned by the top 10 percent of households, with indices denoting state $i$ in year $t$. The following right hand side variables are included in contemporaneous and lagged forms; $g_{i t}$ reflects the state total amount of military contract spending, $y_{i t}$ is gross state product, $e_{i t}$ is state employment rate and $n_{i t}$ is state population. For more comparability across measures and estimates, all variables have been transformed in natural logarithms, denoted by lower case variables. $\sigma_{i}$ is the state fixed effect component.

Baseline fixed effects estimations are carried out on this model, with the results reported in table 3.1. The contemporaneous effect presents with an unexpected sign. The estimate suggests that increases in contracting reduces the ratio of top incomes is opposite to the general findings across the literature. Upon visually inspecting the data in figure 3.1 evidence of unit root processes is present in some of the state series. figure 3.1 displays both the aggregate spending in each state, and the path of the top decile fraction of income. One can see a clear upward trend in inequalities across the time span for all states. The upward trend however less clear for contract spending, with some states seeing a steady increase over time and others stable or decreasing spending levels. While not reported, similar trends are present in the GSP panel and population panels, while the employment rate presents the least visual evidence towards a unit root series.

To safeguard against the possibility of panel unit roots present in the data here, a series of panel unit root tests are deployed on all variables used in the estimations, 
specifically the tests proposed by ? (LLC), ? (IPS) and ? (Hadri) ${ }^{6}$. For each of the five variables used, there is substantial evidence of the presence of a unit root process in at least some of the panels. First differencing all variables produces stationary series for the inequality index and military spending. For GSP, employment, and population however, the Hadri test still suggests evidence of non-stationarity, suggesting a higher order of integration. Second differencing these three series yields sufficiently stationary data, passing all three tests. Also note here that by log differencing the data, estimates produced describe the effects of changes on growth rates for the two main indices of interest.

Equation 3.4 is again estimated now on the appropriately differenced, stationary series. Now we can see in table 3.1 that the results that were previously surprising now yield the correct sign however are not statistically significant. In the presence of unaccounted heteroskedasticity or autocorrelation in the errors, estimation precision will suffer. As the regression estimation contains contemporaneous and lagged values of the data, tests for these characteristics are conducted on the panel to ensure robust standard error estimation.

Estimations through FGLS provides the ability to conduct a likelihood ratio test for a homoskedastic error structure across panels. Conducting a likelihood ratio test with the homoskedastic model nested rejects the notion of homoskedastic errors in favor of a heteroskedastic structure ${ }^{7}$. Furthermore, ? suggests methods for testing

\footnotetext{
${ }^{6}$ The first two of these tests, often referred to as thee Levin-Lin-Chu test and the ImPesaran-Shin tests, consider a null with the existence of unit roots in the panels, while the Hadri test is for a null of stationarity.

${ }^{7}$ The LR test is performed with the assumption of heteroskedasticity as the unrestricted form, and the homoskedastic model nested within, and estimated through iterated GLS framework to provide a log likelihood, for a straightforward LR test. This test yields a $\chi^{2}(50)=293.28$, which strongly favors the use of a heteroskedastic model across panels.
} 
against the presence of autocorrelation in the residuals ${ }^{8}$. The test for serial correlation is less emphatic, with the decision resting just above the 10 percent level, barely rejecting the presence of autocorrelated errors.

To scrutinize the possibility of serially correlated errors two estimation strategies are compared, first using a parameterized panel specific AR(1) error structure and again assuming no serial correlation. The results from these two estimations are displayed in tables 3.2 and 3.3, respectively. Overall the impact on either estimation is not large, failing to increase precision or change the sign for many variables. The first line in each table represents the estimates with the top decile's share as our dependent variable. Estimations utilizing a FGLS model accounting for heteroskedasticity seems to improve estimate precision for some of our variables, however the main variable of interest is still uninformative, suggesting that there is little evidence of a relationship between military spending and the top decile's share of income, at a minimum changing sign from the initial negative coefficient estimate to positive ones that we would expect based on the previous literature.

Tables 3.2 and 3.3 also display the regressions utilizing the top one percent's share of income, which presents some interesting findings compared with the top decile. The results suggest that while there is no measurable effect of contract dollars on the top decile's income share, military contract spending does impact those at the very top one percent. Specifically the regression suggests that a one percentage change in the growth rate of military spending will increase the growth rate of top income shares by around 25 hundredths of a percent contemporaneously and 23 hundredths of a percent the following year.

\footnotetext{
${ }^{8}$ Specifically, Wooldridge suggests conducting the regression with the assumption of autocorrelated errors, collecting those residuals and estimating an $\mathrm{AR}(1)$ regression with them. Significance testing on the resulting autoregressive coefficient is the test for serial correlation in the error structure.
} 
At first it sounds like a small effect, but a large magnitude shouldn't be expected. To provide a foil for comparison, taking the average contracting spending across states and years in this panel, a one percent increase represents an increase of roughly 19 million dollars. The BCA cut an average of 740 million in the defense budget per state in the second half of 2013 alone $^{9}$, and past military buildups have contributed large scale increases in spending. Expanding on this consider that the average growth rate of military procurement dollars across all states and years is .5 percent growth per year. Many individual years experience the average growth rate across states greater than ten percent in absolute value. In the context of past military expansions, an effect of 23 or 25 hundredths of a percent rise in the growth rate of top percentile income shares can compound into an economically large effect quite quickly, particularly in years that experience large and sudden buildups.

To better understand the between these two main results it is necessary to understand what differentiates these groups of households. The work of ? characterizes the distribution of incomes in the United States over the past many decades in great detail. They find that the decades most relevant to this study have seen a shift in the sources of income earned by the top decile compared with earlier in this century; from being in large part rental income towards being predominantly made up of wage income. While this change in sources of income is true across the entire decile, it is more visible for households in the upper decile outside the upper one percent, and accounts for roughly 90 percent of all income for households at the lower end of this range ${ }^{10}$ ? suggest that these upper decile wage earners today are mostly made up of high skilled workers and entrepreneurs, such as doctors, lawyers, and upper level

\footnotetext{
${ }^{9}$ ? discusses the immediate impact of the sequestration, stating that 37 billion was cut from the DoD's budget for the second half of 2013, and expects to amount to upwards of 470 billion over the following decade.
}

${ }^{10}$ Lower end of the range of the decile refers here to the $90^{\text {th }}-95^{\text {th }}$ percentiles 
management, instead of the rentiers of the early 20th century. They also point out that the threshold for the upper 10 percent across the United States in 1998 starts at $\$ 81,700$, while the threshold for the upper one percent begins at $\$ 230,200$. ? also show that within the upper one percent of households, between 20 and 35 percent of income comes from entrepreneurial sources, such as self-employment, partnership, and business ownership incomes.

? propose that the ongoing shift towards the "new" military that is increasingly more capital intense has lead to the relationship where increasing military spending produces more inequality. However, they postulate that this effect is caused by increased demand for high skilled, expert level talent which reduces the demand for low skilled, less trained labor. If the change in labor demand indeed were the case, one would expect a positive estimated effect on the top decile's share of income, which contains many of these high skilled professionals. The upper one percent of incomes here encompasses upper managers, owners and executives of companies involved in contracting. The upper one percent threshold likely surpasses the majority of engineering and scientists that are otherwise captured by the top decile measure, suggesting that the effect noted by ? is not significant.

These results are troubling. Military contracting is not often touted by politicians as a source of economic largess to their constituents. That said, the attempts to direct federal funds towards their districts are well known and even expected by some (?). These results suggest that this may very well be the case. In particular the beneficiaries of an increase in contract dollars are members of the increasingly small owner class, with gains passing over the new upper professional class described by ?.

The average constituent should be alarmed by the use of these funds as pork barrel type spending. Local congressmen and women often stump on records of directing defense contracts to their districts, as engines of job creation. The evidence 
suggests that gains from these dollars are concentrated at the upper one percent of households at the expense of the population at large. Seeing as wealthy households are typically more politically connected these findings are intuitive. To the extent that there is significant fraud and abuse in the contracting system those who have political connections stand to have the most to gain.

\subsubsection{Alternative Measures of Inequality}

As previously mentioned the two measures of inequality discussed so far are likely the most robust to measurement error. Again as described in ?, the preference for income shares is because the IRS does not require tax filings for all households, specifically those below a certain threshold. The top earners share can be computed even without observations on these lower distribution incomes because the information can be supplemented with population and gross state income data. The other data series however rely on the overall distribution of all income earners. Therefore to the degree that these low income households do not report to IRS, these additional measures may be under estimated. Furthermore the Atkinson and Theil index cannot be computed for negative incomes, unlike the other measures. Therefore ? truncates these incomes at zero, again potentially leading to misspecified results.

With the potential shortcomings in mind, it would still be advantageous to conduct estimations using the alternative measures of inequality as a check against the primary results. The regressions are specified analogously to those for the top decile share of income $^{11}$. The remaining four measures of inequality are also listed in tables 3.2 and 3.3.

\footnotetext{
${ }^{11}$ Specifically for each measure of inequality, first differences are taken on the log transformed data, and then used to replace the first differenced top 10 percent income shares.
} 
The signs on significant estimates of interest are as expected. One common trend across regressions is the relatively low magnitude of these coefficients. If we restrict our attention to those coefficients that are significant, four of the five estimates range from three to five thousandths of a percent effect on the inequality growth rate for a one percent change in military contacting growth. Again consider that these inequality measures likely understate the degree of inequality, by conventions of the IRS reporting protocol and the metric's construction. If in fact the true values of inequality are larger than these measures suggest, it is reasonable to consider that these effects are also under estimated.

To provide some intuition on the results, consider the estimates of the effect on the state GINI coefficient. With a one percent increase in the growth of contract dollars, after two years the net impact would be near a hundredth percent rise in the growth rate in inequality. While not particular large in the presence of such a small shock, if there were perhaps a 10 percent shock, we would see sizable effects on income inequality. As already mentioned 10 percent and larger shocks to procurement growth are far from uncommon. A change in the growth rate in inequality by a tenth of a percent in years of significant military expansion is a substantial impact and worthy of notice, particularly considering the vast array of contributing factors to the income distribution.

Therefore the results for the coefficient of interest are generally consistent across all regressions. We typically see a modest and positive effect for both the contemporaneous and lagged values of contract spending on each inequality measure. These estimates confirm the previous results, and bolster the notion that the relationship between contract spending and inequality is positive. 


\subsection{Concluding Remarks}

The goal of the present study was to estimate the connections between inequality and military contracting in the United States. The analysis was achieved using a rich data set on individual military contracts compiled for the span of 1966-2005. In addition, the state level inequality series produced by ? allows a panel level study of the influence on inequality by military contracting in each state. In general the findings of in our study suggest the existence of a positive relationship between defense contracting growth and inequality growth.

While the findings of our study do not suggest any measurable effect of contracting on the top decile household's share of income, there is evidence of an effect on the top one percentile household's shares. Previous studies have demonstrated that the shift towards capital intensive production of military goods have favored high skilled labor and specialists over lower skilled workers, which would suggest more broad based income gains at the top households. The results of this study suggest that the broad income gains are not largely meaningful, as top decile households do not seem

affected by growth in contract dollar. The concentration of income gains caused by procurement spending is at the very richest households, where the beneficiaries of growth in contracting are most likely owners and top managers of firms involved in contracting.

In addition to income shares measures, our study also looks at alternative measures of income inequality. The findings are generally consistent across various metrics: GINI coefficient, Atkinson index, relative mean deviation, and Theil index. The typical effects measured are modest, positive relationships in inequality growth associated with an increase in $\mathrm{DoD}$ contracting growth. ? describes how many of these series are likely underestimated based on several conventions of the IRS procedures 
and metric construction. If the true measures are in fact larger, it is feasible that the true effects are also larger than measured here.

The main findings of this study, that DoD contracting does not affect upper middle class households income shares, but does in fact impact the richest household's incomes, is a troubling result. The impact on only the very highest households suggests that military contracting dollars are a potent force for increasing income inequality at the extreme of the distribution. That said, in the new atmosphere of bipartisan budget cutting zeal, the overall effect of drastically lowered defense spending may yield a net reduction in the share of income garnered by the top one percentile of households.

With the implementation of the BCA, there may be real opportunities for future work to more directly study the effects of contract spending on inequality as a result of this significant law. Since the BCA is the first long term reduction in the defense budget in memory, measuring its resulting effects on inequality will prove to be a useful tool for future econometric analyses. 


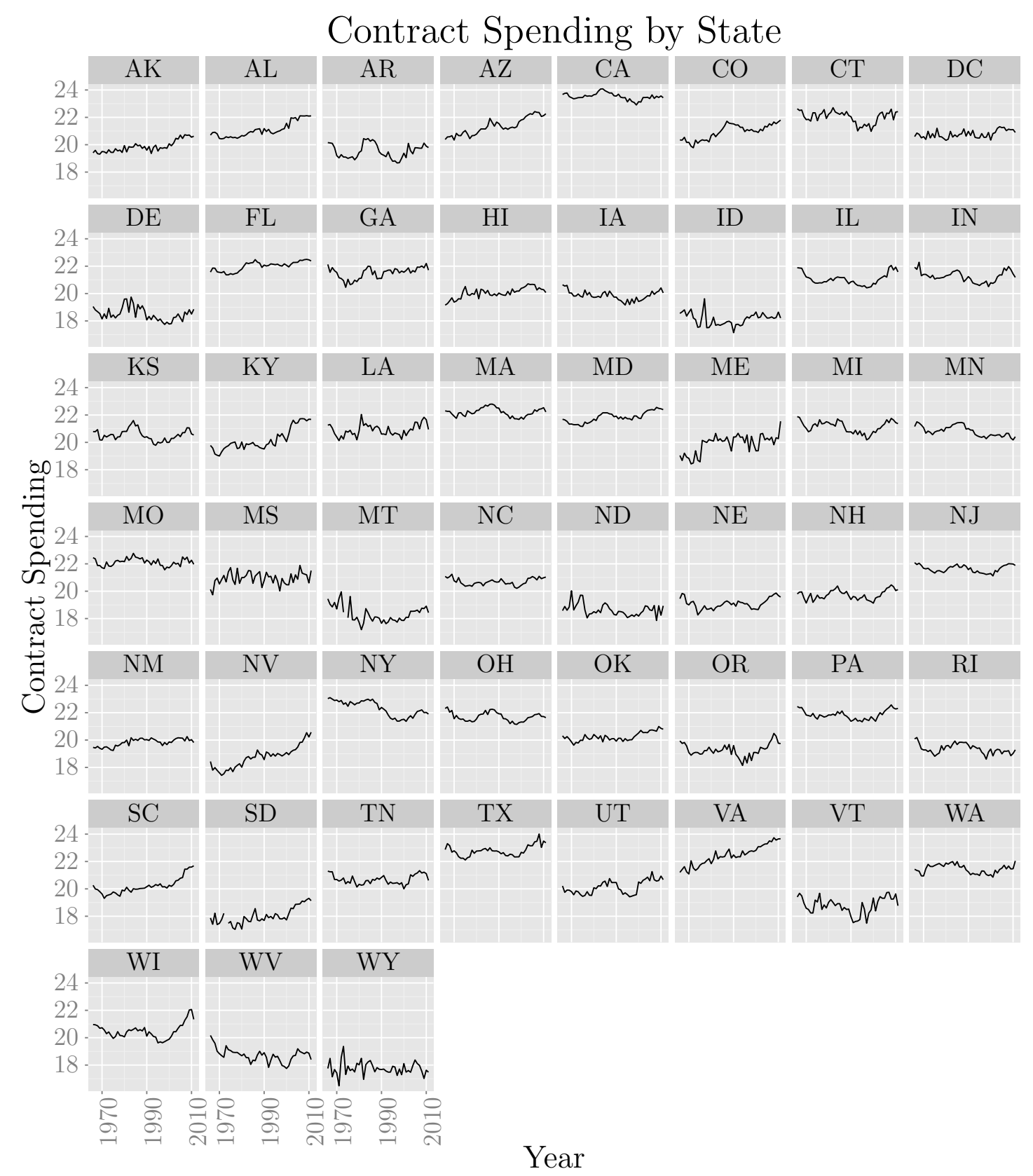

Figure 3.1: This figure lists log transformed, aggregate contract spending for each state, per year. Evidence of non-stationary data occurs in some states, but is hard to find in others. 


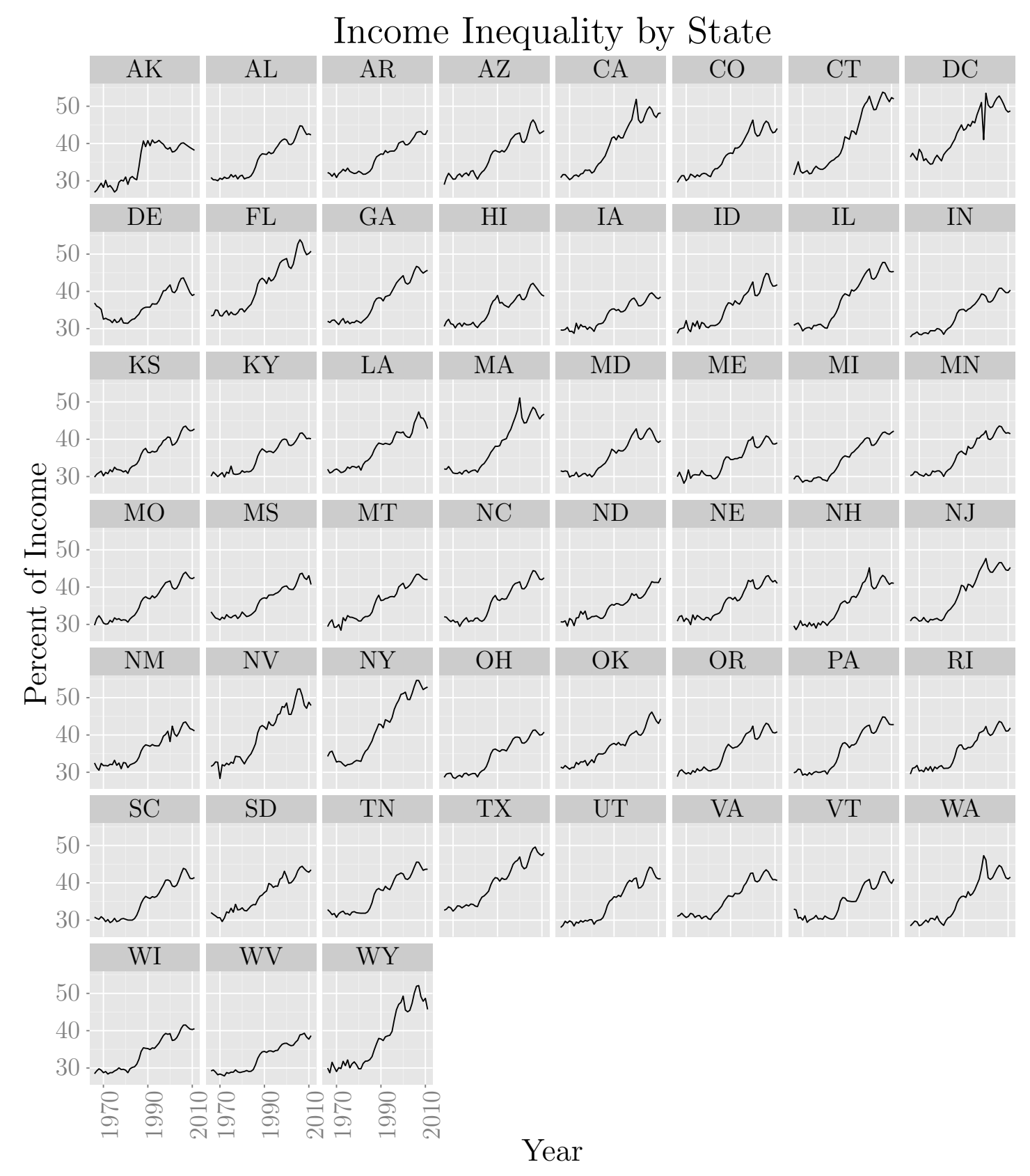

Figure 3.2: This figure lists top decile's share of income for each state, per year. Nonstationarity is much more evident in this data series. 


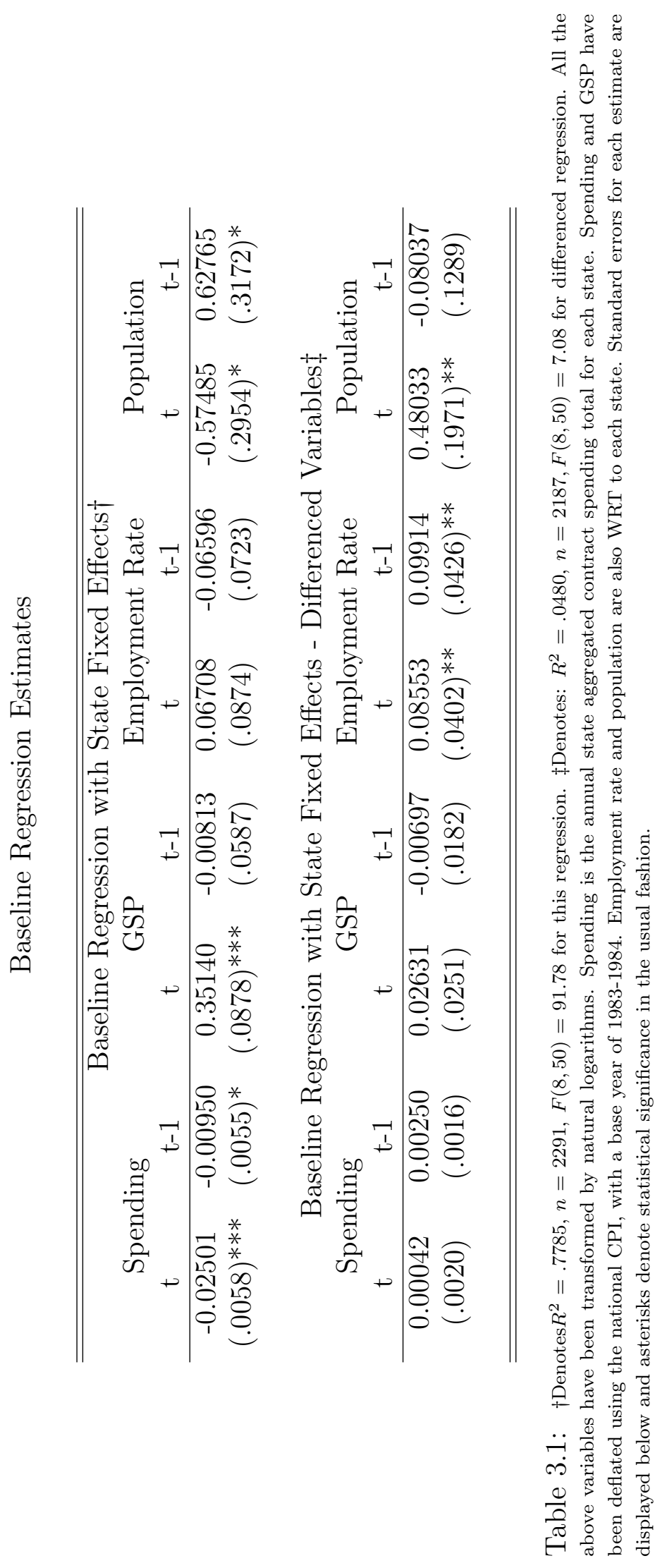




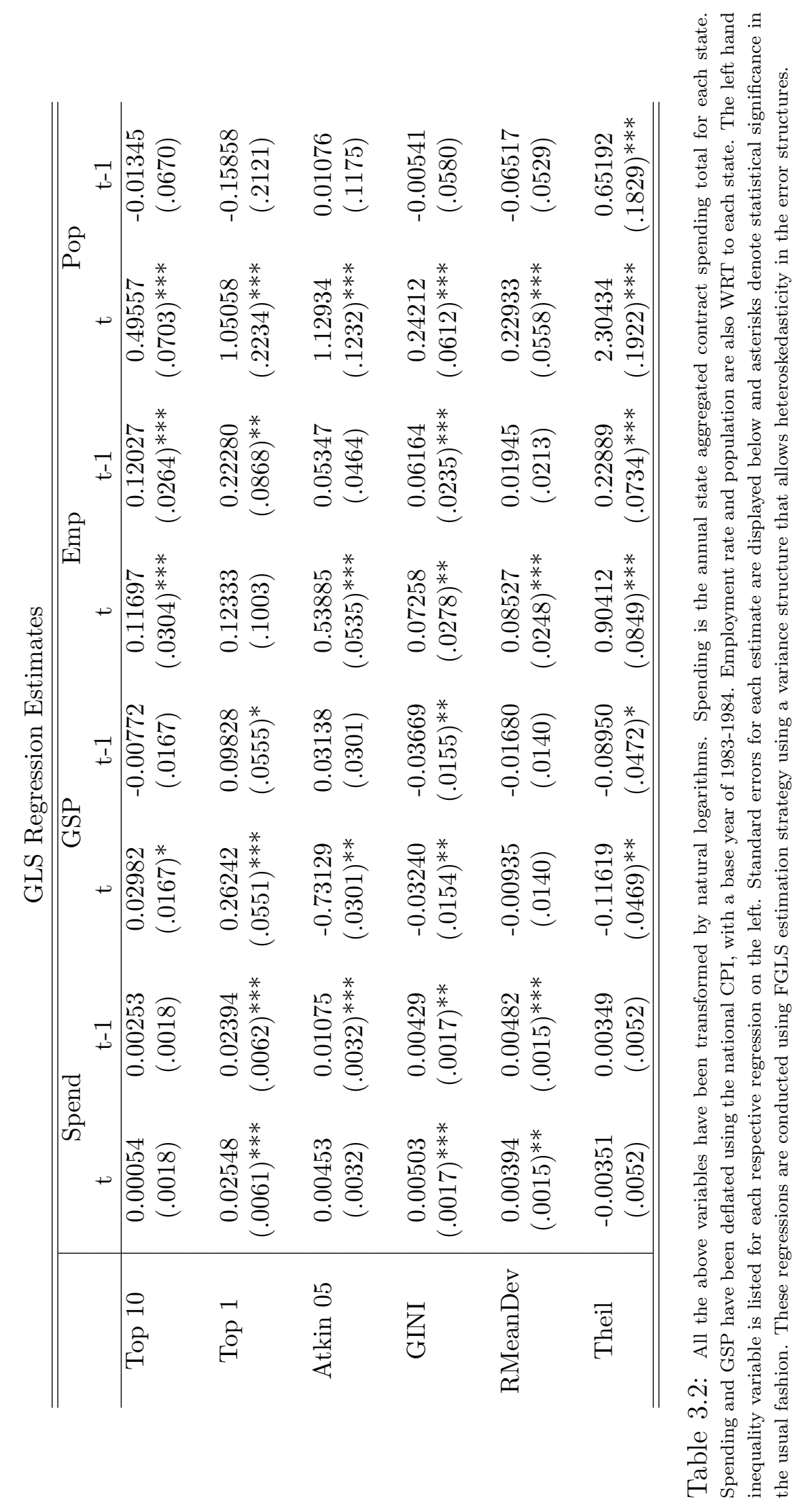







VITA

EDWARD M. DECAMBRA

Setember 23, 1986

2009

2010

2009-2014
Born, Washington D.C.

B.A., Economics

University of South Florida

Tampa, Florida

M.A., Economics

Florida International University

Miami, Florida

Teaching Assistant and Doctoral Student Florida International University

Miami, Florida 